\title{
Efficiency Evaluation of Oxygen Enrichment in Energy Conversion Processes
}

H. J. Bomelburg

December 1983

Prepared for the U.S. Department of Energy under Contract DE-AC06-76RLO 1830

Pacific Northwest Laboratory

Operated for the U.S. Department of Energy by Battelle Memorial Institute 


\title{
DISCLAIMER
}

This report was prepared as an account of work sponsored by an agency of the United States Government. Neither the United States Government nor any agency thereof, nor any of their employees, makes any warranty, express or implied, or assumes any legal liability or responsibility for the accuracy, completeness, or usefulness of any information, apparatus, product, or process disclosed, or represents that its use would not infringe privately owned rights. Reference herein to any specific commercial product, process, or service by trade name, trademark, manufacturer, or otherwise, does not necessarily constitute or imply its endorsement, recommendation, or favoring by the United States Government or any agency thereof. The views and opinions of authors expressed herein do not necessarily state or reflect those of the United States Government or any agency thereof.

\author{
PACIFIC NORTHWEST LABORATORY \\ operated by \\ BATTELLE \\ for the \\ UNITED STATES DEPARTMENT OF ENERGY \\ under Contract DE-AC06-76RLO 1830
}

Printed in the United States of America
Available from
National Technical Information Service
United States Department of Commerce
5285 Port Royal Road
Springfield, Virginia 22161
NTIS Price Codes
Microfiche A01
Printed Copy
Pages
$001-025$
$026-050$
$051-075$
$076-100$


EFF ICIENCY EVALUATION OF OXYGEN ENRICHMENT IN ENERGY CONVERSION PROCESSES

H. J. Bomelburg

December 1983

Prepared for

Energy Conversion and Utilization Technologies Division Office of Energy Systems Research Conservation and Renewable Energy U.S. Department of Energy under Contract DE-AC06-76RLO 1830

Pacific Northwest Laboratory Richland, Washington 99352 


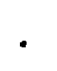




\section{PREFACE}

This study was completed for the Division of Energy Conversion and Utilization Technologies (ECUT) in the Department of Energy. The division's mission is to identify and research long-range technology concepts that are attractive for more efficient energy use. To meet its goals, the ECUT staff established a planning and systems analysis project that was responsible for conducting this study.

This report is one of a series of studies in support of the ECUT research planning effort. Other documents in the series contain assessments of energy conservation technology areas, methods to appraise research projects for support, and data reference sources. Publications from this project include the following:

Abarcar, R., and D. Johnson. 1983. ECUT Data Reference Series: Lightweight Materials for Ground Transportation. Pacific Northwest Laboratory, Richland, Washington.

Abarcar, R., and D. Johnson. 1983. ECUT Data Reference Series: Materials for Advanced Heat Engines. Pacific Northwest Laboratory, Richland, Washington.

Chockie, A., et a1. 1983. An Evaluation of Stationary Combustion Research Needs. Pacific Northwest Laboratory, Richland, Washington.

Chockie, A., and D. Johnson. 1983. ECUT Data Reference Series: Stationary Combustion Systems. Pacific Northwest Laboratory, Richland, Washington.

Hane, G. 1983. Efficiency Evaluation of the DISC, DHC, and DI Diesel Engines. PNL-4568, Pac ific Northwest Laboratory, Richland, Washington.

Hane, G., and D. Johnson. 1983. ECUT Data Reference Series: Otto Cycle Engines in Transportation. Pacific Northwest Laboratory, Richland, Washington.

Hane, G., et al. 1983. Energy Conservation Research and Development Needs: A Review and Synthes is of the Literature, Phase II. PNL-4571, Pacific Northwest Laboratory, Richland, Washington.

Hane, G., et al. 1983. A Prel iminary Overview of Innovative Industrial Materials Processes. PNL-4571, Pacific Northwest Laboratory, Richland, Washington. 
Hopp, W., et al. 1981. An Overview of Energy Conservation Research Opportunities--Executive Summary. PNL-3944Ex.Sum., Pacific Northwest Laboratory, Richtand, Washington.

Hopp, W., et a1. 1982. Identification of Energy Conservation Research Opportunities: A Review and Synthesis of the Literature. PNL-3966, Pacific Northwest Laboratory, Richland, Washington.

U.S. Department of Energy. 1981. The 1981 ECUT Work Element Appraisal. DOE/CE-0024, U.S. Department of Energy, Washington, D.C.

U.S. Department of Energy. 1983. Energy Conversion and Utilization Technologies Program Report, 1981-1982. U.S. Department of Energy, Washington, D.C.

Young, J., and D. Johnson. 1983. ECUT Data Reference Series: Ammonia Synthesis. Pacific Northwest Laboratory, Richland, Washington.

D. L. Brenchley Project Manager 
SIJMMARY

This study sought to determine the extent to which energy conversion efficiencies can be increased by using oxygen or oxygen-enriched air for combustion. Combustion of most fuels with oxygen instead of air was found to have five advantages:

- increases combustion temperature and efficiency

- improves heat transfer at high temperatures

- reduces nitrous oxide emissions

- permits a high ratio of exhaust gas recirculation

- allows combustion of certain materials not combustible in air.

The same advantages--although to a lesser degree--are already apparent with oxygen-enriched air. Because low-Btu fuels usually contain large amounts of inert materials, the benefits of combusting such fuels with oxygen are less significant than those obtainable with high-Btu fuels.

Judging by the production costs for oxygen, the cost-effectiveness of the process must necessarily be improved by about $10 \%$ when using oxygen instead of air before such use could become justifiable on purely economic terms. Although such a modest increase appears to be attainable in real situations, this study ascertained that it is not possible to generally assess the economic gains potentially derived by switching fuel combustion to oxygen. Rather, each case requires its own evaluation. When oxygen is available as surplus at certain installations, onsite or nearby combustion processes using the surplus oxygen are generally cost-efficient. If manufactured on a large scale, the expense of providing oxygen for the combustion of high-grade fuel has essentially the net effect of increasing the total fuel cost by 6 to $20 \%$, depending on whether the oxygen is provided in gaseous or liquid form. Oxygen transportation costs are not considered in these figures.

For certain processes industry has already proven that the use of oxygen leads to more efficient plant operation. As an example, this report describes the combustion with oxygen of blast furnace gas in the steel industry. Several ideas for essentially new applications, which could be made technically feasible or improved by combustion with oxygen, are described. Specifically, 
when oxygen is used with exchaust gas recirculation in external or internal combustion engines, more fuel-efficient engines become conceivable. As examples, new versions of Stirling and of two-cycle automobile engines are briefly described.

It appears also that the advantages of pulse combustion can be amplified further if oxygen is used in the process. Furthermore, when burning wet fuels (e.g., peat) with oxygen, direct steam generation becomes possible, which could lead to more simplified and efficient power generating stations. Likewise, oxygen combustion could also improve processes for in situ gasification of coals, oil shales, peats, and other wet fuels. Enhanced oil recovery by fire flooding methods might also become more effective if oxygen is used instead of air. The "cold energy" contained in liquid oxygen can be substantially recovered by using it to lower the heat rejection temperatures at the low end of certain thermodynamic cycles, such as the closed Brayton cycle. Finally, with oxygen combustion it might be possible to burn and vitrify dangerous wastes in their final burial places so that they cannot adversely affect the environment.

Overall, this study concluded that further efforts to develop certain schemes for using oxygen for combustion appear to be justified from both the technical and economic viewpoints. 


\section{CONTENTS}

PREFACE

SUMMARY

1.0 INTRODUCTION $\ldots \ldots \ldots \ldots \ldots \ldots \ldots \ldots \ldots \ldots \ldots \ldots \ldots \ldots \ldots \ldots \ldots \ldots \ldots \ldots \ldots$

2.0 CHARACTERISTICS OF GENERAL COMBUSTION $\ldots \ldots \ldots \ldots \ldots \ldots \ldots \ldots \ldots \ldots$

2.1 THE ROLE OF DILUENTS $\ldots \ldots \ldots \ldots \ldots \ldots \ldots \ldots \ldots \ldots \ldots \ldots \ldots \ldots \ldots \ldots \ldots \ldots \ldots \ldots \ldots$

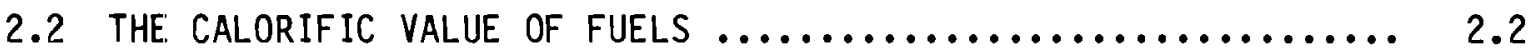

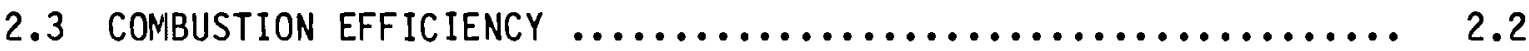

3.0 FEATURES OF COMBUSTING FUELS WITH OXYGEN $\ldots \ldots \ldots \ldots \ldots \ldots \ldots \ldots \ldots \ldots$

3.1 HigheR COMBUSTION TEMPERATURES $\ldots \ldots \ldots \ldots \ldots \ldots \ldots \ldots \ldots \ldots \ldots \ldots$

3.2 LOWER NITROUS OXIDE PRODUCTION $\ldots \ldots \ldots \ldots \ldots \ldots \ldots \ldots \ldots \ldots \ldots . \ldots \ldots$

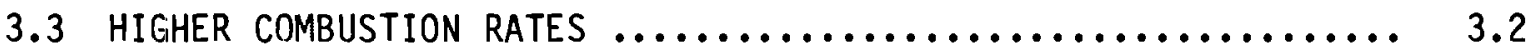

3.4 LOWER IGNITION TEMPERATURES $\ldots \ldots \ldots \ldots \ldots \ldots \ldots \ldots \ldots \ldots \ldots \ldots \ldots \ldots \ldots \ldots \ldots \ldots \ldots$

3.5 WIDER FlaMMABILITY RANGE $\ldots \ldots \ldots \ldots \ldots \ldots \ldots \ldots \ldots \ldots \ldots \ldots \ldots \ldots \ldots \ldots \ldots$

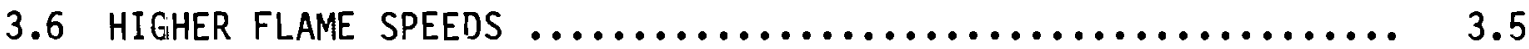

3.7 HIGHER SPECTRAL RADIATION $\ldots \ldots \ldots \ldots \ldots \ldots \ldots \ldots \ldots \ldots \ldots \ldots \ldots \ldots \ldots \ldots$

3.8 HIGHER UPPER FLAME TEMPERATURE LIMITS $\ldots \ldots \ldots \ldots \ldots \ldots \ldots \ldots \ldots$

4.0 COMBUSTION OF HIGH- AND LOW-BTU FUELS WITH OXYGEN $\ldots \ldots \ldots \ldots \ldots \ldots \ldots$

4.1 BURNING HIGH- AND MEDIUM-BTU FUELS $\ldots \ldots \ldots \ldots \ldots \ldots \ldots \ldots \ldots \ldots . . \ldots \ldots$

4.2 BURNING LOW-BTU FUELS $\ldots \ldots \ldots \ldots \ldots \ldots \ldots \ldots \ldots \ldots \ldots \ldots \ldots \ldots \ldots \ldots \ldots$

5.0 PRACTICAL BENEFITS IN USING OXYGEN FOR COMBUSTION $\ldots \ldots \ldots \ldots \ldots \ldots \ldots$

5.1 PREPONDERANT GENERATION OF LATENT HEAT $\ldots \ldots \ldots \ldots \ldots \ldots \ldots \ldots . . \ldots$

5.2 MOLECULAR DISSOCIATION AT HIGH TEMPERATURES $\ldots \ldots \ldots \ldots \ldots \ldots . . . . .2$

5.3 PRESSURE EFFECTS $\ldots \ldots \ldots \ldots \ldots \ldots \ldots \ldots \ldots \ldots \ldots \ldots \ldots \ldots \ldots \ldots \ldots \ldots \ldots \ldots \ldots \ldots$

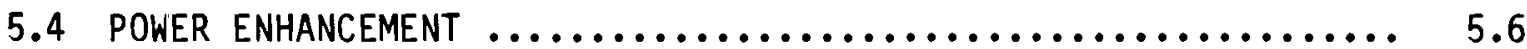


5.5 LOW EMISSION OF NITROUS OXIDES $\ldots \ldots \ldots \ldots \ldots \ldots \ldots \ldots \ldots \ldots, 5.8$

5.6 IGNITION FACILITATION $\ldots \ldots \ldots \ldots \ldots \ldots \ldots \ldots \ldots \ldots \ldots \ldots \ldots \ldots . \ldots \ldots$

6.0 ECONOMIC CONSIDERATIONS $\ldots \ldots \ldots \ldots \ldots \ldots \ldots \ldots \ldots \ldots \ldots \ldots \ldots \ldots \ldots \ldots \ldots \ldots \ldots \ldots .1$

7.0 ACTUAL AND POTENTIAL APPLICATIONS OF COMBUSTION WITH OXYGEN ...... 7.1

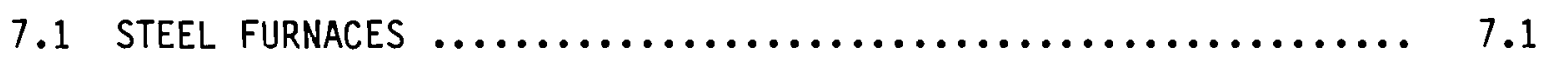

7.2 RECiRCULATION OF COMBUSTION GASES $\ldots \ldots \ldots \ldots \ldots \ldots \ldots \ldots \ldots . . \ldots \ldots \ldots$

7.2.1 Reasons for Recirculation $\ldots \ldots \ldots \ldots \ldots \ldots \ldots \ldots \ldots, 7.3$

7.2.2 Applications of Combustion with Exhaust

7.3 NEW IDEAS FOR THE USE OF OXYGEN IN COMBUSTION $\ldots \ldots \ldots \ldots \ldots \ldots 7.11$

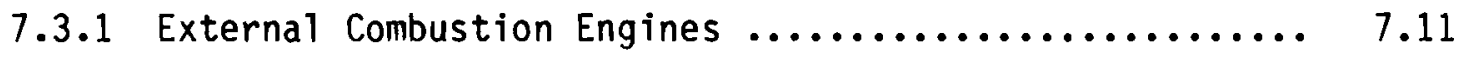

7.3.2 Internal Combustion Engines $\ldots \ldots \ldots \ldots \ldots \ldots \ldots \ldots \ldots . . .1 .16$

7.3.3 Pulse Combustion ........................... 7.20

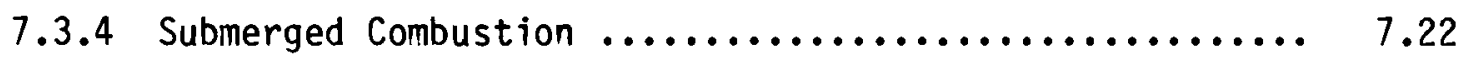

7.3.5 Wet 0xidation and Combustion of Wet Fuels .......... 7.24

7.3.6 In Situ Vitrification of Waste $\ldots \ldots \ldots \ldots \ldots \ldots \ldots \ldots, 7.32$

7.3.7 In Situ Thermal Heating of Tar Sands $\ldots \ldots \ldots \ldots \ldots \ldots .7 .34$

7.3.8 Gasification of Fossil Materials ............... 7.36

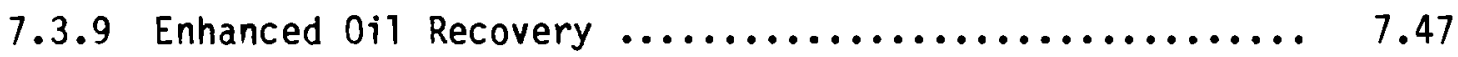

7.4 USE OF "COLD" ENERGY FOR ADDITIONAL IMPROVEMENT
OF THERMODYNAMIC EFFICIENCY $\ldots \ldots \ldots \ldots \ldots \ldots \ldots \ldots \ldots \ldots \ldots, \ldots \ldots \ldots, \ldots \ldots \ldots$

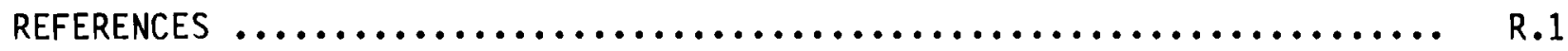

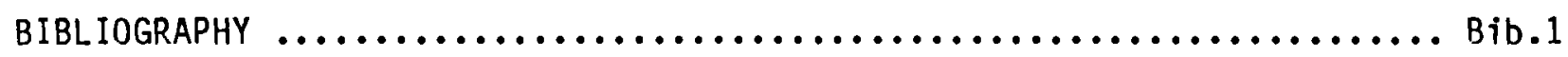

APPENDIX - BURNING COAL WITH AIR $\ldots \ldots \ldots \ldots \ldots \ldots \ldots \ldots \ldots \ldots \ldots \ldots \ldots \ldots \ldots \ldots \ldots \ldots$ A.1 
FIGURES

3.1 Limits of Flammability of Various Methane-Inert Gas-Air

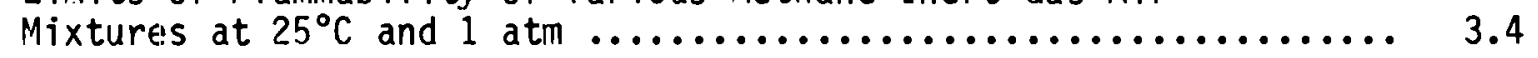

3.2 Closed-Tube Determinations of Variation in Spatial Flame

Speed with Oxygen Concentration ......................... 3.6

3.3 Quenching Distances Between Parallel Plates and Limiting

Tube Diameters for Mixtures of Propane-0xygen-Nitrogen

at Room Temperature and Atmospheric Pressure ................ 3.7

4.1 Factor of Increase in Net Heat Content of Combustion

Gases When Using Pure $0 x y g e n$ Instead of Air ............... 4.4

5.1 Nonl inear Increase of the Total Heat Content of Combustion

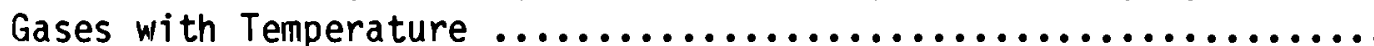

5.2

5.2 Enthalpy-Temperature Diagram for Most Solid

and Licjuid Fuels .................................... 5.3

5.3 Combustion Temperatures as a Function of Oxygen Content ........ 5.3

5.4 Average Dilatation of Combustion Products as a Result of Dissociation ..................................... 5.5

5.5 Combustion Gas Composition at Chemical Equilibrium

for Combusting Coal Gas with Pure Oxygen .................. 5.5

7.1 Basic Arrangement for a Boiler with Exhaust Gas

Recirculation ...................................... 7.4

7.2 Exhaust Gas Recirculation in a Semiclosed Gas Turbine ......... 7.5

7.3 Combustion Gas Recirculation in the MHD Power

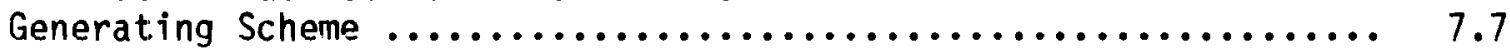

7.4 Typical Open-Cycle Power System $\ldots \ldots \ldots \ldots \ldots \ldots \ldots \ldots \ldots \ldots \ldots \ldots$

7.5 Basic Semiclosed $\mathrm{H}_{2} / \mathrm{O}_{2}$ Rankine Cycle ................... 7.9

7.6 Internal Combustion Engine (Ford F-250 Pickup)

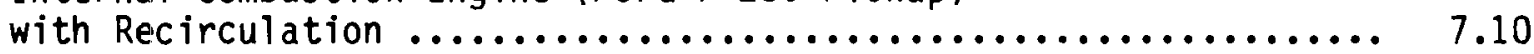

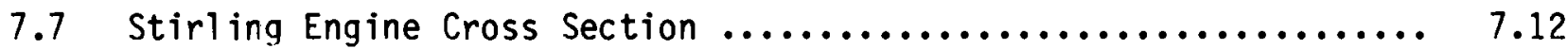

7.8 Sequence of Events in a Stirling Engine Work Cycle ........... 7.13

7.9 Proposed Vortex Combustion Chamber for Stirling Engine 
7.10 Configuration for Operating a Piston Engine on Oxygen

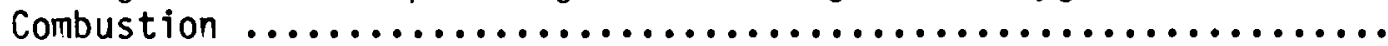

7.11 Internal Combustion Engine Modified to Burn Ammonia ........... 7.19

7.12 Evaporation by Submerged Combustion $\ldots \ldots \ldots \ldots \ldots \ldots \ldots \ldots \ldots \ldots . \ldots \ldots$

7.13 Steam Generation by Submerged Combustion ................. 7.24

7.14 Pressurized Fluidized Bed Arrangement for Use

with Wet Fuels ................................... 7.27

7.15 Burning Wet Fuels with Oxygen for Direct Steam Generation ...... 7.28

7.16 Pressurized Fluidized Bed Combustor in a Combined Cycle

(Gas Turbine with Steam Bottoming) ..................... 7.29

7.17 Pressurized Fluidized Bed Combustor in a Single Cycle with Recirculation ............................... 7.30

7.18 In Situ Waste Vitrification $\ldots \ldots \ldots \ldots \ldots \ldots \ldots \ldots \ldots \ldots \ldots \ldots \ldots \ldots \ldots$

7.19 Alternative Concept for Sol idifying and Isolating Waste

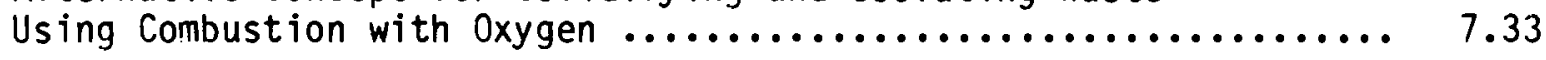

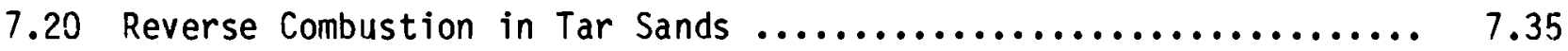

7.21 Coal Gasification Using Oxygen for Production

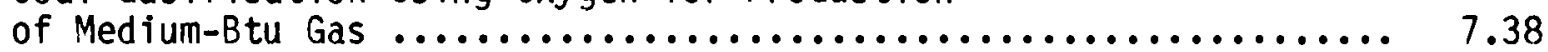

7.22 Ammonia Production from Coal Using Oxygen for Synthesis Gas Generation ................................... 7.39

7.23 Basic Coal Gasification Processes Using Steam/Air

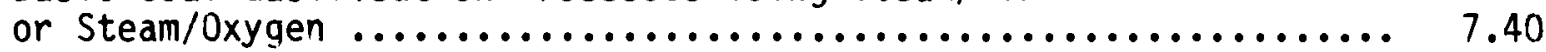

7.24 Underground Gasifier Using 0xygen $\ldots \ldots \ldots \ldots \ldots \ldots \ldots \ldots \ldots \ldots \ldots . \ldots \ldots$

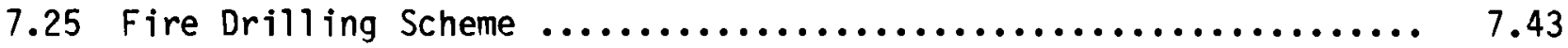

7.26 Drilling Horizontal Holes in Coal Beds from the Surface with water Jets ................................. 7.44

7.27 Cost Comparison of Various Enhanced $0 i 1$ Recovery Methods ....... 7.48 


\section{TABLES}

3.1 Comparison of Gaseous Mixture Ignition Temperatures in Air

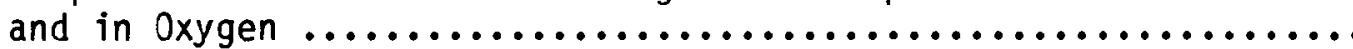

3.2 Comparison of Spontaneous Ignition Temperatures in Air

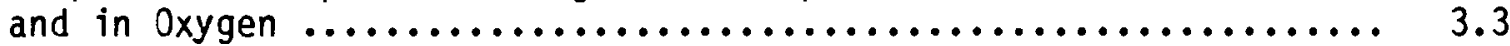

3.3 Comparison of Fuel Flammability Limits in Air and in Oxygen ..... 3.3

3.4 Burning Velocity and Quenching Distance for Combustion

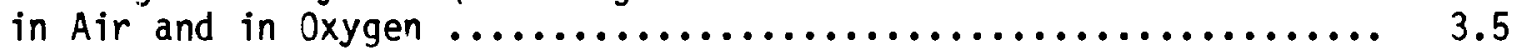

3.5 Approximate Flame Temperatures of Various Stoichiometric Mixtures ......................................... 3.9 


\section{EFFICIENCY EVALUATION OF OXYGEN ENRICHMENT \\ IN ENERGY CONVERSION PROCESSES}

\subsection{INTRODUCTION}

When Linde introduced a process for large-scale production of liquid air about 80 years ago, it was predicted that oxygen would one day be used to enrich or even to replace air in certain industrial processes. Coal gasification, as well as other high temperature chemical processes and new methods for power production, were envisioned (Fehling 1948; Critchley 1954).

For a long time, it was undoubtedly too expensive to produce oxygen in large quantities. However, even since World War II, when abundant low-priced energy supplies in the form of $0 i 1$ and natural gas became available, the expected widespread use of oxygen never came about. Perhaps the same fact, namely that energy was abundant and cheap, led to the attitude that efficiency of a combustion process was of no great concern. However, this favorable energy situation has changed drastically since 1973. It is, therefore, opportune to reexamine the potential advantages of using oxygen for combustion, especially because the many technical and thermodynamic implications of enriching or replacing air by oxygen are generally not yet fully understood.

When oxygen is substituted for air in the combustion of fuels, chemical reaction rates can be expected to accelerate considerably. As a result, combustion temperatures and efficiencies would be increased, which, in turn, would generate higher heat transfer rates. Because nitrogen would be eliminated from the combustion air, emission of nitrous oxides in the exhaust would be greatly reduced, representing a substantial benefit in terms of air pollution abatement.

The reserves of the more convenient liquid and gaseous high-Btu fuels (such as oil and natural gas) inevitably are shrinking. However, large quantities of the less desirable solid fuels (such as coals, which are still highBtu fuels) and those of decidedly lower quality (such as oil shales, tar sands, peats, waste products) fortunately can be found in the U.S. It is, therefore, 
desirable to find ways to use these low-Btu fuels most efficiently. One way is to clean and upgrade them synthetically to a higher calorific value (synfuels) so that they become essentially equivalent to the high-Btu fuels currently used. This now seems to be the preferred method and will probably remain so in the foreseeable future. However, the production of such synthetic fuels requires much energy and large and complex processing plants, which makes the synthetic fuels quite expensive. Another possibility would be to use the lowBtu fuels as they are without (or with only minimal) preprocessing, i.e., burn them directly (Schächter 1979). Unfortunately, their direct combustion is often not very efficient, mainly because the resulting burning rates and flame temperatures are rather low. This disadvantage can be significantly compensated for by various means, such as preheating of the fuel and/or combustion air, mixture with a certain amount of high-Btu fuels, or combustion with oxygen-enriched air or even pure oxygen. The last option has received almost no attention to date.

The last alternative, combustion with oxygen, will be discussed in this report. The work was performed by the Pacific Northwest Laboratory (PNL) (a) for the U.S. Department of Energy (DOE). Funding was provided by DOE's Division of Energy Conversion and Utilization Technologies, which supports longterm, high-risk research and development necessary to expand a technology base that will encourage an increase in energy use efficiency and the use of noncritical fuels.

The current study represents merely a first look at combustion with oxygen. Therefore, a fully comprehensive treatment cannot be expected. Rather, the presentation will remain sketchy, and the need for additional in-depth research is indicated in many instances. The main goal of this effort is to draw more attention to the option of improving the overall energy situation with domestically available resources. How successful this option could eventually become cannot be predicted yet. However, in view of our since 1973 deteriorated energy supply situation, any of the available options for improvement should be given at least a cursory investigation.

(a) Operated by Battelle Memorial Institute for the U.S. Department of Energy. 
This report presents the underlying reasons for using oxygen to enhance the thermal efficiency of combustion and describes several examples where oxygen has been or potentially can be used.

Sections 2.0 and 3.0 briefly examine the effects that the use of oxygen would have on combustion. The potential limitations of such an approach are discussed in Section 4.0 as they would apply to 1ow- and high-Btu fuels. The resulting benefits are outlined in general terms in Section 5.0 for various practical applications. Economic considerations associated with combustion with oxygen are discussed in Section 6.0. The concept of combustion gas recirculation is introduced in Section 7.0 as an effective way to improve combustion efficiency when using oxygen. A major portion of Section 7.0 is devoted to specific applications of combustion with oxygen. It describes both existing technology as well as suggestions for new applications that would need further research and development. 
. 


\subsection{CHARACTERISTICS OF GENERAL COMBUSTION}

The Second Law of Thermodynamics implies, quite generally, that the efficiency of a process for converting heat energy to useful work can be increased by raising the temperature at which heat is introduced into the process and by decreasing the temperature at which it is withdrawn. (a) This means that the flame temperature of a combustion process, when used as a source of energy, should be as high as practically possible. In other words, fuels should be burned in such a way that their combustion provides the highest temperature tolerable under the given circumstances.

\subsection{THE ROLE OF DILUENTS}

The highest temperatures are obtained by the combustion of fuels that provide the highest heat of combustion, where both fuels and oxidizer, mixed at stoichiometric conditions, are free from diluents. Thus, when carbonaceous (fossil) fuels are burned, the highest temperatures (well above $3000^{\circ} \mathrm{C}$ ) are reached by combusting pure carbon or carbohydrates in a stoichiometric mixture with pure oxygen. (b) The combustion temperature decreases when the fuel reactions are less exothermic and when the fuel and/or oxidizers contain inert materials that do not contribute to the generation of heat. Such inert materials are present in almost all combustion processes because air $\left(_{20 \%} \mathrm{O}_{2} ; 80 \%\right.$ inerts, mainly $\mathrm{N}_{2}$ ) is usually used, and because most fuels are mixtures of various combustible and noncombustible substances. In the case of nitrogen diluents (both as a gas and as a fuel-bound component) higher combustion temperatures generally favor higher nitrous oxide $\left(\mathrm{NO}_{x}\right)$ generation rates. This, unfortunately, is a disadvantage; for this reason, higher combustion temperatures must of ten be avoided.

(a) The significance of the low temperature limit of the process will be discussed in Section 7.4.

(b) The cited temperature is for combustion at atmospheric pressure, when both fuel and oxidizer are at ambient temperature before the initiation of the combustion. 


\subsection{THE CALORIFIC VALUE OF FUELS}

The noncombustible materials in low-Btu fuels far outweigh their combustible counterparts. For this reason, low-Btu fuels are of 1 imited practical value and have been largely neglected as sources of energy to date. Not only do they allow only a low flame temperature (and, thus, low thermodynamic efficiency), but they are much bulkier than the higher-Btu fuels for the same amount of energy content. Thus, their specific mining and transportation costs are much higher.

Fuel-bound oxygen usually also reduces the calorific value of a fuel because it is already partially combined with hydrogen or carbon. Because the calorific values of carbon and hydrogen are in the ratio of $1: 4.25$ (by weight), a fossil fuel generally becomes more valuable if its hydrogen-to-carbon ratio is high and its oxygen content is low.

\subsection{COMBUSTION EFFICIENCY}

So long as the end products of the combustion of a given fuel are the same, the exothermic heat generated by its oxidation reaction is constant, no matter whether the combustion takes place with air or with oxygen, at low temperatures or at high temperatures, at low rates or at high rates. However, the efficiency of the combustion (i.e., the amount of heat available for practical use over the total amount of heat theoretically available) depends very much on the manner in which the combustion takes place. Here the potential advantages of oxygen enhancement come into play. In other words, the calorific value of a fuel is by no means the only criterion for its practical usefulness.

To maximize combustion efficiency, the end products of any combustion process should be as close to the theoretical composition (based on complete stoichiometric reactions) as possible; i.e., neither unburned fuel and excess oxidizer, nor any only partially oxidized products (e.g., CO), should be present in the exhaust. Such conditions can be obtained only by thorough mixing of the proper amounts of fuel and oxidizer, and by maintaining the correct reaction conditions (such as temperature). Much of combustion technology deals 
with the expedient generation of these conditions for a particular burning process. The use of oxygen instead of air has a profound influence on these conditions. 


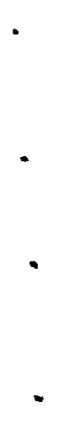




\subsection{FEATURES OF COMBUSTING FUELS WITH OXYGEN}

Fuels have widely different heats of combustion, depending on their chemical constitution, and on the type and amount of contaminants they contain. The highest value is $61,000 \mathrm{Btu} / 1 \mathrm{~b}$ for pure hydrogen, whereas the low values of highly diluted fuels extend almost to zero. Of course, in the very-low-Btu cases, one can hardly speak of "fuels" any more. But what is the lower $1 \mathrm{imit}$ for a fuel that is still of practical value? Evidently, the answer would depend on how much oxygen is present in the combustion air.

\subsection{HIGHER COMBUSTION TEMPERATURES}

When oxygen is substituted for air in a combustion process, the resulting changes are not so much qualitative but mainly quantitative in nature. Because the nitrogen is eliminated, there is no need to heat up this normally present diluent gas to combustion temperatures. Hence, the entire exothermic heat of the combustion reaction is contained in a correspondingly smaller amount of combustion gases. The results are generally higher combustion temperatures and higher volumetric and gravimetric heat contents of the combustion gases. This, in turn, allows higher heat transfer rates to the load (e.g., boiler tubes) and usually more compact furnaces and exhaust gas treatment facilities. As explained later in this report, the higher heat transfer rates result from both higher conductive/convective coefficients and higher radiative transfer. Even though (black body) emissivity of the flames is likely to decrease with oxygen combustion since soot particles will be greatly reduced, this is more than compensated for by the relatively higher spectral radiation of $\mathrm{CO}_{2}$ and $\mathrm{H}_{2} \mathrm{O}$ molecules because the low radiating $\mathrm{N}_{2}$ species have been removed.

\subsection{LOWER NITROUS OXIDE PRODUCTION}

The el imination of $\mathrm{N}_{2}$ in the combustion air also reduces nitrous oxide $\left(N D_{x}\right)$ air pollutants substantially so that higher combustion temperatures can generally be used without the possibility of incurring a higher $\mathrm{NO}_{x}$ production. (However, because fuel-bound nitrogen is not reduced, even with $100 \%$ oxygen 
combustion, a flue gas completely free of ${ }^{\mathrm{NO}} \mathrm{x}$ is practically not achievable unless very clean fuels are used.)

\subsection{HIGHER COMBUSTION RATES}

Higher combustion temperatures are always accompanied by higher combustion rates. The use of oxygen instead of air will usually increase the rate of many chemical processes, often very significantly, because reaction rates are exponential functions of the absolute temperature. Problems potentially aggravated by the oxygen-caused higher combustion rates and temperatures are mainly those connected with materials, such as refractory linings in furnaces or blades in gas turbines. However, extensive efforts are underway to develop better heatresistant materials (Long 1981 ).

\subsection{LOWER IGNITION TEMPERATURES}

Using pure oxygen instead of air normally reduces ignition temperatures of fuels by about 5 to $70^{\circ} \mathrm{C}$ (Brame and King 1967), as shown in Table 3.1. Spontaneous ignition temperatures also are generally a little lower (Table 3.2). The extent of reduction depends on the type of fuel and is usually more pronounced for liquid fuels than for gaseous fuels. Combustion with $\mathrm{O}_{2}$-enriched air lowers the ignition temperature correspondingly less, of course. The

TABLE 3.1. Comparison of Gaseous Mixture Ignition Temperatures in Air and in Oxygen

\begin{tabular}{lccc}
\multicolumn{1}{c}{ Gas } & & \multicolumn{2}{c}{ Ignition Temperature, ${ }^{\circ} \mathrm{C}$} \\
Hydrogen & & 572 & $\frac{\text { In Oxygen }}{\text { In Air }}$ \\
\cline { 3 - 3 } Carbon monoxide & 609 & 560 \\
Methane & 632 & 588 \\
Ethane & 472 & 556 \\
Ethylene & 490 & 450 \\
Acetylene & 305 & 485 \\
& & 296
\end{tabular}


TABLE 3.2. Comparison of Spontaneous Ignition Temperatures in Air and in Oxygen

\begin{tabular}{|c|c|c|}
\hline & Ignitior & ature, ${ }^{\circ} \mathrm{C}$ \\
\hline Gas & In Air & In Oxygen \\
\hline Benzene & 580 & 566 \\
\hline Carbon disulfide & 120 & 107 \\
\hline Ethane & 472 & 432 \\
\hline n-Pentane & 290 & 258 \\
\hline Toluene & 552 & 516 \\
\hline Hydrogen sulfide & 292 & 220 \\
\hline Petrol, 92 octane & 430 & 415 \\
\hline Diesel oil, 60 cetane & 247 & 242 \\
\hline
\end{tabular}

initial ignition of some fuels is rather difficult in air, whereas with oxygen (or even oxygen-enriched air) no problems are encountered. A typical example for such fuels is ammonia (Bomelburg 1980).

\subsection{WIDER FL.AMMABILITY RANGE}

The 1 imits of $\mathrm{flammability}$ for the various fuel/oxidizer combinations are widened if oxygen is substituted for air (Glassman 1977). As shown in Table 3.3, the lower flammability limit generally moves to leaner fuel/oxidizer

TABLE 3.3. Comparison of Fuel Flammability Limits in Air and in Oxygen

\begin{tabular}{|c|c|c|c|c|}
\hline & & \\
\hline Fuel & $\overline{A i r}$ & $\mathrm{O}_{2}$ & $\overline{\text { Air }}$ & $0_{2}$ \\
\hline Hydrogen, $\mathrm{H}_{2}$ & 4 & 4 & 74 & 94 \\
\hline Carbon monoxide, CO & 12 & 16 & 75 & 94 \\
\hline Ammonia, $\mathrm{NH}_{3}$ & 15 & 15 & 28 & 79 \\
\hline Methane, $\mathrm{CH}_{4}$ & 5 & 5 & 14 & 61 \\
\hline Propane, $\mathrm{C}_{3} \mathrm{H}_{8}$ & 2 & 2 & 10 & 55 \\
\hline
\end{tabular}


ratios and the upper limit always moves to richer ratios. However, the upper limit is affected much more than the lower limit.

If the diluent $\mathrm{N}_{2}$ is replaced by other diluent gases (such as $\mathrm{H}_{2} \mathrm{O}$ or $\mathrm{CO}_{2}$ ), the flammability limits of a particular fuel are also influenced. Figure 3.1, based on National Bureau of Standards data (Zabetakis 1976), illustrates this effect.

Generally, these other diluents have a stronger inhibiting effect than nitrogen. In particular, certain halogenated substances (e.g., MeBr in

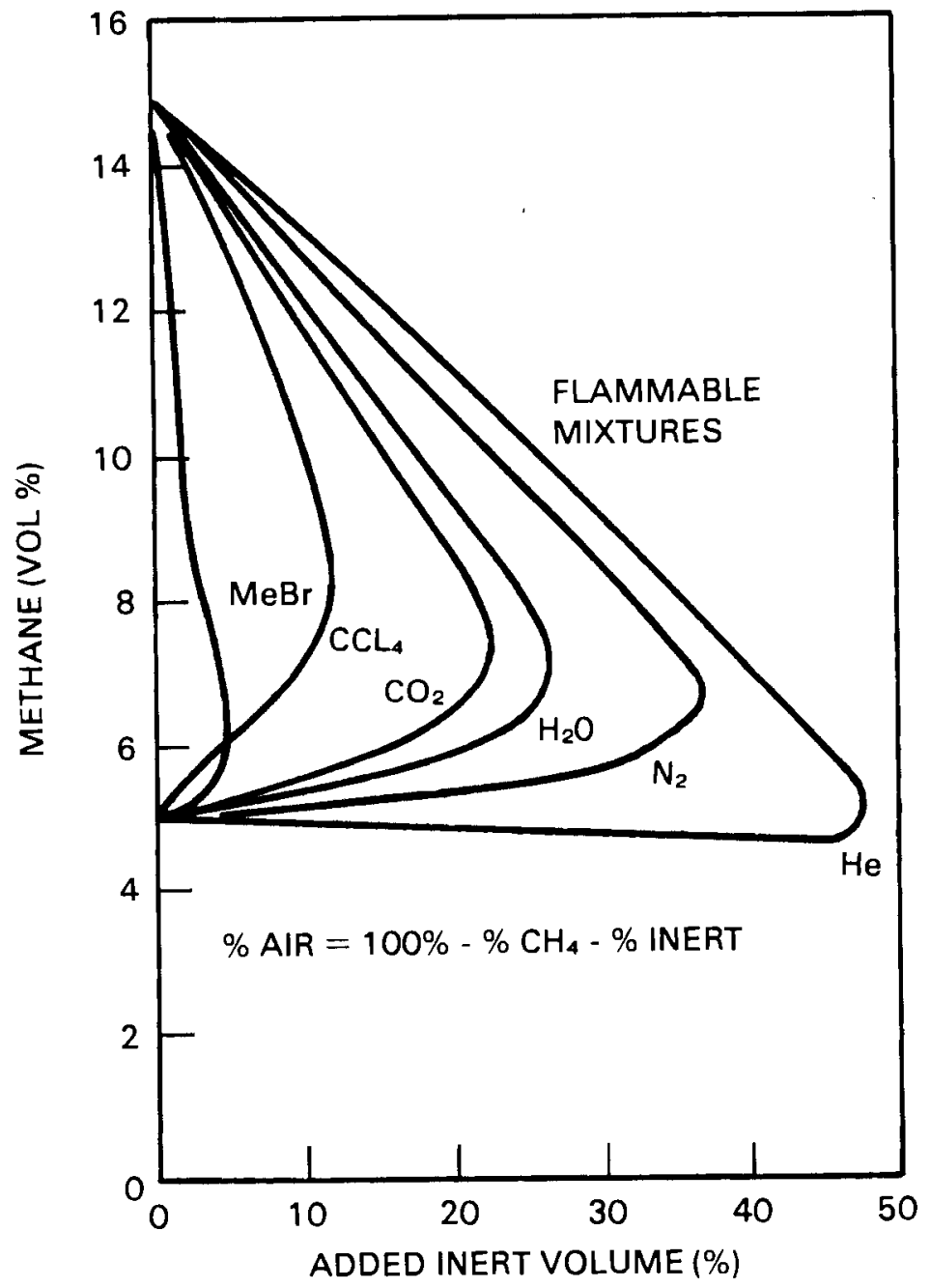

FIGURE 3.1. Limits of Flammability of Various Methane-Inert Gas-Air Mixtures at $25^{\circ} \mathrm{C}$ and $1 \mathrm{~atm}$ 
Figure 3.1) can act as flame suppressants and, therefore, are often used in fire extinguishers. This has al so some implications when exhaust gas recirculation is used in connection with oxygen combustion, as described later in this report.

\subsection{HIGHER FLAME SPEEDS}

The velocity of flame propagation (i.e., the speed--sometimes called burning velocity--at which a flame front will travel through a gas/oxidizer mixture) is increased significantly as air becomes more enriched in oxygen. (a)

The lowest flame velocity for air combustion is $-0.2 \mathrm{~m} / \mathrm{sec}$ for all types of combustion. Pure hydrogen combusted in a stoichiometric mixture with oxygen produces the highest flame velocities (Table 3.4). Because of the increased turbulence level associated with higher flame speeds, oxygen enrichment al so leads to a higher probability of transition to detonation(b) if an oxygen-rich vapor cloud of gaseous fuel is ignited (Lee and Moen 1980).

TABLE 3.4. Burning Velocity and Quenching Distance for Combustion in Air and in Oxygen

\begin{tabular}{|c|c|c|}
\hline $\begin{array}{c}\text { Combustible } \\
\text { Mixture }\end{array}$ & $\begin{array}{l}\text { Standard Burning } \\
\text { Velocity, m/sec } \\
\end{array}$ & $\begin{array}{c}\text { Quenching } \\
\text { Diameter, } \\
10^{-3} \mathrm{~m}\end{array}$ \\
\hline Propane/Air & 0.46 & 2.6 \\
\hline Propane/0xygen & 3.9 & 0.37 \\
\hline Hydrogen/Air & 3.3 & 0.85 \\
\hline Hydrogen/Oxygen & 11.7 & 0.30 \\
\hline Acetylene/Air & 1.7 & 0.78 \\
\hline Acetylene/0xygen & 11.1 & 0.12 \\
\hline
\end{tabular}

(a) Since $\mathrm{CO}_{2}$ and $\mathrm{H}_{2} \mathrm{O}$ have a decreasing effect on flame velocity, it becomes more important to burn with oxygen when parts of the exhaust gases are being recirculated--see page $7.2 \mathrm{ff}$.

(b) It has been shown (Nicholls and Sichel 1980) that if air is replaced by oxygen in a stoichiometric methane vapor cloud, the energy density required to initiate detonation is decreased about a million times. 
The increased reaction rates, when air is replaced by oxygen in a combustion process, are indicated quantitatively in Table 3.4, which compares the burning velocity and the quenching distance(a) for some typical gaseous fuels (Magison 1978). The increase of flame speed when combusting gasoline with oxygen-enriched air is shown in Figure 3.2 (Masi et a1. 1947).

Figure 3.3 vividly shows the much wider range--for both stoichiometric and nonstoichiometric conditions--over which fuels can be burned when air is replaced by pure oxygen (Magison 1978).

The small quenching distance obtainable with oxygen combustion may be of importance when burning oil shales, tar sands, or any substance in which the combustible material is contained in the form of small particles within a

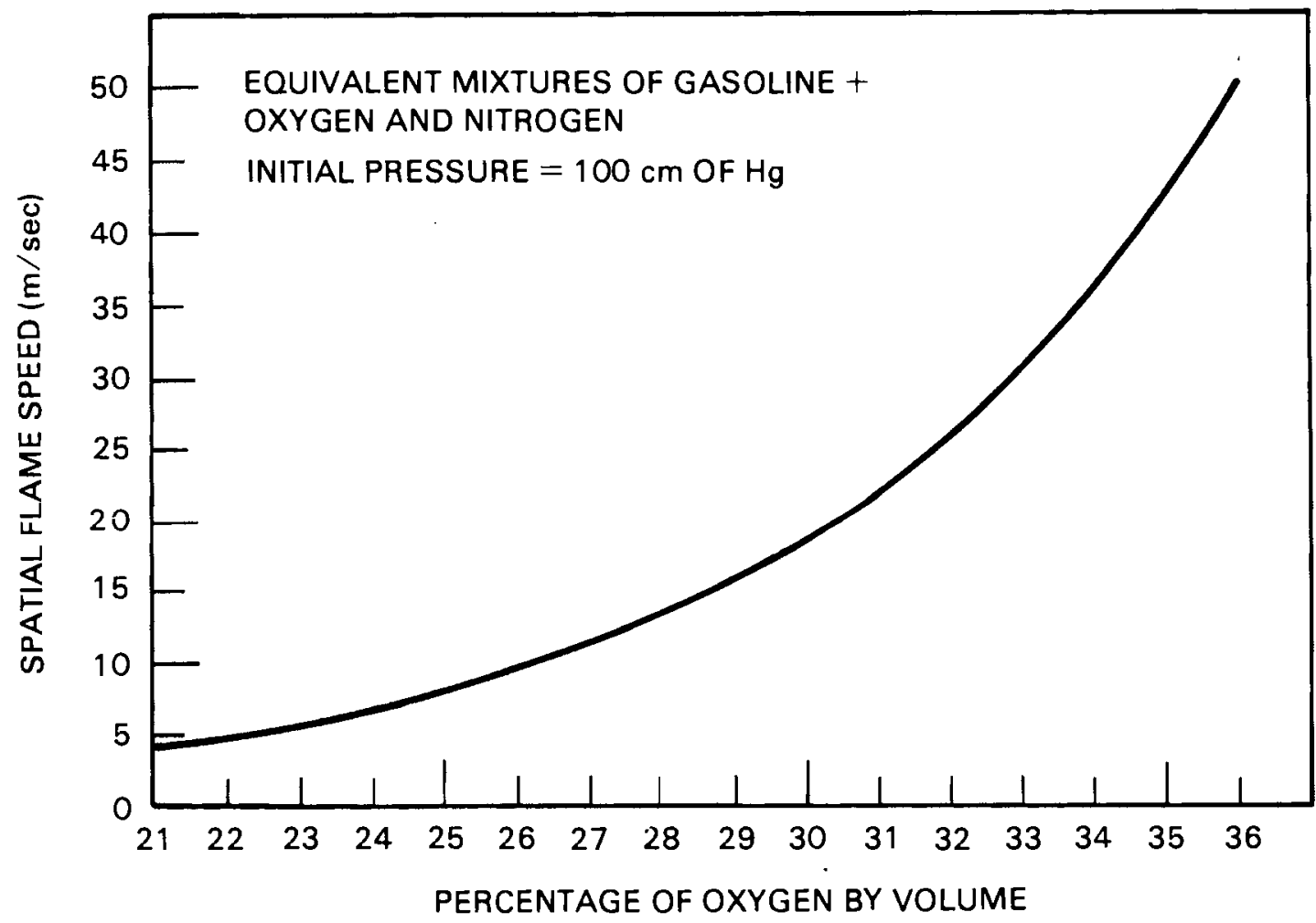

FIGURE 3.2. Closed-Tube Determinations of Variation in Spatial Flame Speed with Oxygen Concentration

(a) For a definition of "quenching distance", see Glassman (1978, p. 99). 


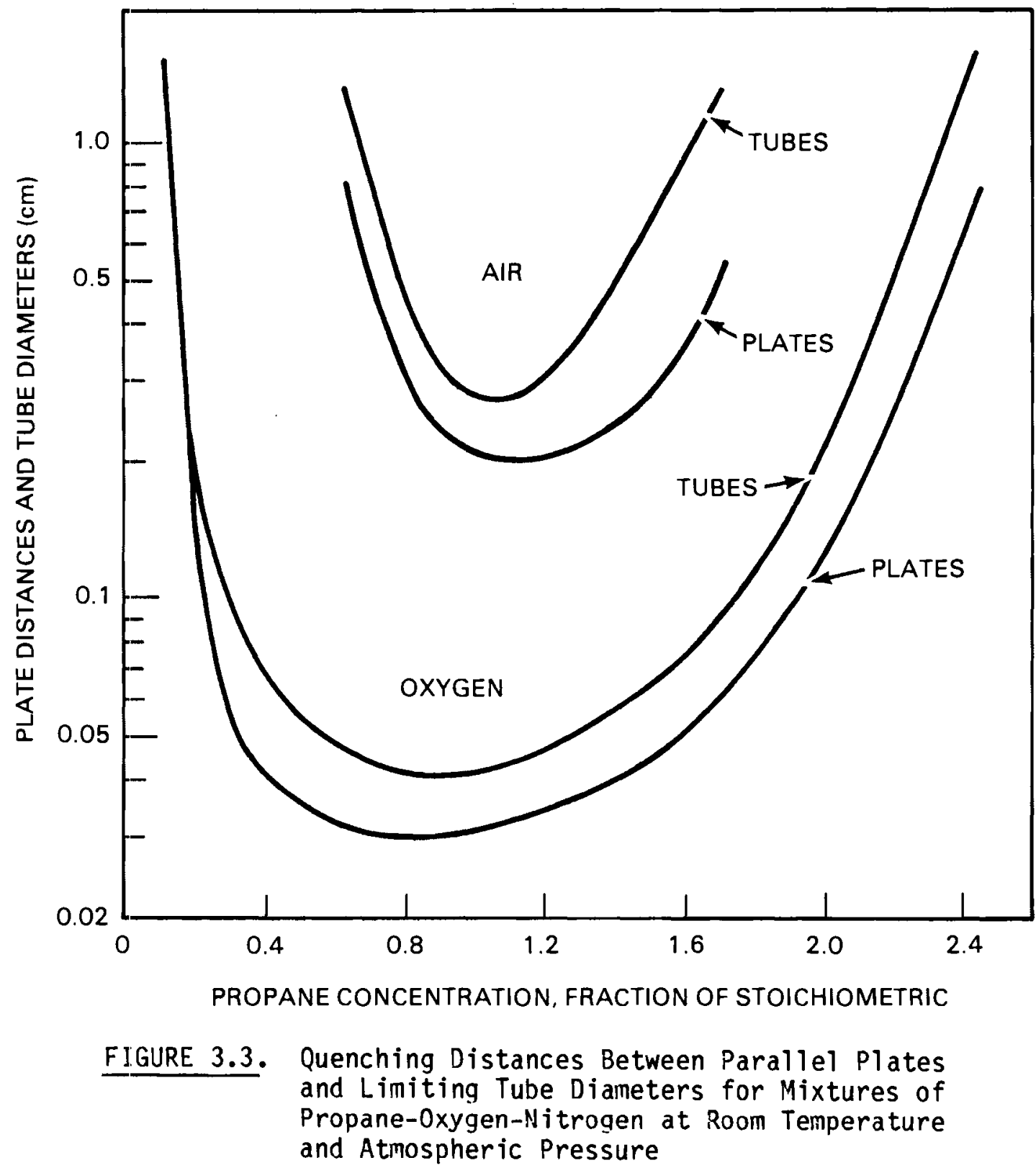

matrix of noncombustible material. It is very likely that such substances can be combusted more easily and more completely in oxygen than in air.

\subsection{HIGHER SPECTRAL RADIATION}

In $\mathrm{flames,}$ oxygen, nitrogen, and hydrogen radiate little and thus practically do not contribute to radiative heat transfer from a combustion source. However, both $\mathrm{H}_{2} \mathrm{O}$ and $\mathrm{CO}_{2}$ are good radiators in $\mathrm{flames.} \mathrm{Therefore,} \mathrm{a} \mathrm{fire} \mathrm{rich}$ 
in those combustion products will be able to transfer more heat by radiation than $\mathrm{flames}$ that carry a large proportion of nitrogen. This is important for the recirculation of combustion gases in semiclosed cycles, to be described below. In these cycles $\mathrm{N}_{2}$ is essentially eliminated and replaced by $\mathrm{H}_{2} \mathrm{O}$ and $\mathrm{CO}_{2}$. Thus, semiclosed cycles should be more efficient in heat transfer. Of course, this holds true particularly in such cases as boilers where radiative heat transfer is dominant over convective heat transfer. However, higher spectral radiation may be less important in semiclosed gas turbine cycles (see page 7.5), because here there is no need for transfer of heat from the combustion gases. On the contrary, here all the heat should stay with in the combustion gases because they themselves are the working fluid. (a) Excessive heat transfer would require some form of cooling, to prevent damage to turbine parts such as blades. Because such cooling always involves some waste of energy, the higher spectral radiation would be counterproductive in this case.

\subsection{HIGHER UPPER FLAME TEMPERATURE LIMITS}

Flame temperatures are generally increased to the extent that the oxygen content of the oxidizer is increased (Glassman 1978). Theoretical flame temperatures can be calculated from the heat of combustion, which has been measured for all known fuels. Combusting with $\mathrm{O}_{2}$ excludes the diluent $\mathrm{N}_{2}$ and the need to heat it. Thus, the entire heat content of the fuel is contained in the combustion products (provided, of course, the fuel $/ \mathrm{O}_{2}$ mixture was stoichiometric), which maximizes their temperature. Table 3.5 presents a comparison of approximate $\mathrm{flame}$ temperatures for fuels oxidized with air and with oxygen.

The theoretical adiabatic flame temperatures represent an upper limit which is never reached in real combustion because of radiant heat losses of the combustion gases themselves and because of partial dissociation of these gasis. These losses increase strongly with increasing flame temperature and thus 1 imit: practically achievable combustion temperatures to <3500K. This limiting characteristic is very important when using oxygen for combustion. On one hand, the higher combustion temperatures produced by using oxygen will automatically

(a) A clean gas of low emissivity and with low radiation is the best working fluid for gas turbines. 
TABLE 3.5. Approximate Flame Temperatures of Various Stoichiometric Mixtures

\begin{tabular}{|c|c|c|c|}
\hline Fuel & Oxidizer & $\begin{array}{c}\text { Pressure, } \\
\text { atm }\end{array}$ & $\begin{array}{c}\text { Temperature, } \\
\mathrm{K}\end{array}$ \\
\hline Acetylene & Air & 1 & 2600 \\
\hline Acetylene & Oxygen & 1 & 3410 \\
\hline Carbon monoxide & Air & 1 & 2400 \\
\hline Carbon monoxide & Oxygen & 1 & 3220 \\
\hline Heptane & Air & 1 & 2290 \\
\hline Heptane & Oxygen & 1 & 3100 \\
\hline Hydrogen & Air & 1 & 2400 \\
\hline Hydrogen & Oxygen & 1 & 3080 \\
\hline Methane & Air & 1 & 2210 \\
\hline Methane & Air & 20 & 2270 \\
\hline Methane & Oxygen & 1 & 3030 \\
\hline Methane & Oxygen & 20 & 3460 \\
\hline
\end{tabular}

(according to the Second Law of Thermodynamics) increase the thermodynamic efficiency of a power cycle. On the other hand, however, heat losses will increase also, tending to reduce the efficiency. To counteract this efficiency loss, the combustion air is usually preheated by heat exchange with the heat lost from the combustion process itsel $f$ by regeneration or recuperation schemes. Because preheating and dilution of combustible mixtures are very important factors in practice, most modern furnaces allow for a heat exchange from flue gases to the fuel gases and/or air. If dilution of the combustible mixture is necessary, it is frequently achieved by recirculating hot flue gas rather than by increasing the excess air. With the use of oxygen this type of process can be taken a step further, thereby making it possibly even more efficient as well as cleaner. 


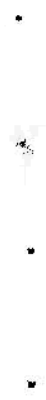




\subsection{COMBUSTION OF HIGH- AND LOW-BTU FUELS WITH OXYGEN}

The only chemical elements useful for combustion purposes are carbon and/or hydrogen in reactions with oxygen. Certain metals and other materials (e.g., sulfur, phosphorus) that can sometimes burn vigorously are not considered practical fuels for various reasons such as cost or noxious combustion products. Both elemental carbon and hydrogen possess a high heat of combustion; therefore, their compounds (known as hydrocarbons) generally al so yield a high heat output when burned. The so-called low- and medium-Btu fuels al so contain carbon and/or hydrogen as their combustible ingredients, but they are usually mixed with a more or less large amount of noncombustible (i.e., diluent) materials, such as water or various kinds of mineral matter. Many of the pure fuels actually are already partially oxidized and, therefore, also belong in the medium-Btu category, even though they do not contain any diluents. Carbon monoxide, methanol, and many other carbohydrates are of this type. However, few pure carbohydrates of practical significance belong to the low-Btu fuel category. Therefore, it can generally be assumed that low-Btu fuels are almost always mixtures of medium- and high-Btu fuels with variously large amounts of diluents.

\subsection{BURNING HIGH- AND MEDIUM-BTU FUELS}

If a fuel is combusted with oxygen instead of air, its heating value does not change; e.g., carbon has a heating value of $14,540 \mathrm{Btu} / 1 \mathrm{~b}$, whether burned in air or oxygen. However, when the heat content of the combustion gases is considered, a significant difference becomes apparent. For example, for the reaction $\mathrm{C}+\mathrm{O}_{2}=\mathrm{CO}_{2}, 1 \mathrm{lb}-\mathrm{mol}$ of $\mathrm{C}(12 \mathrm{lb})$ and $1 \mathrm{lb}-\mathrm{mol}$ of $\mathrm{O}_{2}(32 \mathrm{lb})$ are required to give $1 \mathrm{lb}-\mathrm{mol}$ of $\mathrm{CO}_{2}(44 \mathrm{lb})$. Thus, $14,540 \times 12 \mathrm{Btu}$ are contained in $44 \mathrm{lb}$ of hot $\mathrm{CO}_{2}$. If the combustion takes $\mathrm{place}$ in air, $3.32 \mathrm{lb}$ of $\mathrm{N}_{2}$ are present as a diluent for each $1 \mathrm{~b}$ of oxygen. That means that $32 \times 3.32=106 \mathrm{lb}$ of $\mathrm{N}_{2}$ are present for each $44 \mathrm{lb}$ of $\mathrm{CO}_{2}$, so that the total heat of combustion is divided among $150 \mathrm{lb}$ of hot combustion gases. Thus, for combustion with pure oxygen, the heat content/1b of combustion gases is $150 / 44=3.41$ times larger than for combustion with air. 
When considering gaseous combustion products, it makes more sense to conduct all computations on a volumetric basis, since ideally the mol-volume occupied by a gas is constant (i.e., 22 liters at ambient conditions). Also, many engineering applications require the computation of the mechanical energy available from combustion gases, which is usually expressed as $\int p d v$.

According to the chemical equation for burning carbon (a pure solid fuel), 1 mol-volume of $\mathrm{C}$ requires 1 mol-volume of $\mathrm{O}_{2}$ to produce 1 mol-volume of $\mathrm{CO}_{2}$. If air is used, 3.81 mol-volumes of $\mathrm{N}_{2}$ are carried along as a diluent, so that the total amount is 4.81 mol-volumes of hot gas after combustion. In other words, if pure oxygen is used as the combustion agent, only 1 volume of combus.tion gases is produced, compared to 4.81 volumes in the case of air; i.e., the combustion gases contain nearly five times the energy per unit volume when the combustion is performed with oxygen instead of air. Thus, even though the total energy output remains the same, the energy density of the combustion gases is dramatically increased.

For gaseous fuels the change in energy density of combustion gases is not as drastic as for solid and liquid fuels. For example, consider the combustion of hydrogen or carbon monoxide:

$$
\begin{aligned}
& 2 \mathrm{H}_{2}+\mathrm{O}_{2}=2 \mathrm{H}_{2} \mathrm{O} \\
& 2 \mathrm{CO}+\mathrm{O}_{2}=2 \mathrm{CO}_{2}
\end{aligned}
$$

If combusted with pure oxygen, 2 volumes of fuel plus 1 volume of oxygen will yield 2 volumes of combustion gases. If combusted with air, $\sim 4$ volumes of $\mathrm{N}_{2}$ dilute the gases before and after combustion. In that case $\sim 6$ volumes of combustion gases will result, instead of only 2. Thus, the increase in the volumetric energy density for the two gases is 3, i.e., smaller than for carbon, above, which was shown to be about 5. For ammonia combustion,

$$
2 \mathrm{NH}_{3}+3 \mathrm{O}_{2}=\mathrm{N}_{2}+3 \mathrm{H}_{2} \mathrm{O}
$$


the trend continues. With pure oxygen combustion, 4 volumes of combustion gases will result, compared with 10 volumes of combustion gases for air combustion. Thus, the energy density of the combustion gases increases by a factor of only 2.5 when switching from air to oxygen combustion.

The gaseous fuels just discussed require only a relatively low amount of oxygen for combustion. However, in burning acetylene,

$$
\mathrm{C}_{2} \mathrm{H}_{2}+\frac{5}{2} \mathrm{O}_{2}=\mathrm{H}_{2} \mathrm{O}+2 \mathrm{CO}_{2} \text {, }
$$

a relatively large amount of oxygen is required. This means, however, that in air combustion the dilution with $\mathrm{N}_{2}$ is also quite large $\left(10 \mathrm{~N}_{2}\right)$. Thus, when burning with air, 13 mol-volumes of combustion gases are generated, instead of only 3. Or, conversely, with pure oxygen combustion, the combustion products contain 4.3 times as much energy per volume. This ratio is one of the highest(a) of all chemical reactions and thus theoretically explains why acetylene gives such hot flames when combusted with oxygen (acetylene torch). Basically, this "amplification factor" gives a quantitative indication of the increase in energy density obtainable when substituting oxygen for air in the combustion of a particular fuel. As shown by Fehling (1948), the factor can vary from slightly above 1 to almost 5 (see Figure 4.1 ).

The higher energy density of the combustion gases generally manifests itself in a corresponding temperature increase. This is coupled al so with a correspondingly higher pressure if the combustion takes place in a closed container. As already mentioned, increased temperature basically means a higher thermodynamic efficiency in converting the energy contained in the combustion gases into other forms of energy. Therefore, enriching or replacing air by oxygen for combustion can lead to a better utilization of the fuels.

\subsection{BURNING LOW-BTU FUELS}

For most low-Btu fuels the factor of increase is less than 2. As pointed out above, low-Btu fuels generally contain a considerable amount of

(a) It is the highest for all gaseous fuels. Carbon (a solid fuel discussed above) has the highest factor (4.8) for all types of fuels. 

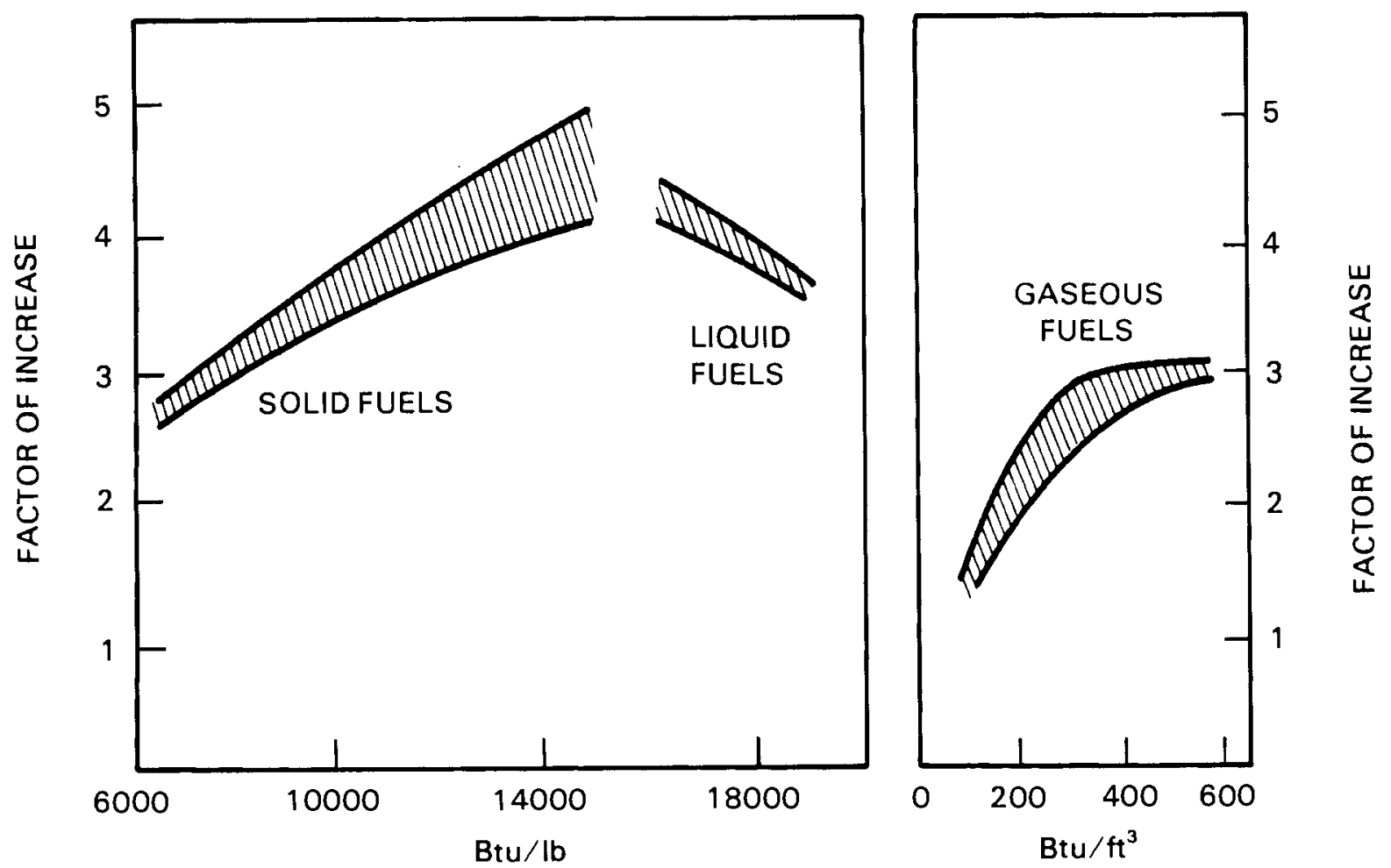

FIGURE 4.1. Factor of Increase in Net Heat Content of Combustion Gases When Using Pure Oxygen Instead of Air

noncombustible matter (e.g., water), which acts as diluent in the combustion process in the same way as the nitrogen in the air does. When pure fuels are combusted with oxygen, it is possible to el iminate essentially all the diluents. However, this is obviously not readily possible in the case of the lowBtu fuels.

The primary reason for using oxygen in burning low-Btu fuels would be to eliminate the large amounts of nitrogen in the combustion air so that flame temperatures and, thus, the efficiencies of the combustion reactions can be increased. Such an approach would be most beneficial for low-Btu fuels that do not generate hot flames when burned with air and that contain little or no diluents. However, as pointed out above, such fuels practically do not exist. 
Hence, essentially any use of oxygen with low-Btu fuels is less than optimal(a) and may, therefore, not be economical in many cases.

Medium- and high-Btu fuels normally can be combusted quite satisfactorily with air. The use of oxygen is, therefore, justified here only for special purposes, which would require separate case-by-case analys is to show whether they would entail significant technical or economic advantages.

The feasibility of making certain applications involving the combustion of low-Btu fuels with oxygen cost-efficient depends on many variables and, thus, also requires special case-by-case analysis for evaluation.

When this study was originally started, it was assumed that by using oxygen instead of air, the flame temperature and the energy yield from low-Btu fuels could be increased significantly because nitrogen as a diluent would be eliminated. However, as indicated above, this is possible only to a limited extent. Thus, combustion efficiency improvements tend to remain small and seemingly do not justify the use of oxygen on an economic basis for most lowBtu fuels. If there were a pure combustible substance in existence which would combine with oxygen under low exothermic conditions, then the use of pure oxygen instead of regular air would, clearly, lead to a marked increase in combustion energy and efficiency.

Unfortunately, these circumstances had not been properly recognized in the beginning. But, on the other hand, it would not be justified to assume that because of these adverse circumstances it would make no economic sense at all to consider the use of oxygen in combustion processes. As will be shown in this report, there are not only certain cases for which the use of oxygen is necessary (i.e., otherwise they would not work at al1), but there are also cases for which the use of oxygen represents a process improvement that could make the additional cost of providing pure oxygen worthwhile economically. A few such processes will be discussed in Section 7.0.

(a) It must be expected that elimination of nitrogen from the combustion air alone will, with low-Btu fuels, not fully achieve all the benefits of combustion with oxygen described in Section 5.0 . 


\subsection{PRACTICAL BENEFITS IN USING OXYGEN FOR COMBUSTION}

Raising the flame temperature through the use of pure oxygen or oxygenenriched air increases not only the thermal efficiency in combustion processes but usually also the heat transfer rate. The thermal efficiency(a) may be defined here as the fraction of the total heat of combustion $\left(H_{t}\right)$ that is available above the heat content of the waste gases $\left(H_{W}\right)$ leaving a furnace $(b)$ and other heat losses $\left(H_{\ell}\right)$ through the furnace walls:

$$
\eta=\frac{H_{t}-\left(H_{w}+H_{l}\right)}{H_{t}}
$$

The numerator represents the heat transferred to the charge. Its terms generally increase with increasing temperature. Thus, in order to keep $\mathrm{H}_{w}+\mathrm{H}_{\ell}$ small, it would be desirable to keep the flame temperatures low. On the other hand, in order to reduce $H_{w}$, the heat transferred to the charge via the heat exchanger surface should be as high as possible. This would call for a high flame temperature, because heat transfer increases with increasing temperature. Thus, there is a dilemma because the requirements for minimizing $H_{w}$ and $H_{l}$ oppose each other.

A compromise solution would be possible if $\mathrm{H}_{t}$ would increase more than linearly with temperature because in such a case, $H_{\ell}$ and also $H_{w}$ would, at higher temperatures, represent a smaller fraction of $H_{t}$; thus, the thermal efficiency would rise. Fortunately, this is exactly what happens in combustion with oxygen.

\subsection{PREPONDERANT GENERATION OF LATENT HEAT}

As the temperatures of the combustion process for the particular fuel increase with an increasing amount of oxygen in the $\mathrm{O}_{2}$-enriched air, proportionally more and more heat is generated in the combustion gases, as shown in Figure 5.1. Most of this heat is in the form of latent heat rather than

(a) The efficiency so defined should be distinguished from the Second Law of Thermodynamics efficiency mentioned previously.

(b) It is assumed for comparison purposes here that the waste gases leave at a distinct constant temperature. 


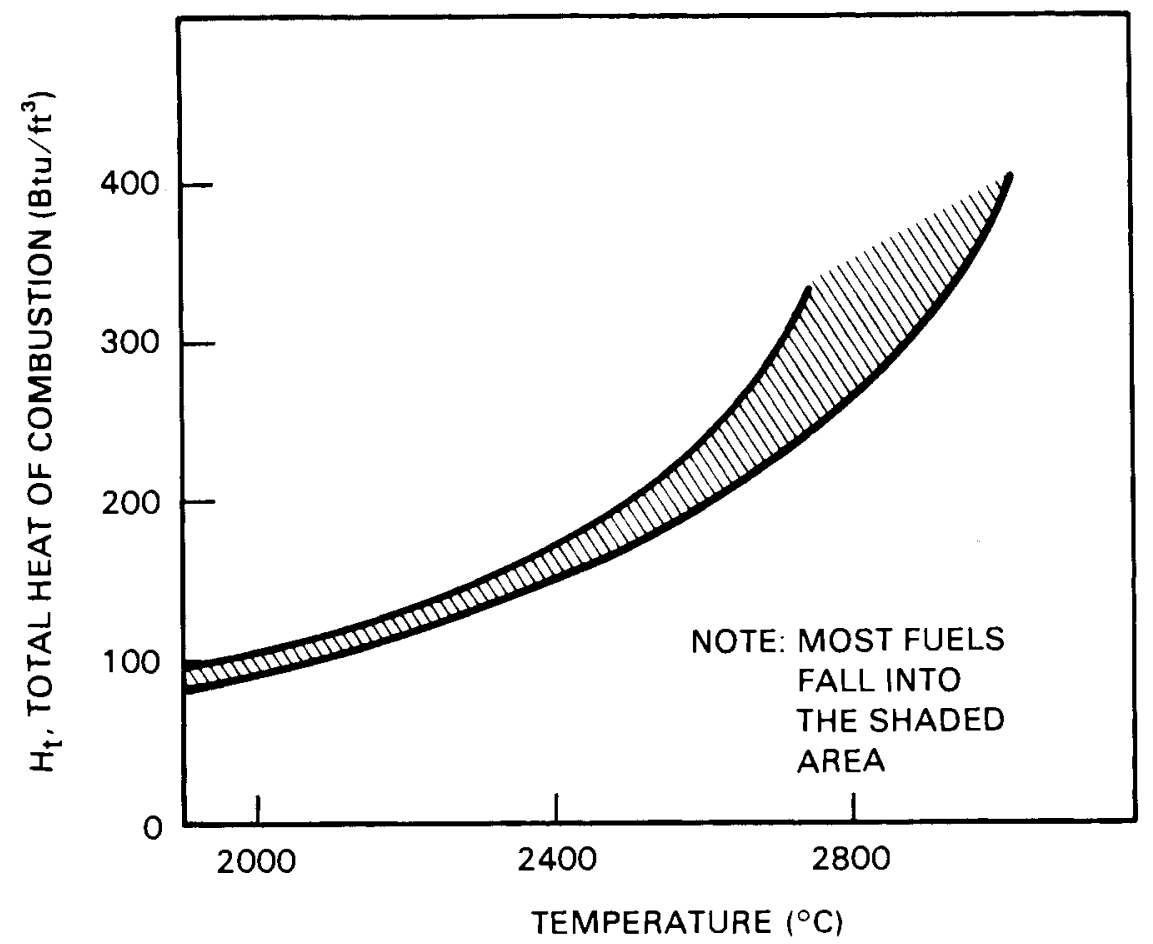

\section{FIGURE 5.1. Nonl inear Increase of the Total Heat Content of Combustion Gases with Temperature \\ (Fehl ing 1948, p. 231)}

sensible heat. Such latent heat (mainly in the form of heat of dissociation) does not contribute to an increase in temperature, but only to an increase in enthalpy (see Figure 5.2). This, in turn, causes a flattening of the temperature versus $0_{2}$-enrichment curves, as shown in Figure 5.3. Figure 5.3 shows al so that increasing the oxygen content of the air from its normal $21 \%$ to $-40 \%$ is relatively more effective than still higher $0_{2}$-enrichments. This characteristic has important implications when considering the economics of oxygen use.

\subsection{MOLECULAR DISSOCIATION AT HIGH TEMPERATURES}

The dissociation of the most common combustion gases $\left(\mathrm{CO}_{2}\right.$ and $\left.\mathrm{H}_{2} \mathrm{O}\right)$ results in molecular species $\left(\mathrm{CO}, \mathrm{O}_{2}, \mathrm{H}_{2}\right)$ as well as a variety of atomic and radical species $(\mathrm{O}, \mathrm{H}, \mathrm{OH}$, etc.).(a) Consequently, the specific volume of the

(a) This is merely a highly simplified explanation of what actually happens. 


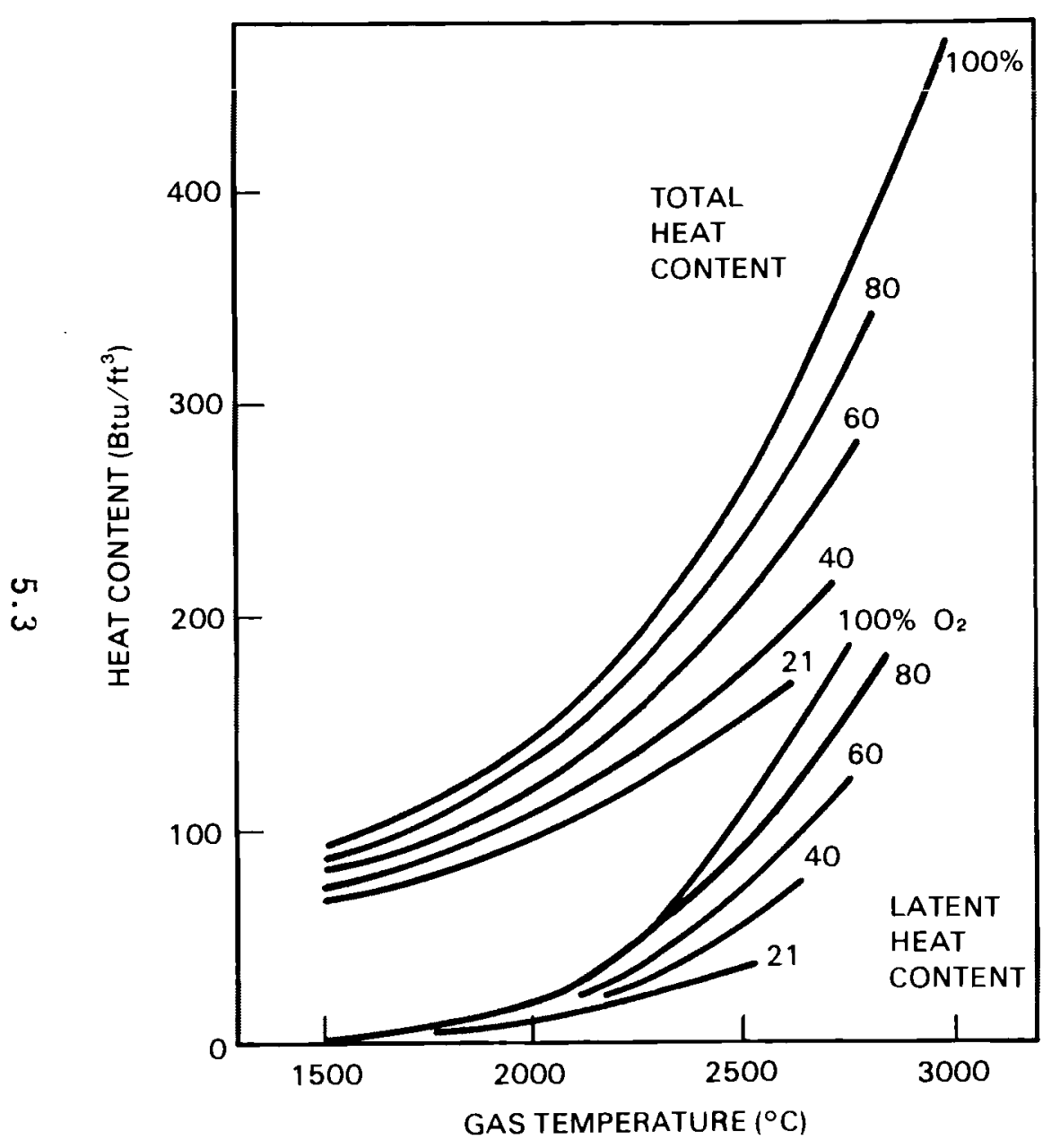

FIGURE 5.2. Enthalpy-Temperature Diagram for Most Solid and Liquid Fuels (Fehling 1948, p. 230)

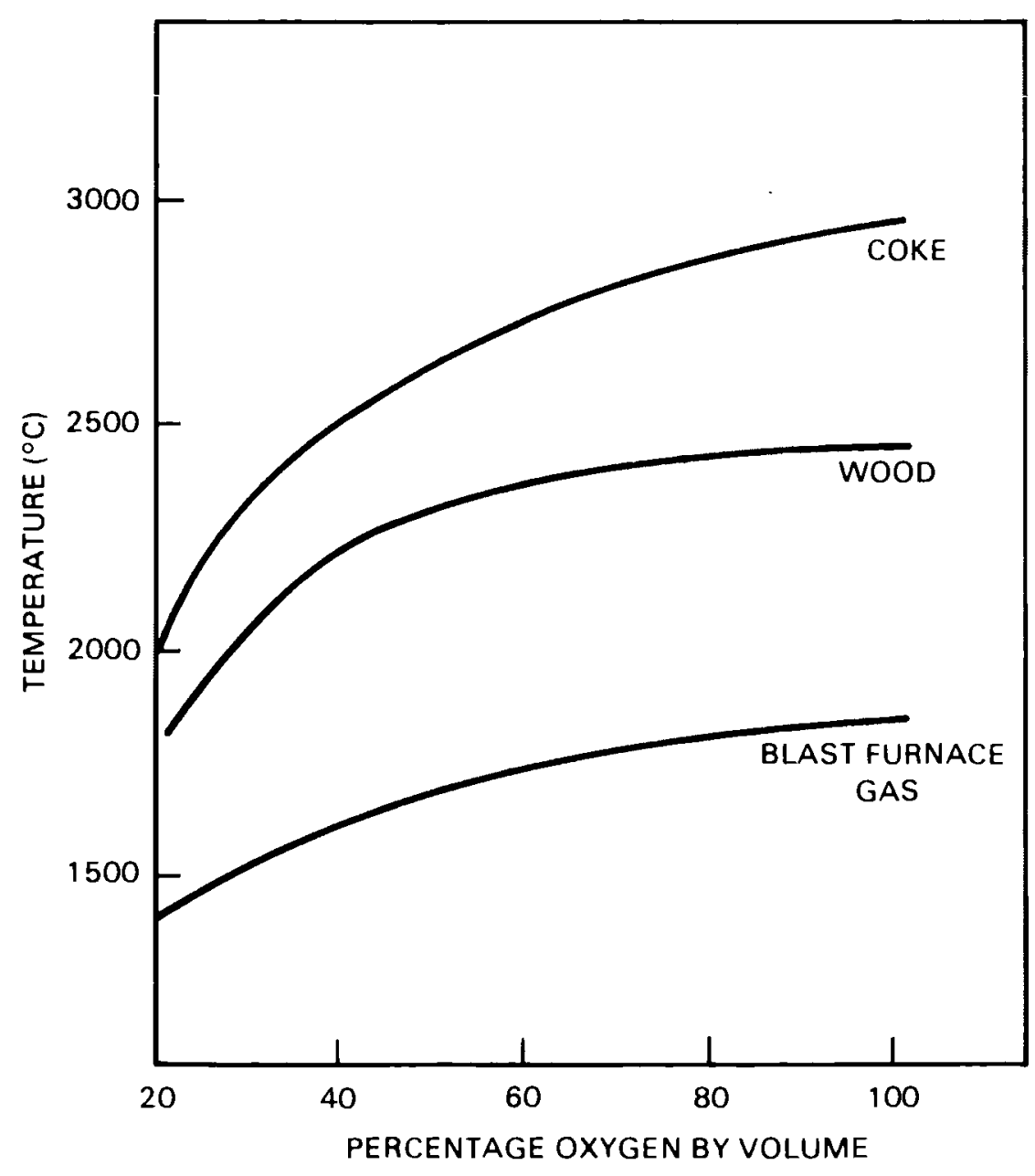

FIGURE 5.3. Combustion Temperatures as a Function of Oxygen Content (Fehling 1948, p. 231) 
combustion gases is increased accordingly (Figure 5.4). The equilibrium concentrations of the various species for combustion with pure oxygen are given in Figure 5.5. If nitrogen is present (as in combustion with air), the picture becomes much more complex due to formation of nitrogen compounds ( $\mathrm{N}_{\mathrm{x}}$, etc.). It can be seen that there is 1 ittle dissociation up to $-1600^{\circ} \mathrm{C}$. At $\sim 3000^{\circ} \mathrm{C}$ most of the combustion gases are already largely dissociated. If given enough time to cool and mix, most of the dissociated species would recombine again, giving off their latent heat of dissociation, so that only the regular combustion gases (undissociated $\mathrm{CO}_{2}$ and $\mathrm{H}_{2} \mathrm{O}$ ) would be discharged. (a) It is generally believed that recombination is aided by the presence of cooler solid surfaces such as heat exchanger surfaces (Fehling 1948). Thus, it must be expected that the effective heat transfer coefficient of recombining combustion gases is significantly higher than that of the corresponding undissociated gases. (This is somewhat analogous to the heat transfer by condensing vapors, in which the latent heat of condensation is transferred to the cool, solid surface upon contact.) This phenomenon, not the mere increase in flame temperature, makes the combustion with oxygen more efficient.

Indeed, Ivernel and Vernotte (1979) have shown experimentally that the convective heat transfer to a heat exchanger surface (at 1000K) in their test furnace increased by a factor of $6.3(b)$ when the oxygen content of the combustion air was increased from $25 \%$ to $100 \%$. They attributed this remarkable increase in heat transfer primarily to the recombination of the dissociated gas species when the hot flames impinge on the solid interface. Although this phenomenon (known in French as "convection vive") has been known since the 1940s, it has been exploited very little technologically.

(a) Recombination of dissociated molecules generally requires a third body, $M$, which is not changed chemically in that reaction (Halstead and Jenkins 1970), e.g., for the recombination of atomic hydrogen: $\mathrm{H}+\mathrm{H}+\mathrm{M} \rightarrow \mathrm{H}_{2}+$ M. Such a third body can be another molecule, which absorbs the energy set free in the recombination process, mainly in the form of kinetic energy. It is possible that a solid surface (heat exchanger) takes over the function of the third body. In that case, the energy of recombination is converted into an increase of temperature of that heat exchanger surface.

(b) The $\Delta T$ between flame and heat exchanger surface increased by only a factor of -1.5 (from $-1400 \mathrm{~K}$ to $-2000 \mathrm{~K}$ ); thus, the increase in heat transfer due to a higher $\Delta T$ was only a minor contribution factor to this phenomenon. 


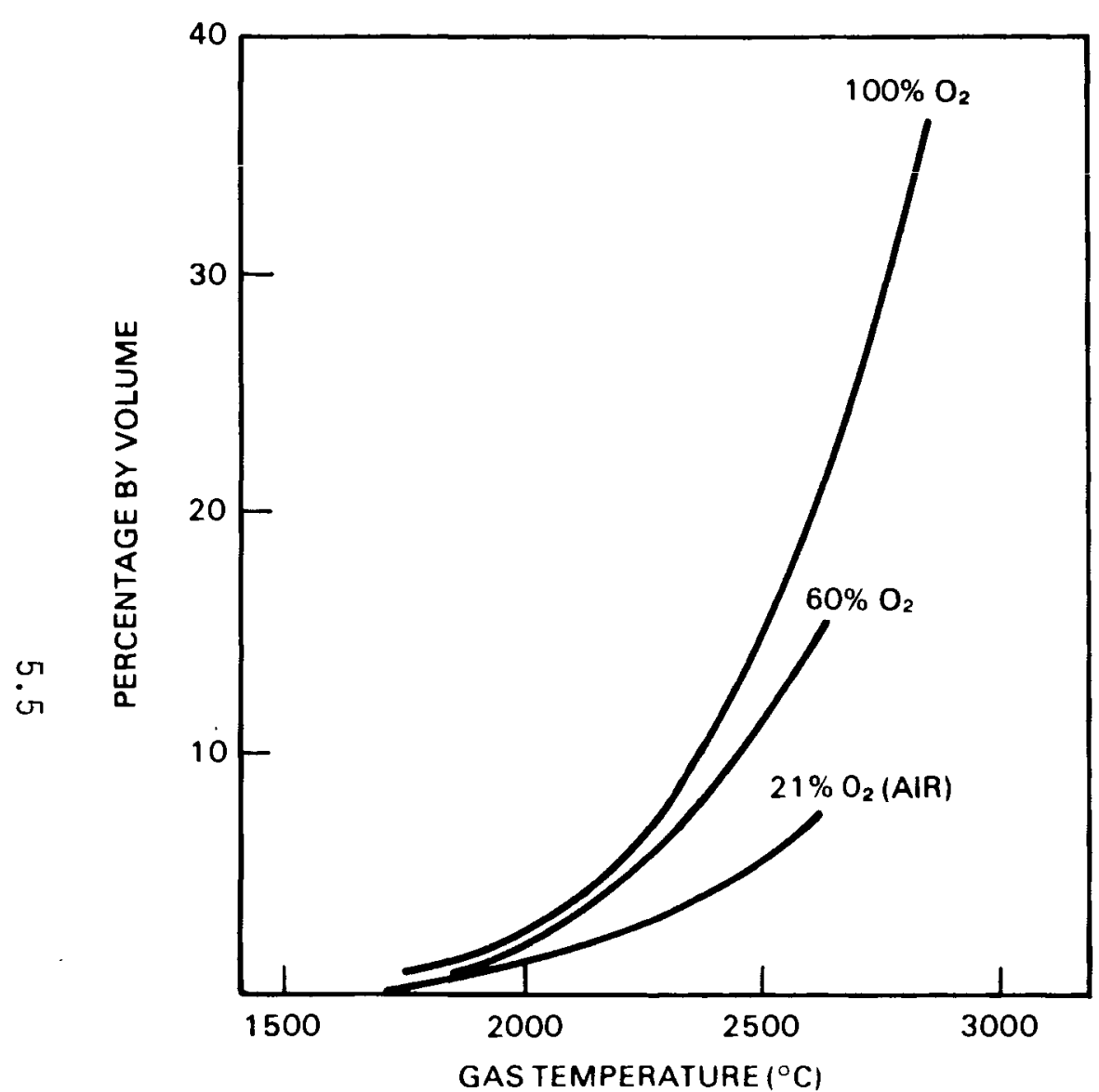

FIGURE 5.4. Average Dilatation of Combustion Products as a Result of Dissociation (Fehling 1948, p. 230)

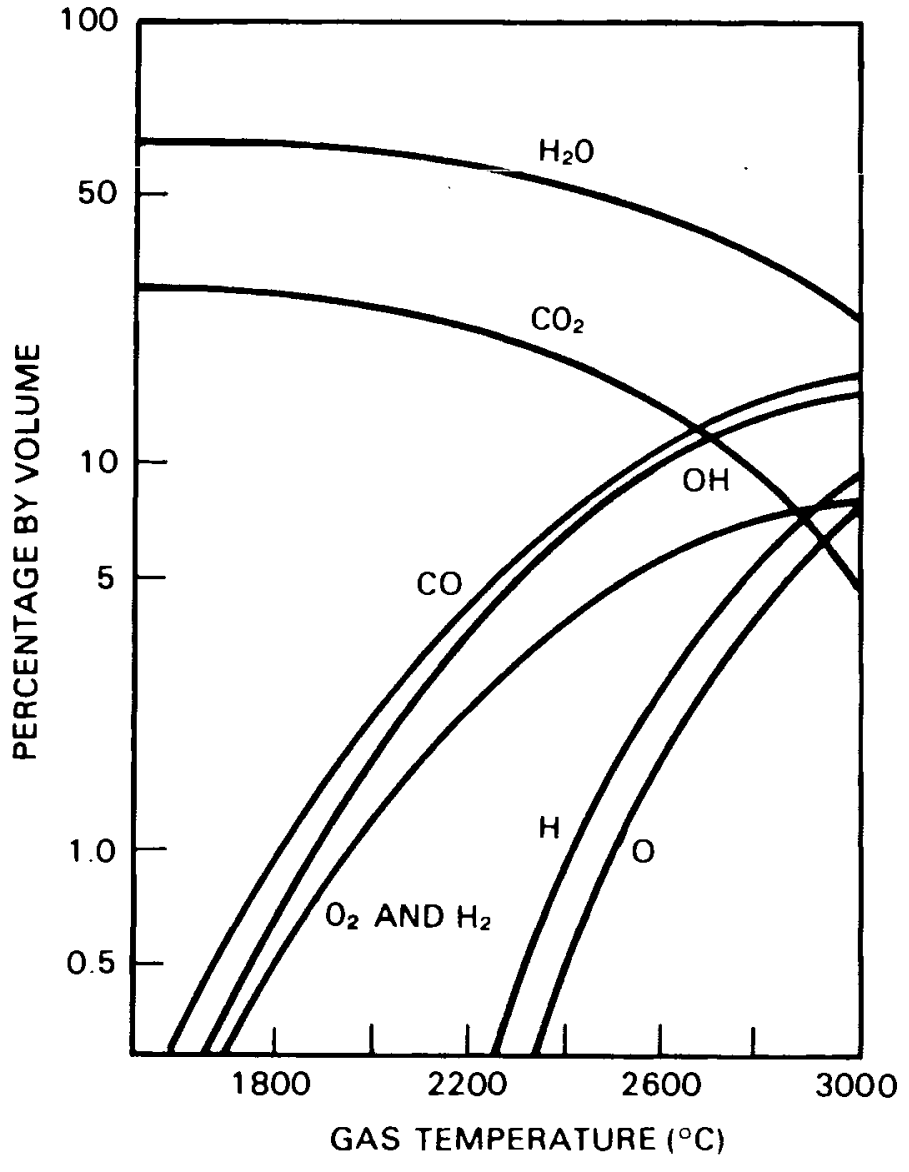

FIGURE 5.5. Combustion Gas Composition at Chemical Equilibrium for Combusting Coal Gas with Pure 0xygen ( $F$ ehl ing 1948, p. 229) 
Of course, in certain applications, the primary objective of using oxygen for combustion is to obtain higher temperatures. The best known of these applications is the acetylene/oxygen torch, which achieves the highest temperatures available for any fuel/oxidizer combustion (see page 4.3). (Electric arc jets can generate still higher temperatures.) Another application of oxygen is the heating of the working gas to very high temperatures in magneto hydrodynamic (MHD) generators (Griswold and Wehrey 1981). Submerged welding and cutting is also made practical, mainly by oxygen used for combustion. There may be still other applications. The maximum temperatures obtainable with pure oxygen combustions are often in excess of $3000^{\circ} \mathrm{C}$.

\subsection{PRESSURE EFFECTS}

Another attribute of combustion with oxygen is the higher than proportional rise in pressure of the combustion gases with temperature. Up to $-1500^{\circ} \mathrm{C}$ the ideal gas equation can be applied to the combustion gases. This equation postulates that, in constant volume combustion, the pressure increases linearly with the absolute temperature. However, as gases begin to dissociate at the high temperatures obtainable by combustion with oxygen, the deviations from the ideal gas law must be taken into account (see Figure 5.4). With constant pressure combustion (e.g., in a furnace) the result is a larger volumetric flow, i.e., higher velocities across heat exchanger surfaces, which also leads to higher heat transfer rates. With constant volume combustion (e.g., in an internal combustion engine) larger pressures are generated, which can result in a higher power output.

\subsection{POWER ENHANCEMENT}

If a fuel/oxygen mixture were combusted in an automobile engine, the pressure rise would be larger than would be expected (according to the ideal gas law) from the obtainable flame temperature. This, of course, is a significant advantage, because $\int p d V$, and not some 1 inear function of $T_{\max }$, represents the usable energy output of the engine. Conversely, the fact that a certain pressure can be obtained with a less-than-the-normally-expected temperature reduces the otherwise-anticipated heat losses and thus improves the efficiency of the 
engine. Although this increase may be less than proportional, the engine must still be able to tolerate the increased temperatures obtained as a result of combustion with oxygen for a reasonable time (e.g., 10,000 hours). The development of high temperature engines with ceramic liners is underway, al though for different purposes (Long 1981). It is likely that the utilization of such engines would yield substantially higher efficiencies with oxygen combustion than obtainable with standard engines under standard operating conditions. As explained above, the increased efficiency would accrue partly from the fact that the combustion temperatures are higher but, to an even larger extent, from the more than proportional increase in peak pressures. However, because materials restrictions will limit the achievable gain in efficiency, another way of taking advantage of combustion with oxygen in an internal combustion engine would be to utilize partial recirculation of the combustion gases as outlined on page 7.2 .

Another general benefit from substituting air with oxygen would be that the combustion device, such as an engine, could be made more compact. When gasol ine is combusted with normal air, the heat of combustion per unit volume of the combustion gases is about $95 \mathrm{Btu} / \mathrm{ft}^{3}$. As shown by Taylor (1977) this value would increase to nearly $500 \mathrm{Btu} / \mathrm{ft}^{3}$ when pure oxygen is used for combustion. Thus, from the same size engine (as expressed in effective cylinder volume), one would get about five times as much power with oxygen combustion. The question, of course, arises again whether an engine can be built that can safely and reliably accommodate such an increase in energy density or power, which would manifest itself in higher internal peak temperatures and pressures. Such benefits would, theoretically, accrue just from combustion with oxygen, even without any exhaust gas recirculation. Parallel with the increased energy density (caused by higher combustion temperatures) it can be expected that the efficiency of the combustion process itself would also increase becaluse of the higher temperatures. (a)

(a) There may also be some efficiency benefits from the increased pressures that result from the higher temperatures. However, compared to the temperature effect itself, this would be only a second-order effect (Schmidt 1956) and will, therefore, be disregarded here. 
The 1 iterature search performed as part of this study revealed that a gasoline-fueled internal combustion engine has never been operated on straight: oxygen. The only close case that was found (Masi et al. 1948) reported tests of reciprocating aircraft engines that were operated on oxygen-enriched air when flying at high altitudes, where regular air pressure is greatly reduced. These tests were conducted during and shortly after World War II before the introduction of jet engines, which subsequently obviated such measures for obtaining higher power.

\subsection{LOW EMISSION OF NITROUS OXIDES}

Still another benefit from combustion with oxygen is the potential reduction of $\mathrm{NO}_{x}$ in the exhaust gases. Because in the normal combustion of most common fuels (such as coal) the gaseous products consist of up to $70 \%$ of $\mathrm{N}_{2}$, there is always a chance that the nitrogen from the air will combine with oxygen to form $\mathrm{NO}_{\mathrm{x}}$. If the air nitrogen is eliminated by pure $\mathrm{O}_{2}$ combustion, only the traces of nitrogen found in the fuel (e.g., coal) itself could conceivably combine with $\mathrm{O}_{2}$ to form $\mathrm{NO}_{x}$. Thus, the source for potential $\mathrm{NO}_{x}$ reactions is greatly reduced. The effectiveness of this approach cannot be determined because no conclusive research toward this end has apparently been conducted. The case is by no means clearcut because fuel-bound nitrogen is possibly more likely to form $\mathrm{NO}_{x}$ than air-nitrogen. Nevertheless, there appears to he a great environmental benefit from using pure oxygen for combustion.

\subsection{IGNITION FACILITATION}

Combustion of ammonia could benefit greatly if accomplished using oxygen instead of air because ammonia is relatively hard to ignite in air. Partial dissociation into $\mathrm{H}_{2}$ and $\mathrm{N}_{2}$ (e.g., by a catalyst) is usually used to overcome this difficulty (Bomelburg 1980). If $\mathrm{O}_{2}$ (or even $\mathrm{O}_{2}$-enriched air) is used, there are no ignition problems. Also, because $\mathrm{NH}_{3}$ has only a moderate heat of combustion (compared with hydrocarbons), it could use the extra increase in $\mathrm{fl}$ ame temperature resulting from higher $\mathrm{O}_{2}$ concentration without increasing problems of overheating. However, even though $\mathrm{NH}_{3} / \mathrm{O}_{2}$ combustion has proven 
very successful in liquid rocket propulsion, no attempts have been made to utilize $\mathrm{NH}_{3} / \mathrm{O}_{2}$ in internal combustion engines. Other hard to ignite fuels could similarly benefit from the utilization of oxygen. 


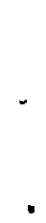




\subsection{ECONOMIC CONSIDERATIONS}

Although oxygen is available in the atmosphere in almost unlimited amounts, an energy-intensive process must be applied to separate the oxygen from the nitrogen and to transform it to the liquid state. According to Shen and Wolsky $(1980)$, the air separation process requires $278 \mathrm{kWh}(\mathrm{e}) /$ ton of oxygen gas.

In comparison, pure hydrocarbon fuels contain energy in the order of $20,000 \mathrm{Btu} / 1 \mathrm{~b}$ or about $12,790 \mathrm{kWh}(\mathrm{th}) / \mathrm{ton}$. However, because thermal energy can be converted to electrical energy at only about $33 \%$ efficiency, a ton of hydrocarbons will yield only about 4,270 kWh(e) electrical energy. Thus, approximately $6.5 \%$ (or 278/4270) of the energy contained in a hydrocarbon fuel $0 i 1$ would have to be expended to provide the gaseous oxygen if the fuel were burned in pure oxygen instead of in air. If the oxygen were provided in liquid form, the fraction would be about $18.7 \%$ instead of $6.5 \%$.

Thus, if the efficiency of a certain energy generating process can be increased by a factor of about 1.1 by using oxygen instead of air for combustion (e.g., increasing an efficiency from $30 \%$ to $33 \%$ ), the use of oxygen might become economically justifiable. (a) Because such relatively modest increases appear to be technically feasible, the use of oxygen for improving combustion processes ought to be studied more extensively.

Using oxygen on a large scale for combustion appears to be economically even more attractive because, for each ton of oxygen generated, between 3 and 4 tons of nitrogen can be obtained at very little additional cost. This nitrogen could be used for ammonia (fertilizer) production, for example. of course, to take full advantage of the essentially free nitrogen available, it would be best to locate the ammonia plant in the immediate vicinity of the oxygen plant. Because the economics of scale favor high capacity plants (Shaner 1978), future energy efficient installations might consist of a combination of large oxygen generating plants in conjunction with ammonia production plants and electric power plants.

(a) For most such applications the oxygen need not be very pure, so additional cost savings are possible (Baker 1981). 
In some chemical processes, oxygen is obtained as a byproduct; as such, it is often discarded if it is of no practical local use. An example of this wastage is a $300 \mathrm{t} /$ day ammonia plant in Kennewick, Washington. During normal operation, this plant generates and wastes about $5 \times 10^{4} \mathrm{~m}^{3}$ of oxygen daily, because no facilities close by can utilize the oxygen. Although not very pure, this byproduct oxygen could still be used for some of the combustion schemes as suggested in this report. 


\subsection{ACTUAL AND POTENTIAL APPLICATIONS OF COMBUSTION WITH OXYGEN}

This section describes various unconnected cases in which oxygen is used for combustion. These examples include some schemes that have already been tried out and are now finding industrial applications. Other schemes are merely in the conceptual stage and probably would require additional analytical work and/or development tests to confirm their technical viability. Some of these cases include exhaust gas recirculation, which al so will be described.

\subsection{STEEL FURNACES}

The stee: 1 industry is a large consumer of energy and must always search for more energy-conserving processes to remain competitive on the world market. This has become particularly crucial since the mid-1970s because of the steep escalation of energy costs. The French and German steel makers have attempted to utilize blast furnace gas (10w-Btu gas of $\rightarrow 80 \mathrm{Btu} / \mathrm{ft}^{3}$, which is frequently disposed of as being useless) in a new scheme of energy conservation by showing that combustion of such a low-Btu gas with oxygen can indeed be technically and economically desirable (Ivernel 1978).

To date, industry's preferred methods of increasing the heating value in low-Btu gas combustion have been the admixture of high-Btu gases or the preheating of the gas and/or combustion air. To these two conventional methods must now be added the oxygen enrichment of the combustion air. Basically, any one of these three processes can be carried out either by keeping the enthalpy per unit volume of the combustion gases constant or by increasing the combustion enthalpy through the use of oxygen. Bonnekamp (1978) considers both methods and compares them in detail to determine the effect on the overall energy consumption.

His study concludes that, in keeping the enthalpy of the combustion gases constant (as, e.g., for firing coke oven batteries, sintering plants, hot blast furnaces, heat treating furnaces), the use of oxygen with low-Btu gases is economically justified only if oxygen is available essentially as surplus. The overall energy consumption is generally higher in these cases, as when using high-Btu gases. However, in increasing the enthalpy of the combustion gases by 
the use of oxygen (as in slab pusher type furnaces, for example) the increase of oxygen content in the combustion air can lead to a reduction of the overall energy consumption and is, therefore, economically preferable, particularly because no high-Btu fuels (such as natural gas or fuel oil) need to be consumed. Bonnekamp (1978) shows that, in this case, the improvement of the combustion efficiency more than outweighs the energy requirements for the production of the oxygen. (a) For the future he assumes that sufficient nuclear energy, in one form or other, will become available and could then be used to produce oxygen to upgrade the heat content of low-Btu fuel combustion.

Bonnekamp's work has been discussed here in some detail because it can exemplify a specific application in which the use of oxygen for the combustion of low quality fuels can be economically attractive. Bonnekamp's paper also points out that the benefits derivable from using oxygen depend very much on the prevailing circumstances. As already pointed out in other parts of this report, combustion of low-Btu fuels with oxygen cannot always be assumed preferable over combustion with air.

\subsection{RECIRCULATION OF COMBUSTION GASES}

In most applications of combustion for energy conversion, the combustion gases are exhausted to the atmosphere while they are still quite hot. In practice, it would be very difficult and rather inefficient to convert all, or even nearly $\mathbf{2 1 1}$, of the heat contained in the combustion gases to useful energy. To do so would entail extremely large heat transfer equipment, which, of course, is seldom economically justifiable. In combustion processes with air, the main constituent of the combustion gases is usually nitrogen. Although basically unnecessary for the chemical reactions taking place in combustion, the nitrogen is nevertheless heated up along with the combustion products and, thus, contains part of the total heat content of the combustion gases.

From a materials viewpoint, it is usually preferable to combust at rather low temperatures, because high temperature materials, which could withstand the

(a) Oxygen is being used, of course, in various steel-making furnaces, but so far, not in blast furnaces which produce the pig iron from which basically all kinds of steel are derived. 
high flame temperatures obtainable with oxygen combustion, are rather scarce, difficult to fabricate, and thus highly expensive. For this reason, the presence of diluents is normally a requirement in most practical applications. Also, higher flame temperatures would usually entail higher $\mathrm{NO}_{x}$ emissions, which are environmentally objectionable.

In principle, any nonreacting gas can be used as a diluent. Therefore, it is suggested here that a major part of the exhaust gases be recirculated back to the combustion zone, where they can then act as the necessary diluents for keeping a fuel/oxygen combustion within its proper temperature range. This can be a significant step toward saving energy, because the exhaust gases often still contain considerable heat when they are discharged through the stack.

\subsubsection{Reasons for Recirculation}

In a typical example of burning $1 \mathrm{~kg}$ of carbon with air, about $12 \mathrm{~kg}$ of combustion gases are generated, $8.5 \mathrm{~kg}$ of which are nitrogen. (a) Instead of discharging the entire $12 \mathrm{~kg}$ of combustion gases to the atmosphere, it appears also to be possible to recirculate 8 to $9 \mathrm{~kg}$ back to the inlet after mixing them with $2.2 \mathrm{~kg}$ of pure oxygen. In such a case, $\sim 70 \%$ of the energy contained in the exhaust gases, otherwise rejected to the atmosphere, could be saved.

When burning low-Btu fuels, the energy savings would be less substantial because relatively more diluents are contained in the fuel than in regular combustion air. Nevertheless, recirculation may still determine whether the fuel is practically useful or not; e.g., a very low quality fuel may burn only at a low rate or burn hardly at all in air, whereas with enriched oxygen its combustion rate would be speeded up and its flame temperature increased sufficiently so that it may prove a valuable fuel indeed. The increase in combustion rate and flame temperature would result partially from the increased oxygen content of the air and partially from the moderately high temperature of the recirculated exhaust gases.

(a) The computational basis for this example is presented in Section 4.1. The case for real coal is treated in the Appendix. 


\subsubsection{Applications of Combustion with Exhaust Gas Recirculation}

The advantages of exhaust gas recirculation become really attractive only when oxygen is used for combustion, so it is not surprising that such recirculation schemes have hardly ever been adopted for energy conservation purposes. However, they have been used for reducing unburned hydrocarbons and $\mathrm{NO}_{\mathrm{X}}$ which, when exhausted, would contribute to atmospheric pollution (Gat 1980). Some modern automobile engines use such schemes in one form or another.

\subsubsection{Basic Furnace}

A potential example of a combustion gas recirculation scheme is shown in Figure 7.1. The furnace is fed by fuel and oxygen. Approximately $80 \%$ of the combustion gases is returned (after being cleaned of particulates in a cyclone separator) by a blower to the combustion chamber. The rest is discharged through the stack after having exchanged most of its sensible heat content with the incoming oxygen flow in a small regenerator.

A discharge temperature of $320^{\circ} \mathrm{C}$ used in this furnace would require fairly large heat exchange equipment to bring the temperature of the combustion gases

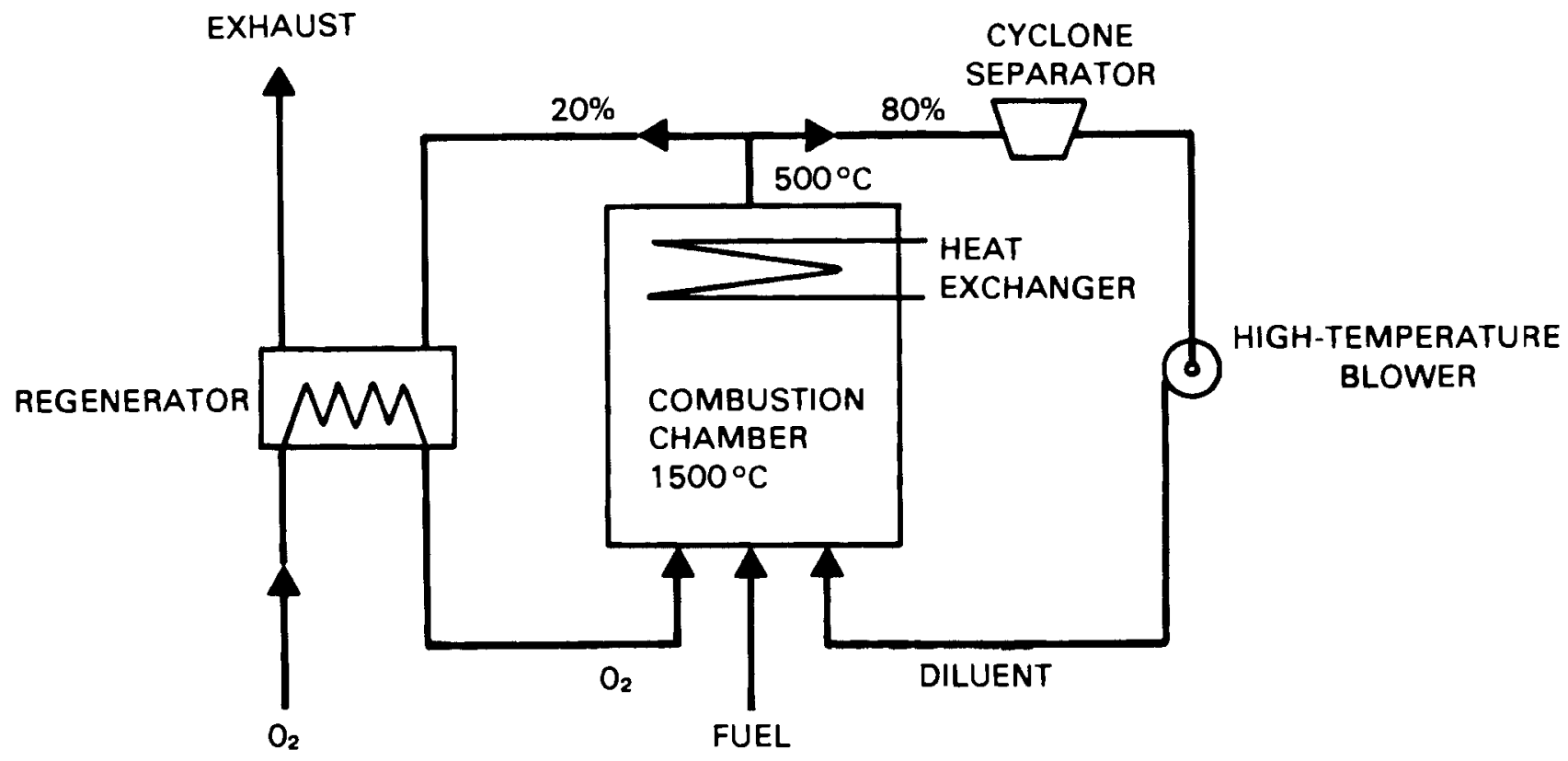

FIGURE 7.1. Basic Arrangement for a Boiler with Exhaust Gas Recirculation 
down to this value. If the discharge would be at $500^{\circ} \mathrm{C}$, a much smaller heat exchanger would be acceptable. Also, a recuperator could be eliminated so that recirculation would become still more efficient. The recirculation of the hot gases would diminish the fuel requirements for the same net heat output of the furnace. Because both flame temperatures $(a)$ and the median $T$ in the heat exchanger would be increased, the heat exchanger could be smaller for the same capacity. A quantitative analytic evaluation of these effects would be desirable but is outside the scope of this study.

\subsubsection{Semiclosed Gas Turbine Cycle}

One of the applications of exhaust gas recirculation for heat recovery known to this author is a semiclosed gas turbine developed by Westinghouse (Baumeister and Marks 1967), as shown in Figure 7.2. However, it does not use oxygen, or even oxygen-enriched air, and apparently has not been very successful.

The gas from the main compressor (consisting of a mixture of turbine exhaust gas and fresh air) is passed through a regenerator in which it absorbs

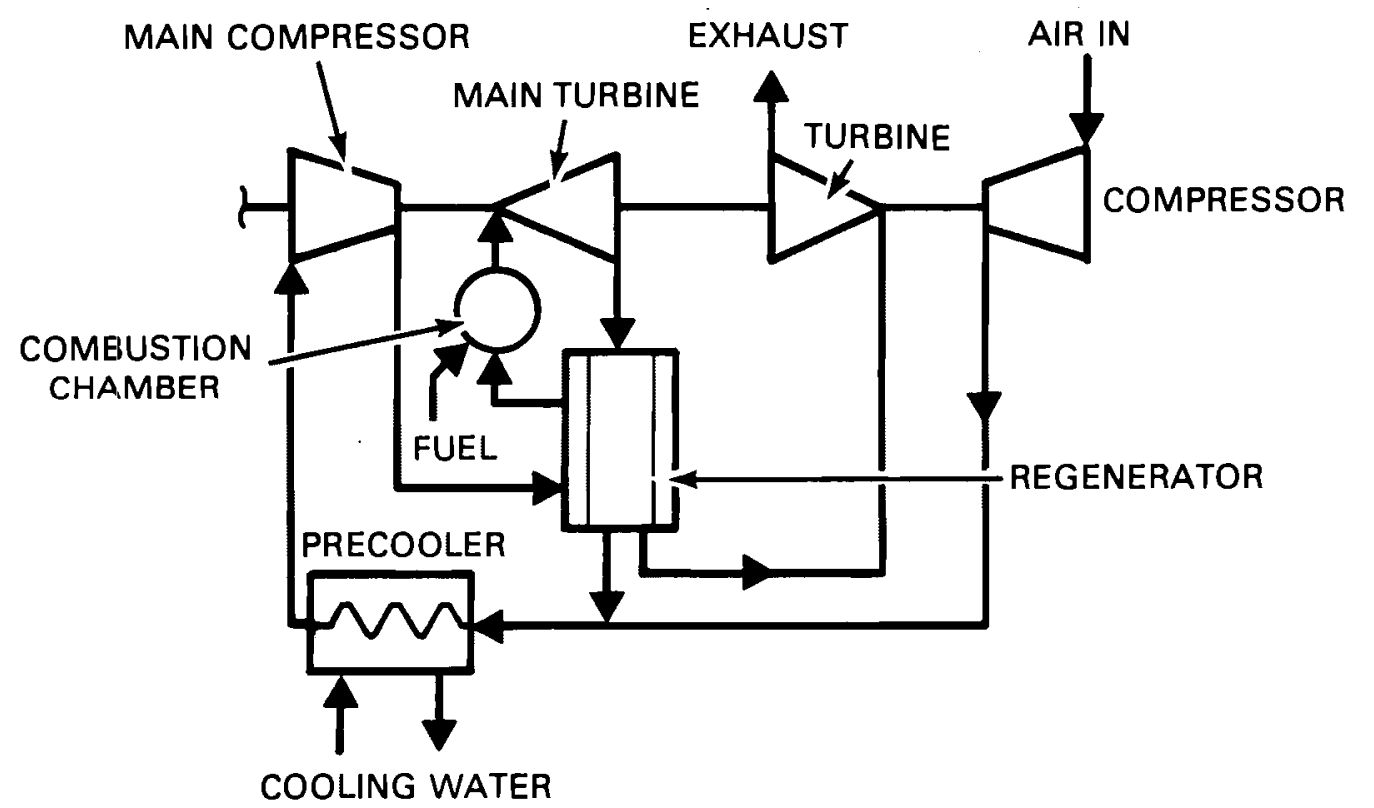

FIGURE 7.2. Exhaust Gas Recirculation in a Semiclosed Gas Turbine (a) Upper limit of the flame temperatures depends on material limitations. 
some heat from the main turbine exhaust gas before it enters the combustor, where the fuel is added to $i t$. The exhaust gas leaving the regenerator is divided between the half that returns to the main compressor (via the precooler) and the other half that is discharged to the atmosphere through a smal1, low-pressure turbine. The necessary amount of fresh air is brought up to the pressure level of the exhaust gas at the regenerator exit by a small "charging" compressor. This compressor is driven by the low pressure turbine. Thus, basically, this semiclosed cycle, similar to the fully closed cycle type (Bammert 1975), can be operated at high densities and approximately constant efficiency over a wide load range. The major disadvantage of this type appears to be the corrosion and fouling problems that occur with the recirculation of the products of combustion, particularly when fuels having high sulfur or high ash content are used.

\subsubsection{Magneto Hydrodynamic Power Generation}

A recently proposed MHD power station (Griswold and Wehner 1981), shown schematically in Figure 7.3, utilizes combustion with oxygen-enriched air and recirculation of a large fraction of the combustion gases. The MHD cycle essentially acts as a topping cycle in a conventional steam power plant. Retrofitting of existing plants with this type of MHD cycle is possible.

\subsubsection{Diesel Engines with Recirculation}

Diesel engines operating by oxygen combustion of regular diesel fuel with exhaust gas recirculation were under development for submarine propulsion several decades ago (MacNair 1971). In the scheme shown in Figure 7.4, only $\mathrm{H}_{2} \mathrm{O}$ is recirculated as diluent, whereas the $\mathrm{CO}_{2}$ is discarded (Catterson and Swain 1968). In this Rankine cycle engine, a fuel such as diesel oil or JP-4 and an oxidizer such as liquid oxygen are burned in a combustor with water added to control combustion temperature. Products of combustion pass through a turbine or expander to produce mechanical power. Condensible aases are removed in a condenser; noncondensible gases are compressed and discharged overboard.

As reported by Weil (1972), the potential use of $\mathrm{H}_{2} / \mathrm{O}_{2}$ internal combustion engines in submarines had already been studied extensively in Germany and 


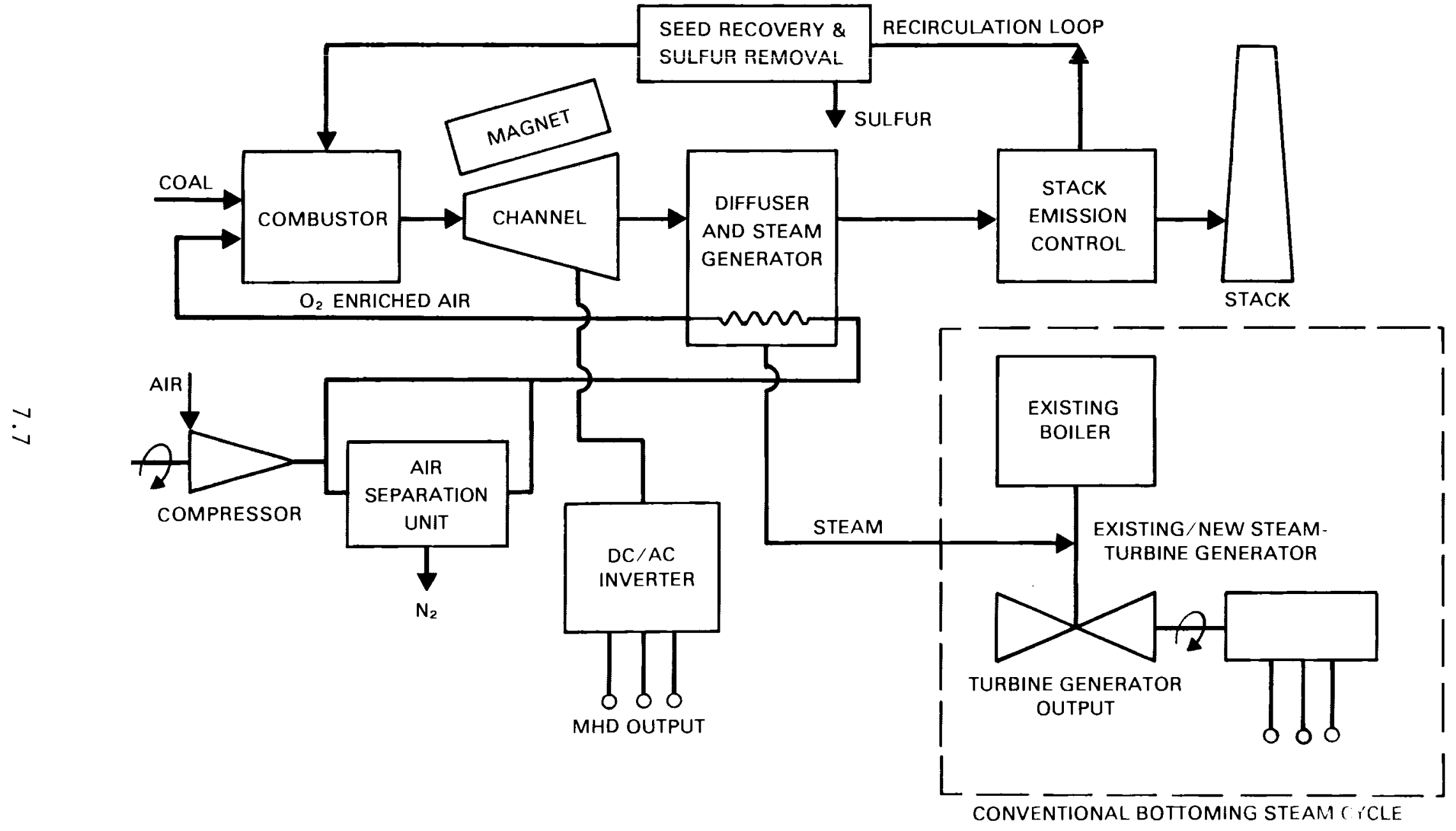

FIGURE 7.3. Combustion Gas Recirculation in the MHD Power Generating Scheme 


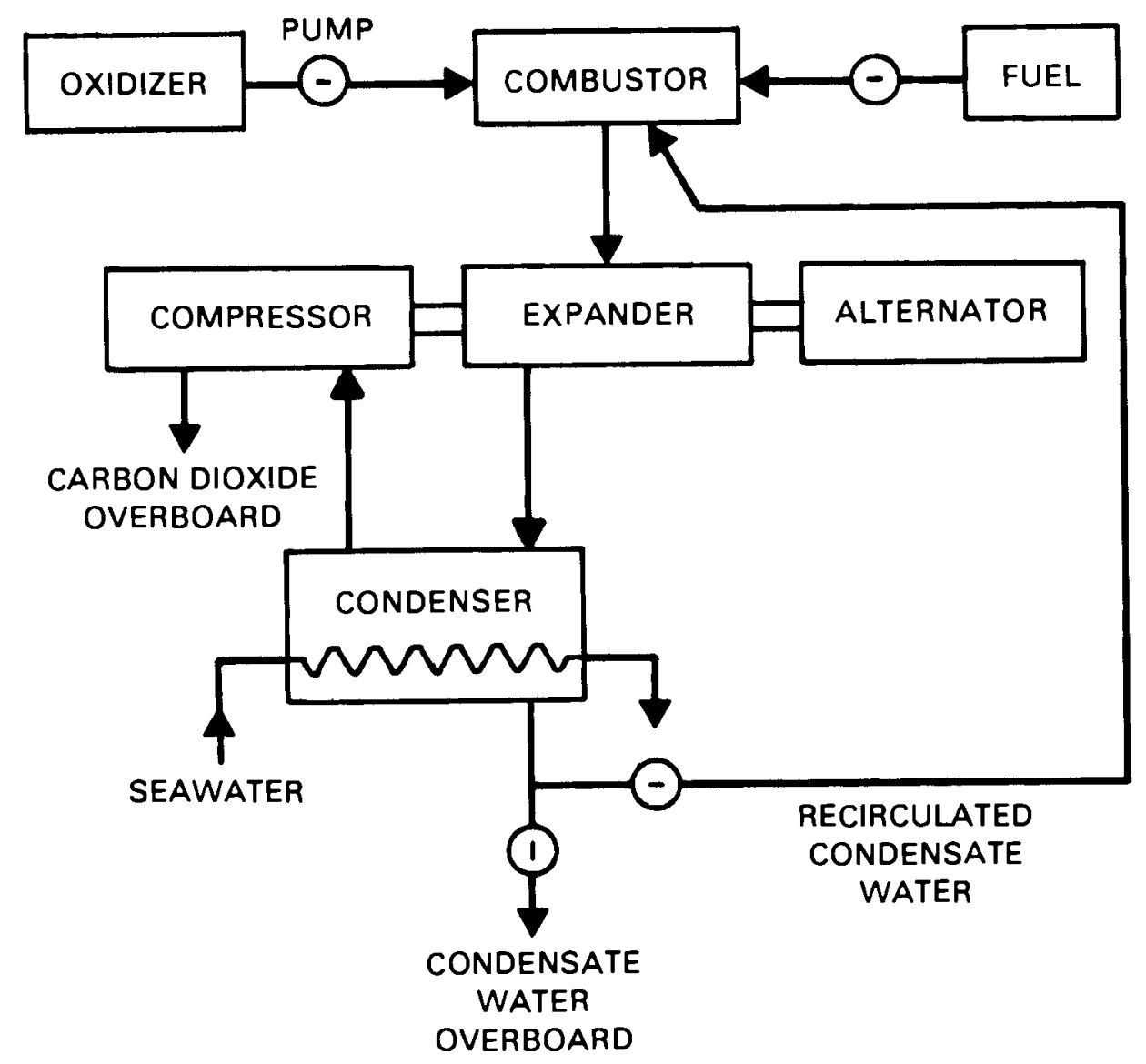

FIGURE 7.4. Typical Open-Cycle Power System

England during the 1920s and 1930s. However, a practical version apparently has never been introduced, probably because of the eventual successful introduction of nuclear submarines.

\subsubsection{Rankine Engines with Recirculation}

A semiclosed Rankine cycle (Reese and Carmichael 1971), as shown in Figure 7.5, has also been suggested for submarine and torpedo propulsion. In this case the fuel is pure hydrogen combusted with pure oxygen, so that the combustion product is only water, which is partly recirculated as diluent in the combustion process.

\subsubsection{Otto Engines with Recirculation}

About 40 years ago, the power of standard piston engines for military aircraft at high altitudes was demonstrated to be substantially increased by 


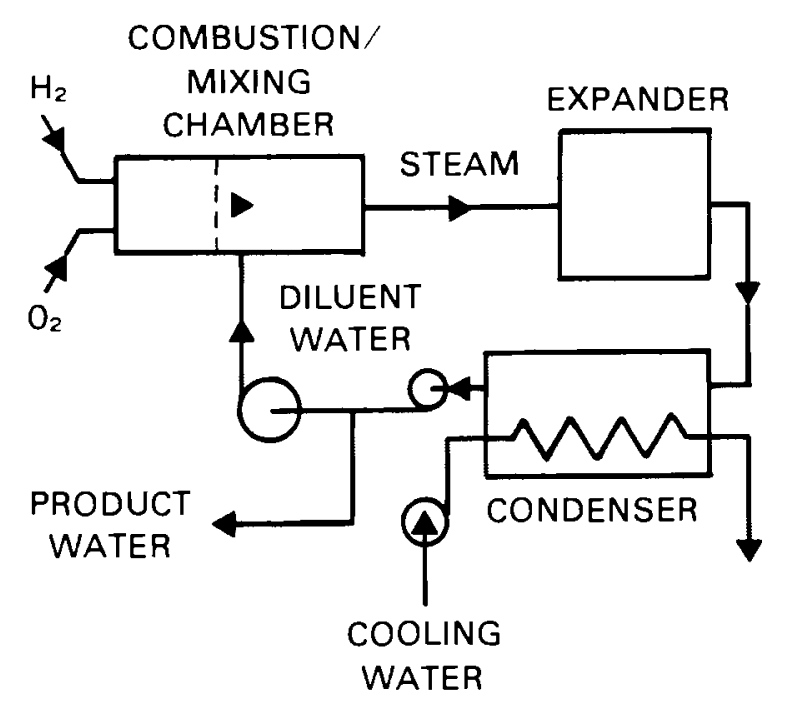

FIGURE 7.5. Basic Semiclosed $\mathrm{H}_{2} / \mathrm{O}_{2}$ Rankine Cycle

injecting gaseous or liquid oxygen directly into the intake manifold of such an engine (Masi et al. 1947). The power increase was limited mainly by the cooling system of the engine, because overheating generally occurred at higher power levels. However, this could be overcome to some extent by simultaneously injecting some liquid water into the cylinders. The evaporated water acted as a heat sink and as a diluent in the combustion process.

The invention of jet engines obviated the actual application of the oxygen booster for aircraft engines. Further, the oxygen scheme has since never been revived, except in proposals or experimental demonstrations of various new ideas. For example, Escher (1976) reported that the operation of piston engines running on liquid hydrogen and liquid oxygen was demonstrated by the Perris Smogless Automobile Association of California and by Musashi Institute of Japan.

Underwood and Dieges (1971) have experimented with pure hydrogen/oxygen combustion in a standard automobile engine. In this case the necessary diluent was the fuel $\left(\mathrm{H}_{2}\right.$ gas) itself, which was supplied in excess to the combustible $\mathrm{H}_{2} / \mathrm{O}_{2}$ mixture. The unburnt portion of the $\mathrm{H}_{2}$ was recirculated as shown in Figure 7.6. The combustion product $\left(\mathrm{H}_{2} \mathrm{O}\right)$ was first condensed to separate the $\mathrm{H}_{2}$ and then vaporized again and discharged to the atmosphere. As pointed out el sewhere in this report, the logistic problems of carrying large amounts of 


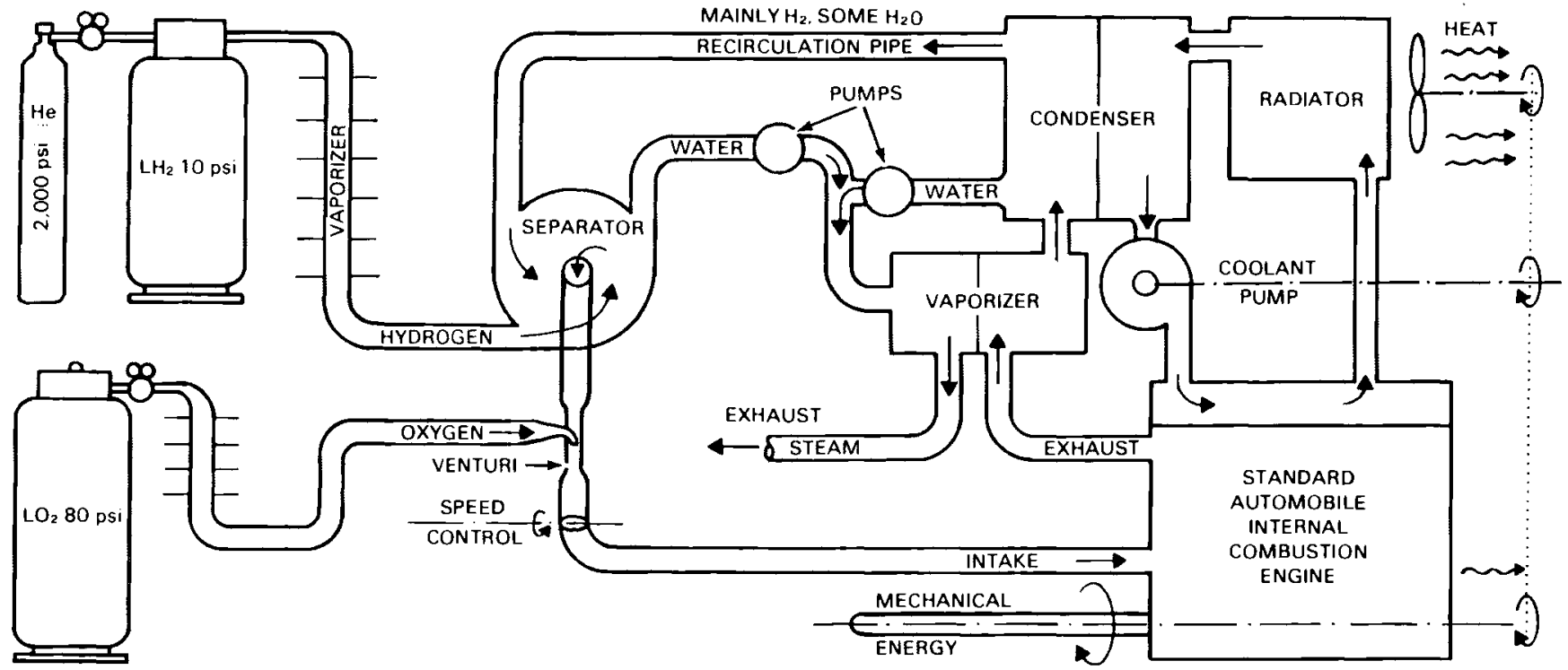

FIGURE 7.6. Internal Combustion Engine (Ford F-250 Pickup) with Recirculation 
oxygen along in a vehicle turned out to be practically insurmountable, even though the engine operating principle was proven to be technically sound.

\subsection{NEW IDE.AS FOR THE USE OF OXYGEN IN COMBUSTION}

This section describes proposals for other potentially useful oxygen combustion schemes that have not yet been tried out. They all utilize partial recirculation of the combustion gases.

\subsubsection{External Combustion Engines}

Conventional spark ignition and diesel engines operate by intermittent internal combustion; the Stirling engine operates using continuous external combustion. It is, therefore, easier to control pollutant emission in the Stirling engine.

Because of its basic thermodynamic simplicity, the Stirling engine provides a good example of using oxygen in combustion engine applications. A prototype of this engine, developed by United Stirling of Sweden, is illustrated cross-sectionally in Figure 7.7 (Schuetz 1980). Basically, the Stirling engine converts heat energy derived from the burning of a fuel-air mixture to mechanical energy by the alternating compression and expansion of a confined working gas. The working gas (usually a small quantity of hydrogen under high pressure) is cooled during the compression stage and heated during the expansion stage. Residual heat energy is recycled through a regenerator, which acts as a storage device for a large portion of the heat of the working gas after expansion and returns the heat to that gas as the gas reverses direction. The pistons in the Stirling engine have two functions: they move the gas back and forth between the hot and cold locations, and they transmit mechanical work to the drive shaft. Each piston operates simultaneously in two cycles: the hot upper surface of one piston is coordinated with a cooled undersurface of the next piston, and so on.

Figure 7.8 explains the sequence of four events that occur during a full work cycle of the engine. Basically, in the Stirling engine energy (heat from combustion) is supplied at a high temperature $\left(T_{H}\right)$, and a portion of this 


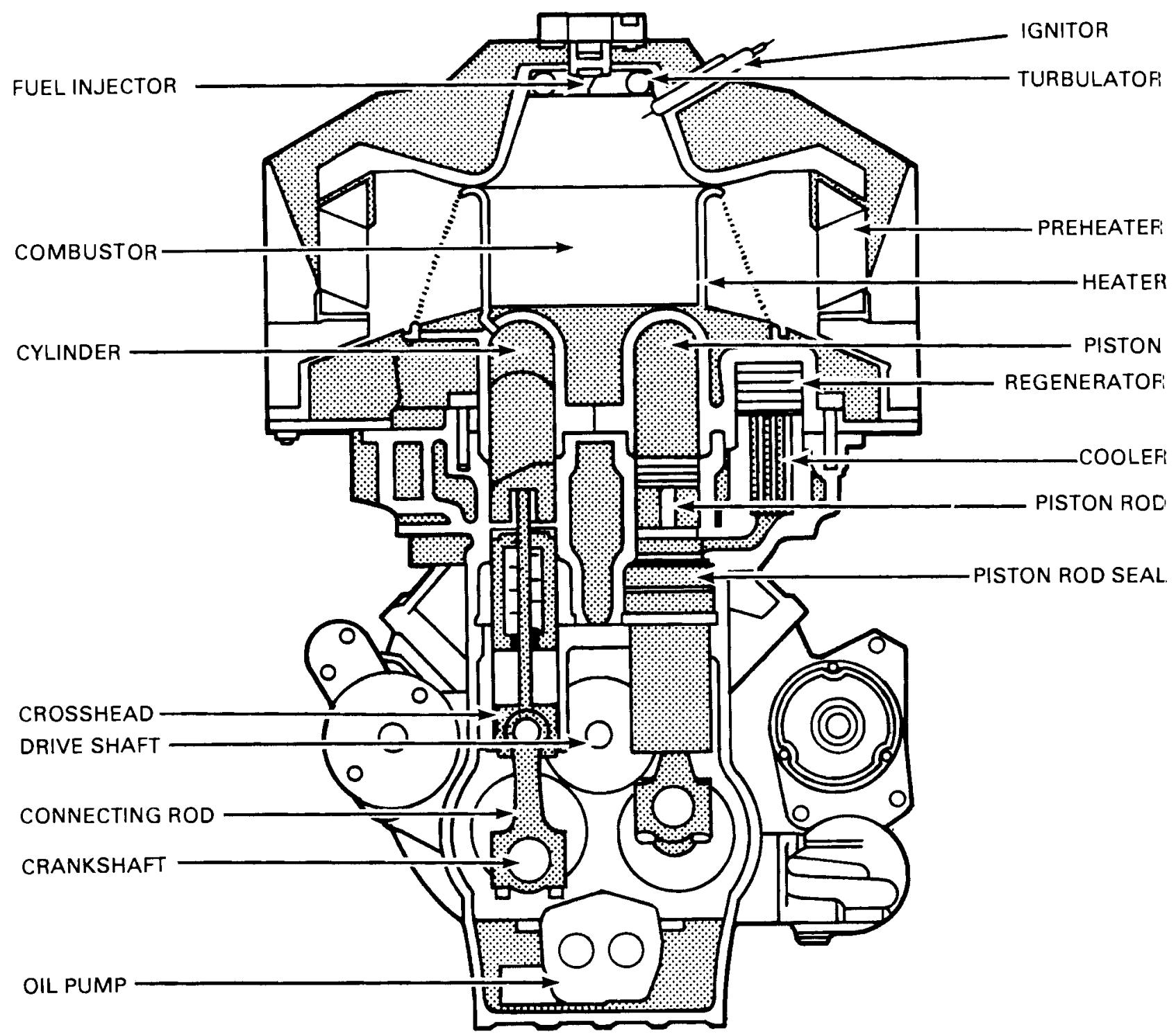

FIGURE 7.7. Stirling Engine Cross Section

energy (waste heat) must be withdrawn at a low temperature, $T_{L}$. It can be shown that the efficiency (under ideal conditions) of this process is $n=1-T_{L} / T_{H}($ Nunz 1975).

Thus, to maximize efficiency, it would be desirable to have $T_{H}$ as high as practically possible and $T_{L}$ as low as practically possible. $T_{H}$ is limited by combustion conditions and material considerations. $T_{L}$ is usually determined by the use of water as the cooling agent and by the normal procedure of rejecting the waste heat to the atmosphere. 


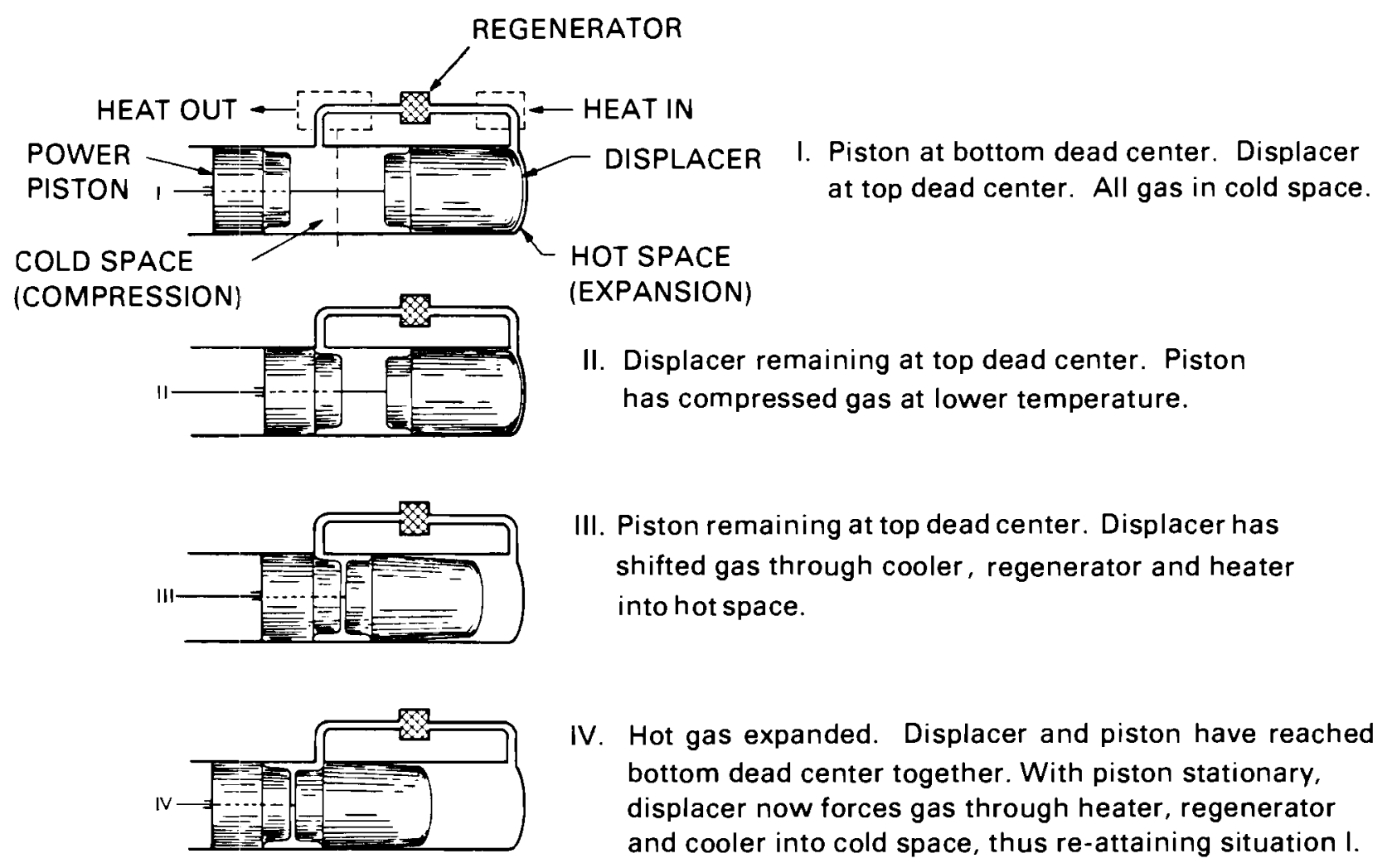

FIGURE 7.8. Sequence of Events in a Stirling Engine Work Cycle

If liquid oxygen $\left(\mathrm{LO}_{2}\right)$ were to be used for combustion instead of air, it would be possible to simultaneously increase $T_{H}$ and decrease $T_{L}$. The following advantages could be gained:

- The thermodynamic efficiency could be significantly improved.

- The waste heat, otherwise rejected to the atmosphere, could be used to vaporize and pressurize the $\mathrm{LO}_{2}$, thus effectively lowering $T_{L}$.

- The combustion could be at high pressures because the energy required for pressurization of the oxidant could also be derived from the waste heat, provided the fuel is nongaseous (e.g., oil, pulverized coal, LNG). The high pressure increases convective heat transfer from the combustion gas to the heat exchanger in the cylinder head.

- Because air-nitrogen is excluded in the combustion, the heating of cold diluents is avoided. The advantages of this feature have been explained in other parts of this report. 
- Recirculation of the combustion gases is easily accomplished within the combustion chamber, as shown in Figure 7.9. If oxygen is used for combustion, such recirculation is required to keep the combustion temperatures within tolerable limits. Recirculation can be induced by the tangential injection of both the fuel and the vaporizer (jet pump action). As a result, high convective velocities across the heat transfer surfaces are possible, supported by centrifugal action involving boundary layer crossflow. This greatly increases heat transfer.

- Because of such vortex movement, unreacted fuel and oxidizer tend to remain in the outer regions of the vortex because they are cold and, thus, heavier. Combustion will take place closest to the heat exchanger surfaces. Because the hot combustion products become lighter (with respect to freshly injected fuel and oxidizer), they will tend to move toward the center of the vortex, thus generating intense cross-movement and turbulence. This guarantees thorough

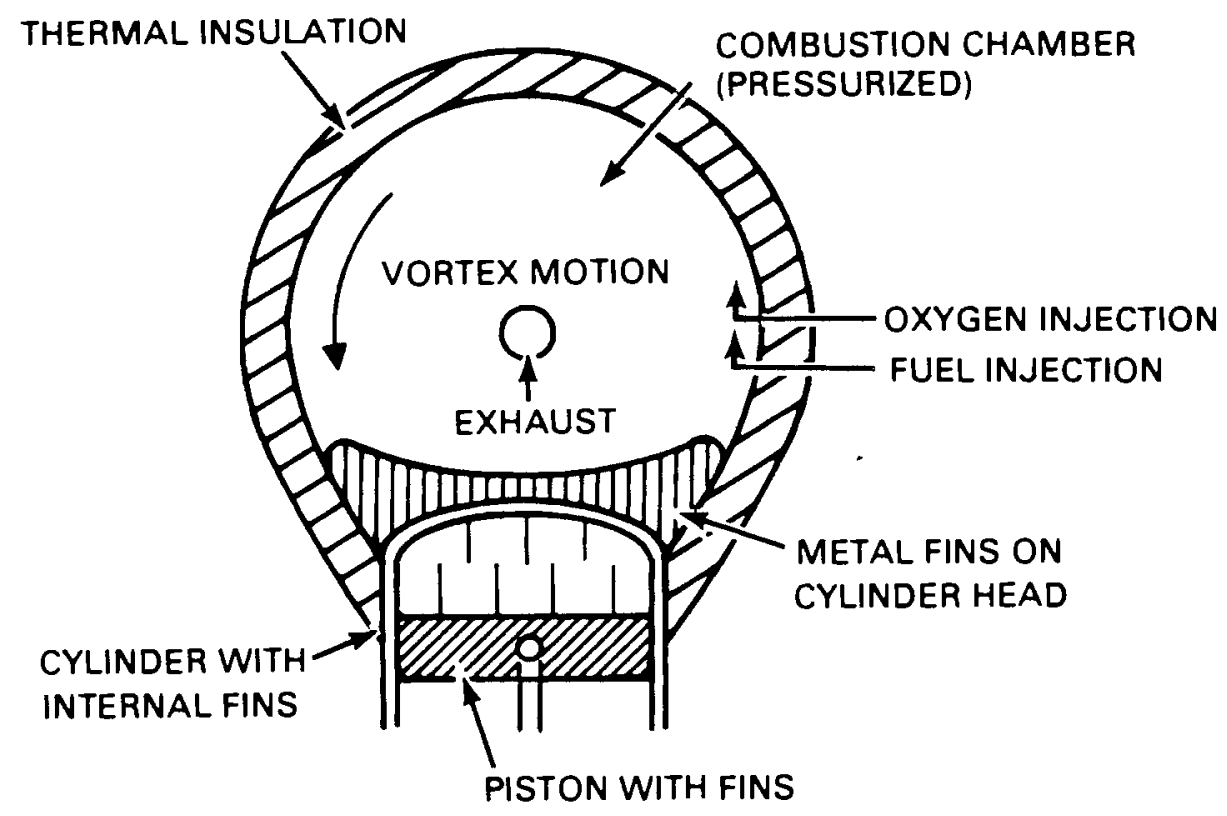

FIGURE 7.9. Proposed Vortex Combustion Chamber for Stirling Engine Operating on Direct Fuel/0xygen Injection 
mixing of fuel and oxidizer. Fuel and oxidizer will travel around the vortex several times before their combustion products are withdrawn in the center. In this way, complete combustion is assured.

- In the absence of nitrogen and because the combustion is quite complete, exhaust gases would be very clean, provided the fuel itself is clean with no or very low nitrogen and sulfur content.

- Because the exhaust gases are still quite hot and under high pressure, they can be used to drive a small expansion turbine. Conditions could be adjusted so that discharge from the turbine would be at essentially ambient pressure and temperature. This feature would obviate the need for large heat exchanger equipment to utilize some of the waste heat rejected from the Stirling engine.

- If the combustor side of the heat exchanger in the heater head is kept at high pressures, the pressure differential between working fluid and combustion gas is reduced significantly. This allows reduced wall thickness in the heat exchanger (heater tubes or whatever), thereby increasing heat transfer still further.

It must be expected that the amount of heat to be removed on the cold side of the engine is larger than that of the heat required for vaporization and pressurization of the $\mathrm{LO}_{2}$. Therefore, it might be possible to use LNG (Bourget 1981) as fuel for the engine. The LNG would be vaporized and pressurized in essentially the same way as the $\mathrm{LO}_{2}$ by regenerative heat exchange with the exhaust gases.

To quantify the above-listed advantages an extensive numerical analysis would be required, which would exceed the scope of the current study.

If liquid hydrogen $\left(\mathrm{LH}_{2}\right)$ were used as fuel in connection with $\mathrm{LO}_{2}$, the result would be a small, highly-efficient Stirling engine, probably having a higher power/weight ratio than any other known engine. The power/weight ratio for the fuel oxidizer $\left(\mathrm{LH}_{2} / \mathrm{O}_{2}\right)$ would al so be one of the highest of any known combinations. Because of the self-contained oxidizer feature, such an engine system could be used in outer space as well as under the sea. An added 
advantage is that the combustion product is pure water, which may be highly important for tactical reasons in submarine or torpedo propulsion.

It can, therefore, be concluded that for oxygen combustion in Stirling engines:

- A wide variety of fuels--even of low quality--can be used, including wood and peat.

- The effective engine operating efficiency can be improved because the effective $\Delta T$ is increased, particularly if LOX is also used for cooling.

- The operating efficiency can be further improved by recirculation of the combustion gases.

- Emission levels for $\mathrm{NO}_{x}$ can be drastically reduced, allowing combustion at higher temperatures.

It must be expected, however, that these advantages can be economically exploited only in stationary engines for which a source of oxygen is readily available. Stationary Stirling engines have been under development (Schuetz 1980; Uherka et al. 1981) both in the U.S. and abroad.

\subsubsection{Internal Combustion Engines}

As with external combustion engines, it is possible again to devise new types of internal combustion engines (ICE) that would run on oxygen with combustion gas recirculation. Again, it can be expected that several benefits, especially in efficiency, would result.

The basic configuration of a novel type of ICE is shown in Figure 7.10. It represents a fuel injection engine in which fuel and oxidizer are injected separately at high pressure and that employs combustion gas recirculation. The fuel can be any standard liquid fuel (e.g., gasoline); the oxidizer is liquid oxygen. An injection pump delivers liquid oxygen from its cryogenic tank to the cylinder head. The oxygen can be routed along the cylinder wall, where it would cool the walls, thereby increasing its temperature (possibly beyond its critical temperature). Initially, when the piston is in its top position, the injected fuel/oxygen mixture is ignited by a spark, which increases the 


\section{INJECTION}

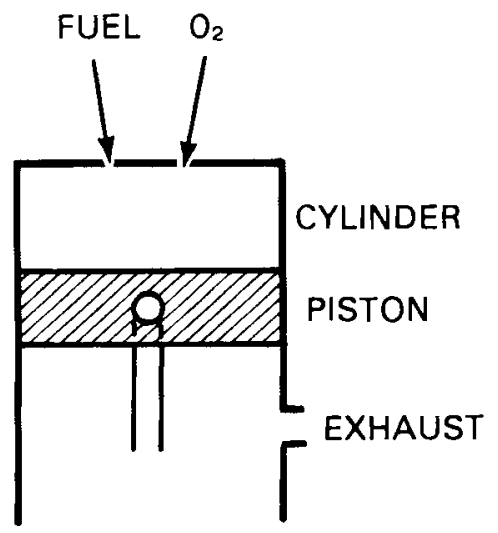

FIGURE 7.10. Configuration for Operating a Piston Engine on Dxygen Combustion

internal pressure and temperature of the working gases in the cylinder. Spark plugs may not: be needed, because the injected fuel/oxygen mixture would be self-igniting when it hits the hot piston surface. The subsequent expansion drives the piston downward. When the piston is in its lowest position, it momentarily uncovers the exhaust opening so that burned combustion gases can escape. However, the opening is sized such that only part (e.g., 20\%) of the combustion gases contained in the cylinder are discharged. Thereafter, the opening is closed again by the upward movement of the piston. By this arrangement the bulk of the combustion gases are recompressed again and serve as diluents for the next ignition cycle.

The described engine is thus basically a two-cycle version. The main difference from the standard two-cycle engine is that it exhausts only a fraction of the combustion gases in each cycle. In this way the heat loss experienced through the hot exhaust is greatly reduced. Furthermore, because the exhausted gas is still under fairly high pressure, its energy could rather easily be put to practical use in a small expansion turbine, which could power some auxiliary equipment (generator, air conditioner) or could be tied in (via a continuously variable transmission) with the main drive shaft of the engine.

As in the case of the oxygen-driven Stirling engine discussed previously, this piston engine (either otto or diesel type) would be able to operate at 
significantly higher efficiencies. Other advantages would be higher compactness and a simplified mechanical design of the engine because valves, carburetor, and other parts are eliminated. These parts are usually the more troublesome components in standard internal combustion engines.

The exhaust gases can be expected to be very $10 \mathrm{w}(\mathrm{a})$ in $\mathrm{NO}_{X}$, soot, and hydrocarbons because the fuel goes through an average of four ignition cycles before its combustion products are finally exhausted. Thus, combustion will be quite complete compared to that in a standard internal combustion engine. Also, the possibility of achieving higher combustion temperatures and pressures is readily available because the initial precompression temperatures of the diluent gases are already rather high, whereas in standard engines they are at ambient temperatures. Ceramic liners $(b)$ could be used for the cylinders and pistons to protect the metal walls from oxidation and corrosion. Higher compression ratios could also be used because fuel and oxidizer are not compressed together in the cylinder, as they are in regular IC engines. Only the diluent is compressed in the cylinder. This would improve efficiency and would allow the use of low octane gas, because the possibility for knocking is eliminated by this inherent design feature.

The same basic type of engine would also be quite suitable to burn ammonia as a fuel. When using ammonia in a regular combustion engine, there is some difficulty in igniting the fuel/air mixture (Bomelburg 1980). This can easily be overcome in an engine sketched in Figure 7.11. Here the fuel (ammonia) is injected at the beginning of the compression cycle. As the ammonia is compressed along with the exhaust gases left over from the previous cycle, it is heated up and will dissociate. The dissociation takes up some energy, i.e., the temperature is held down to lower than adiabatic values. The dissociation causes the ammonia molecule to split into two molecules $\left(1.5 \mathrm{H}_{2}\right.$ plus $\left.0.5 \mathrm{~N}_{2}\right)$, causing an additional pressure increase. Thus, the compression cycle results in a compressed gas, the pressure of which may correspond to a polytropic exponent of $\sim 1.1$. Because this is closer to an isothermal process than to an adiabatic process, the compression efficiency should be higher. Also, because

(a) Emission of $\mathrm{NO}_{\mathrm{x}}$ is low, primarily because air-nitrogen is eliminated.

(b) Ceramic parts for high temperature engines are under active development (Long 1981). 


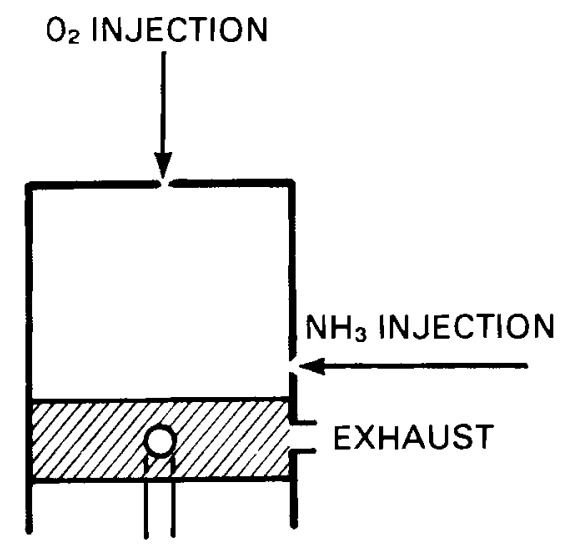

FIGURE 7.11. Internal Combustion Engine Modified to Burn Ammonia

the initial charge (leftover combustion gases) is still quite hot, this is equivalent to a preheating of the fuel/air mixture. Whereas the ammonia can be injected at a relatively low pressure, the oxygen required for combustion must be injected at rather high pressures. Both injections are accomplished by fuel injection pumps operating on the 1 iquids. Initial evaporation may take place in cooling passages around a cyclinder ( $i . e .$, engine waste heat is utilized for evaporation and heating of the cryogenic fuels while cooling the cylinder walls). The inlet valves have to be suitable to handle and meter the gas flow (solenoid valves). Power control will be effected by these valves, which, in turn, may be electronically controlled by a microprocessor.

Very high compression ratios are again possible with this scheme because only fuel and diluents are compressed, not a fuel/air mixture as in regular engines. As the oxygen is injected into the hot fuel vapor mixed with diluents, the mixture will start burning immediately. Thus, the combustion will take place at essentially equal pressure (not at equal volume as in regular engines). This also improves efficiency.

Because the compression process results in lower temperatures and higher pressures than what is normal in four-cycle engines, power density is increased correspondingly (e.g., as if using a turbocharger). The decreased peak temperatures result in still lower $\mathrm{NO}_{\mathrm{X}}$ levels of the exhaust gases. 
A serious disadvantage for using oxygen in nonstationary applications, such as automobiles, is the relatively large amount of oxidizer required to burn a given amount of fuel (i.e., about 3 parts (wt) $0_{2}$ per 1 part (wt) of hydrocarbons). This would require large oxidizer tanks that would have to be carried along with the regular fuel tanks, which essentially renders the idea of using oxygen in vehicular applications impractical under currently prevailing conditions. (a) Even a substantial gain in engine efficiency would probably not be enough to compensate for such a severe disadvantage.

This then restricts the use of oxygen in combustion primarily to stationary applications. It is likely, however, that in most such stationary combustion facilities $\mathrm{LO}_{2}$ could be used with at least some advantage.

\subsubsection{Pulse Combustion}

Pulse combustion is still not completely understood. Basically, it is a process in which combustion takes place not continuously at a steady rate but in an oscillating manner within a properly shaped resonance tube such as a Helmholtz resonator. With in the combustion zone both temperature and pressure oscillate around a medium value. ${ }^{(b)}$

The inherent advantages of pulse combustion 1 ie in improved process efficiencies. According to Marzouk and Kentfield (1974) the efficiency $n$ of a combustion process is given by

$$
n=1-\frac{T}{T_{2}-T_{1}} \cdot \ln \frac{T_{2}}{T_{1}}-\frac{\gamma-1}{\gamma} \ln \frac{P_{2}}{P_{1}}
$$

in which the subscripts 1 and 2 refer to the heating of a gas by combustion (before and after); $\gamma=c_{p} / c_{V}$, the ratio of the specific heats of the gas. The equation shows that, for given values of $T_{1}$ and $T_{2}$, a pressure gain between states 1 and 2 always leads to an increase in effectiveness of the heating process, whereas a pressure loss does the opposite. In regular combustion a

(a) This argument does not even take into account the vast distribution system that would be required for delivering the $\mathrm{LO}_{2}$ from the $\mathrm{plant}$ to the consumer. Also not considered here are the additional substantial hazards of carrying $\mathrm{LO}_{2}$ in the vehicles.

(b) For a more detailed discussion of pulse combustion see Raeder (1978) and Clinch (1980). 
pressure loss (usually $-5 \%$ ) is practically unavoidable. However, in pulse combustion a pressure gain is encountered, which, in actual experiments, was measured to be generally in the range from 5 to $10 \%$. In particular, it has been shown that, for a certain type of gas turbine, the overall thermal efficiency could increase from $-23 \%$ to $-27 \%$ when using pulse combustion instead of regular combustion (Kentfield et al. 1977).

It is believed that the pulse combustion process could benefit significantly if oxygen were used instead of air. The inmediate effect would be the possibility of more compact combustors because both temperature and pressure fluctuation amplitudes would be higher. Thus, n would increase not only because of the higher peak temperatures (an effect that is quite obvious), but also because of the higher pressure excursions. Under normal continuous combustion conditions, an increased temperature could have a detrimental effect on the material of the combustion chamber. (This is, as stated before, a major problem with the use of oxygen, but not so in pulse combustion where the peak temperatures are experienced only for short time intervals.) (a)

Regular pulse combustion usually suffers from incomplete combustion since residence times with in the combustor are rather small. It has been estimated that, on the average, a fuel/air change takes -3.5 cycles to pass through the system. If oxygen and exhaust gas recirculation were to be used instead of air, the residence time could probably be increased to -10 to 12 cycles, thus affording more complete combustion. Also, because the total throughput and, thus, the exhaust volume is lower, less heat is lost through the stack. With a lower throughput, the cross section of the exhaust pipe could be made smaller, which, in turn, would further increase the pressure oscillation amplitude and, with it, the overall efficiency of the process.

Increased heat transfer (because of the intense back and forth movement of the combustion gas) is another advantage of pulse combustion. With oxygen combustion the oscillating gas becomes hotter and its movement still more intense, so the convective heat transfer coefficient should also become still 1arger.

(a) This situation is similar to that in regular combustion engines, which also would not be able to tolerate the peak temperatures on a continuous basis. 
A new type of gas furnace, based on pulse combustion, (a) was introduced commercially by the end of 1981 (Lennox News 1981). It is claimed that a special proprietary design has overcome the noise problem and that the annual fuel utilization efficiency of this furnace is said to be in the 92 to $96 \%$ range, compared with a 55 to $78 \%$ range for currently manufactured furnaces. Although this very high efficiency level is achieved partly by condensing the water vapor contained in the combustion gases by means of an additional condensing heat exchanger ( $f 1$ ue gas leaves at $\approx 120^{\circ} \mathrm{F}$ ), (b) this application indicates the magnitude of potential energy savings obtainable by pulse combustion. However, like other home heating furnaces the new pulse combustion furnace is still rather bulky.

Pulse combustion, even with air, shows good promise in burning heavy oils and even pulverized coal with little adverse environmental impacts (Kentfield et a1. 1977). This favorable feature should also become still more pronounced with the use of oxygen. It probably would be possible to use coarser coal than the relatively fine dust required for conventional pulverized coal combustion.

It is felt that pulse combustion with oxygen has the potential of being able to provide a much more efficient use of fuels than hereto possible without: the use of large heat exchanger equipment. So far, even pulse combustion with ordinary air has not received the attention it deserves, in the opinion of this writer. Because it involves essentially a nonstationary gas dynamics process with heat addition, it contains many analytical and experimental problems that have not yet been satisfactorily solved. Thus, much additional R\&D is probably' required before a full quantitative understanding of the involved phenomena is obtained.

\subsubsection{Submerged Combustion}

It is well known that oxyacetylene torches can operate below water, without being quenched. The main purpose of such devices is, of course, the cutting of metals below water. With essentially the same arrangement it is also possible to heat and vaporize the water. Such devices using regular fuels have

(a) R\&D leading to this application was conducted by the Gas Research Institute (GRI) and Lennox Industries, Inc. (GRI 1980).

(b) Conventional furnaces do not contain this special heat exchanger. 
become knowr as immersion heaters and "tunnel" burners (Kurz 1968; Keilor 1948). A tunnel burner is illustrated in Figure 7.12. Although these devices are usually operated with air, their performance is improved when oxygenenriched air or even pure oxygen is used.

With such a device it would be possible to directly generate steam and $\mathrm{CO}_{2}$ under pressure by "submerged combustion." Fuel and oxygen burn within a vapor cavity inside a water-filled pressure vessel, as shown in Figure 7.12. The end of the closed pipe is perforated by many holes through which the combustion gases flow into the main water tank. Submerged combustion is used for various purposes, such as evaporation of saline water or concentrating highly corrosive liquids, e.g., sulfuric acid (Iyer and Chiu 1971; Gerlach 1969).

The steam generated by such direct methods would essentially be saturated and, as such, would generally not be very suitable for expansion through steam turbines, which operate best with superheated steam. To produce this type of steam, the scheme shown in Figure 7.12 could possibly be modified to resemble the configuration shown in Figure 7.13. The oxygen and fuel are injected into

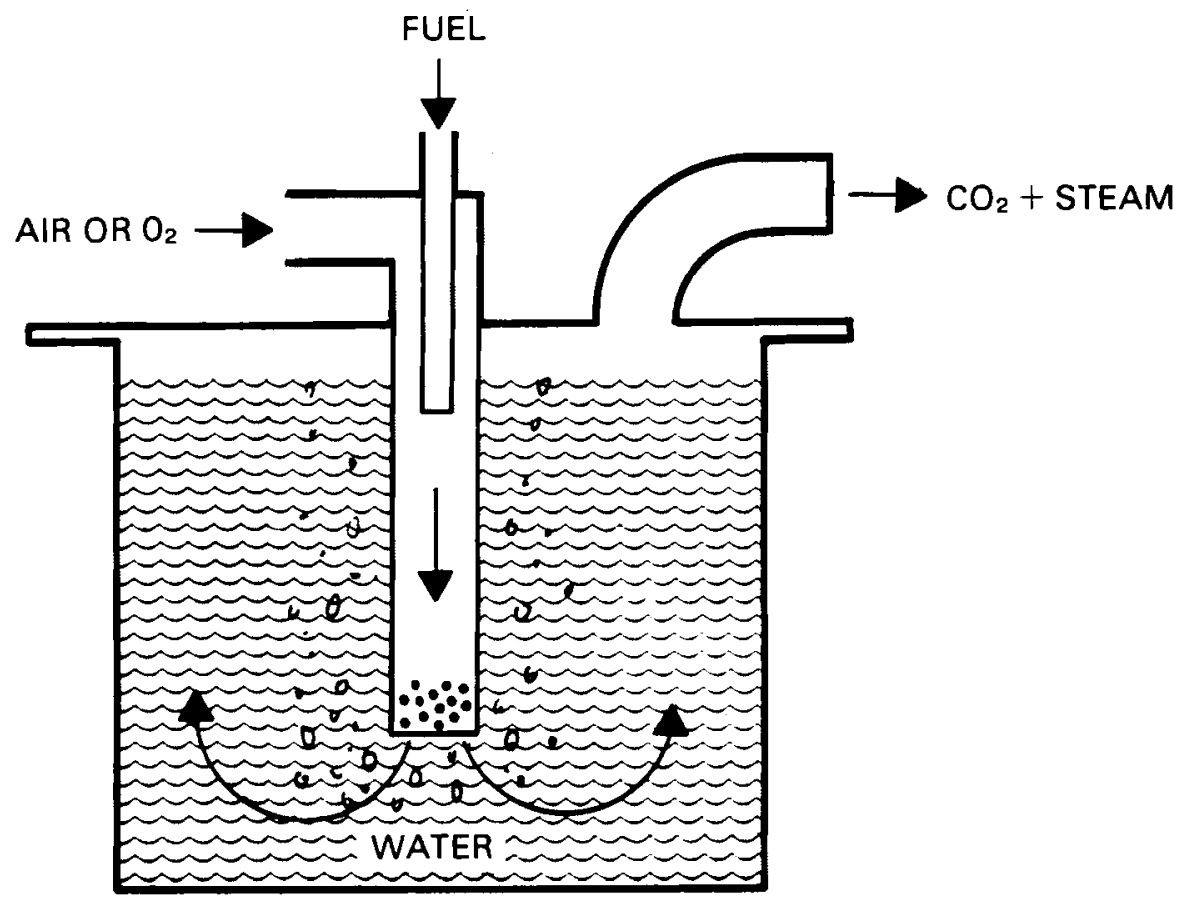

FIGURE 7.12. Evaporation by Submerged Combustion 

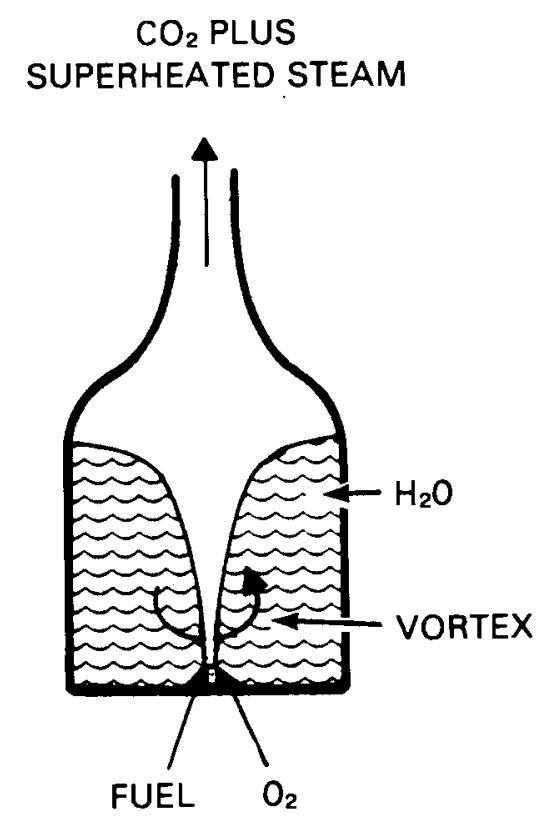

FIGURE 7.13. Steam Generation by Submerged Combustion

the combustor from below in a swirling motion so that the water in the chamber forms and maintains a vortex with a hollow core. The flame extends through the gaseous vortex core high into the exit. Water is entrained and vaporized only in the lower parts and is superheated in the upper parts of the flame.

\subsubsection{Wet Oxidation and Combustion of Wet Fuels}

Apart from the commonly mined coals that are fairly dry, there is an abundance of solid fuels (coals, lignites, peats) that often are rather wet in their original state. Therefore, drying operations are sometimes interspersed before such fuels are used. Unfortunately, water removal from coal is so expensive that it is almost nonexistent, even for high moisture coals which, if dried, would offer many advantages such as higher thermal efficiency, higher flame temperature, easy maintenance of ignition and flame, and the possibility of operating single power generation units much larger in capacity (Potter and Keogh 1981). Peats are often so wet that they cannot be burned at all without 
at least some previous drying. (a) Because of such problems, burning these wet fuels with pure oxygen or, at least, with oxygen-enriched air, could be considered.

As showr in the Appendix, the burning of $1 \mathrm{~kg}$ dry coal requires $-2.5 \mathrm{~kg}$ oxygen, which inevitably is linked up with $8.3 \mathrm{~kg}$ of diluent nitrogen, when regular air is used for combustion. The burning of $1 \mathrm{~kg}$ of wet coal would still require only $2.5 \mathrm{~kg}$ oxygen, no matter how wet the coal is, if only proper combustion conditions could be maintained. If all nitrogen $(8.3 \mathrm{~kg})$ were removed from the air, i.e., if combustion were to take place with pure oxygen, the water in the coal would then act as the main diluent. If $1 \mathrm{~kg} l i q u i d$ water diluent would be thermally equivalent to $1 \mathrm{~kg}$ nitrogen diluent, $1 \mathrm{~kg}$ coal could contain $8.3 \mathrm{~kg}$ water and still be combustible in pure oxygen with the same results as $1 \mathrm{~kg}$ of dry coal in air. However, because of the relatively high heat of vaporization and high specific heat of water, $8.3 \mathrm{~kg}$ of diluent nitrogen might be thermally equivalent to only roughly(b) $4 \mathrm{~kg}$ of water. Even under these more stringent assumptions, $1 \mathrm{~kg}$ coal could contain $\sim 4 \mathrm{~kg}$ of water and still be combustible in pure oxygen with the same thermal output as if dried and combusted in air. However, because coals are hardly ever that wet, coals with lesser amounts of water (e.g., $2 \mathrm{~kg}$ of water per $\mathrm{kg}$ of coal) could probably be combusted with oxygen-enriched air $\left(\sim 60 \% \mathrm{O}_{2}, 40 \% \mathrm{~N}_{2}\right)$ with good results. Because providing oxygen at this concentration is fairly inexpensive and might add only a few percent ( 2 or $3 \%$ ) to the fuel cost, it appears to be economically justifiable to burn wet fuels with oxygen-enriched air. In comparison, it would cost $\sim 2.5$ to $\$ 3(1980$ dollars) per ton of dry coal to el iminate the moisture by the most advanced drying operations(c) (Potter and Keogh 1981). Based on a 1980 price of $\$ 23$ for dry coal at the pit, this represents an 11 to $13 \%$ increase in cost for drying. (d)

(a) It has recently been demonstrated that fluidized bed combustion of dried peat is possible with at least the same efficiency as obtainable for coal (Hampartsoumian and Gibbs 1981).

(b) The influence of various types of inert diluents on combustion characteristics is known quantitatively only to a limited extent (Zabetak is 1976).

(c) Such advanced drying operations are not yet commonly applied. The current conventional methods are still more expensive.

(d) Additional transportation costs are not considered in this comparison. 
In practice, wet coal/oxygen combustion could be applied in standard boiler operations for generating steam in the conventional way, or the coal could also be oxidized at relatively low temperatures by "wet oxidation." Such a process is analogous to simple burning, i.e., the amount of heat 1 iberated and the end products formed are the same as when oxygen gas (usually in air) reacts directly with organic matter, as in the hot combustion of coal to form carbon dioxide and water. Kinetically, however, wet oxidation differs significantly. Because it proceeds at much lower temperatures, the rates are usually quite slow. However, if reacted at high pressures and with oxygen instead of air at temperatures above about $300^{\circ} \mathrm{F}$, wet oxidation may show some practical merit (Lamparter 1979).

Obviously, such processes might be particularly attractive for use with wet coals or peat, which almost always contains large quantities (up to $90 \%$ ) of water. About 50\% of the moisture is trapped as a colloidal gel (Smith 1981). This colloidal moisture cannot be removed by conventional dewatering methods (e.g., filter presses) and must be removed by thermal drying, solvent extraction, or solar drying before the peat can be utilized as a fuel feedstock for direct combustion with air or for gasification. To circumvent the drying problem, alternative technologies such as wet oxidation, wet carbonization, and biogasification are possible for producing energy or enhanced fuel from peat. Such methods are apt to be more efficient with oxygen than with air.

The method that immediately suggests itself for application in wet oxidation schemes is the pressurized fluidized bed (PFB) system (Crowther 1981). Al though it is primarily intended for combustion at much higher temperatures, it would be usable for wet oxidation also, because there appears to be a continuous transition from wet oxidation to normal combustion as reaction temperatures are increased. To date, however, the economics of wet oxidation approaches apparently have not been evaluated. Pressurized fluidized bed technology itself is also quite new and is still in the demonstration phase. It is, therefore, initially suggested here that a wet oxidation/combustion scheme using peat could be operated basically as shown in Figure 7.14.

Wet peat is pumped as a slurry into the reactor under pressure $(10 \mathrm{~atm}$ or higher). Also injected is oxygen gas under pressure. The reaction products 


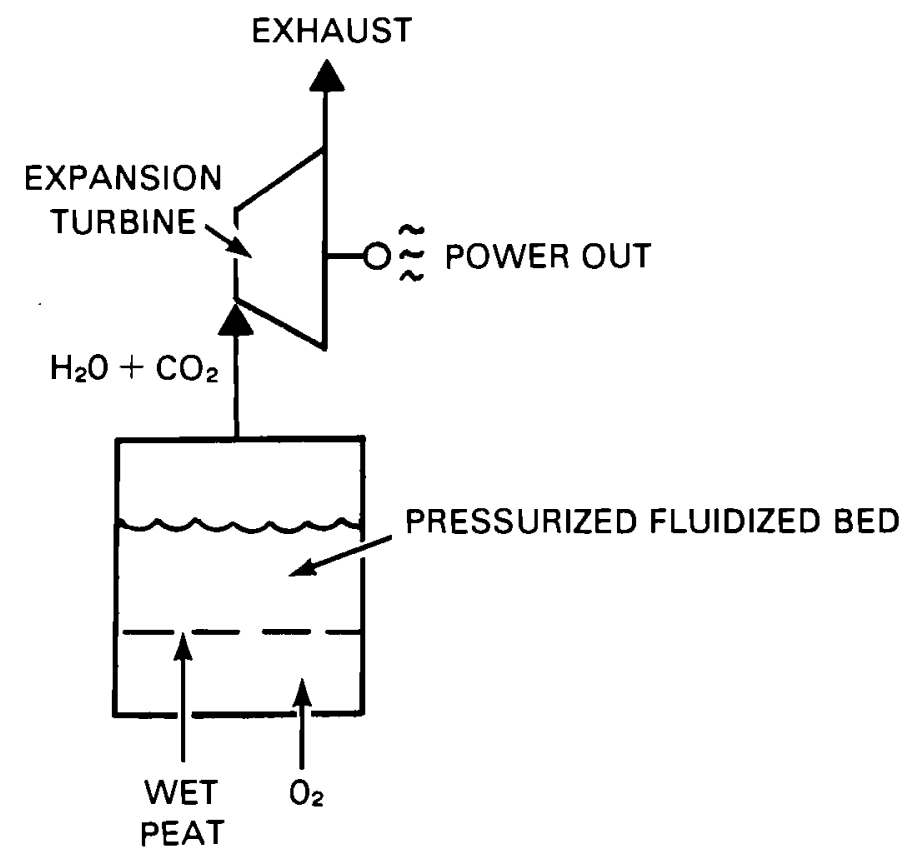

FIGURE 7.14. Pressurized Fluidized Bed Arrangement for Use with Wet Fuels

are mainly $\mathrm{CO}_{2}$ and $\mathrm{H}_{2} \mathrm{O}$ (steam), combined with the plentiful diluent liquid $\mathrm{H}_{2} \mathrm{O}$, which is also converted to steam. These gaseous products (presumably at $\sim 10$ atm and $\sim 360^{\circ} \mathrm{F}$ ) are then used (after some cleanup) directly in a turboexpander for power generation and are subsequently discharged to the environment. Because the peat is so wet, recirculation is not required in this process. The gases could also be condensed by a two-stage condenser by the counterflow of cold oxygen from the cryogenic $\mathrm{LO}_{2}$ storage as shown in Figure 7.15. In such a case, the discharged products would be liquid $\mathrm{H}_{2} \mathrm{O}$ and solid $\mathrm{CO}_{2}$, which could be sold. Again, no recirculation would be required if the fuel were sufficiently wet. However, some of the recovered water may have to be recirculated, as indicated by the dashed line in Figure 7.15.

The main incentive for developing hot PFB combustion schemes has been the possibility of combusting high-sulfur coals with very little pollution emission 


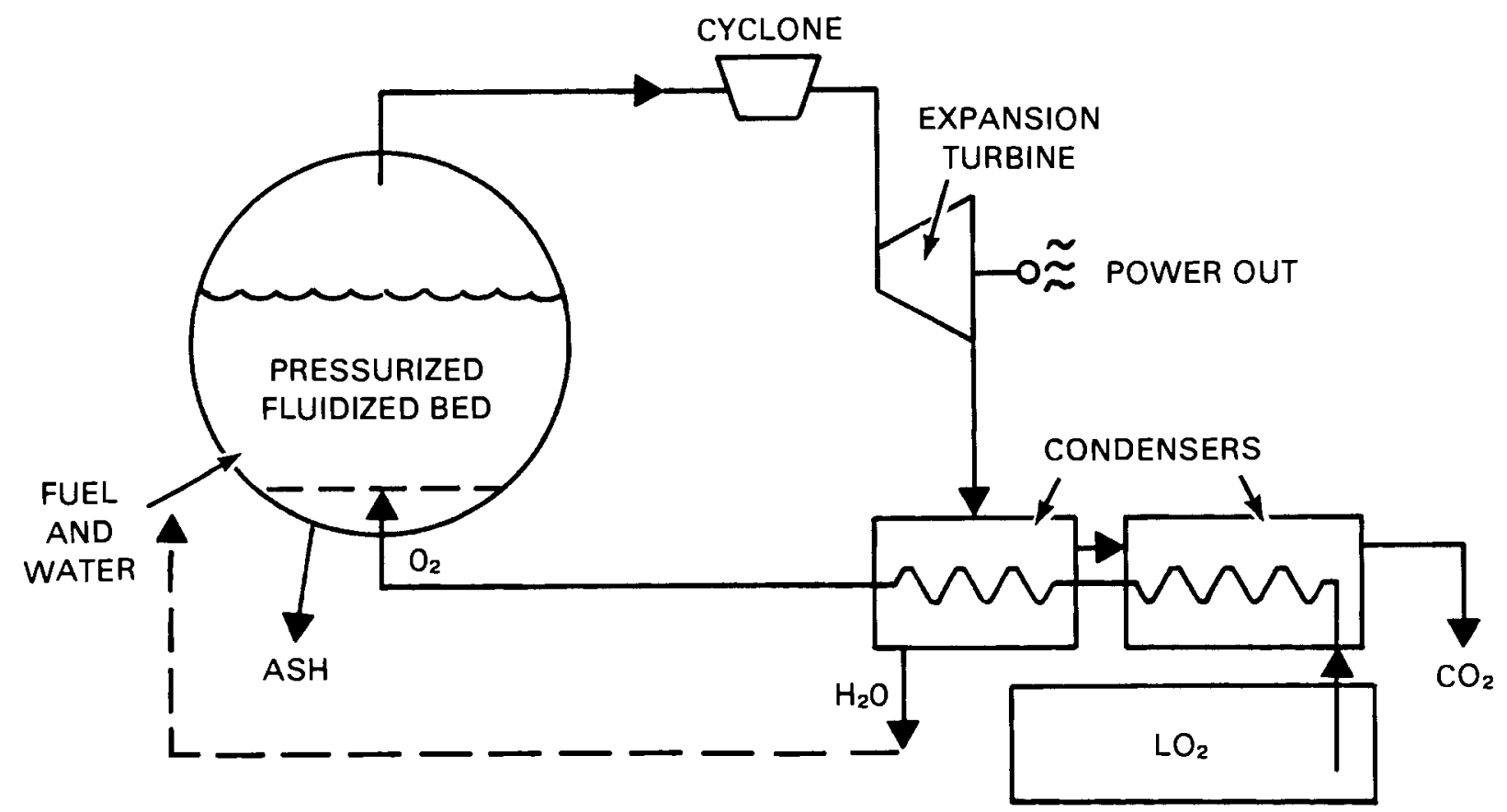

FIGURE 7.15. Burning Wet Fuels with Oxygen for Direct Steam Generation

problems, (a) because the sulfur is retained in the bed by reacting with limestone added to the bed. In the scheme proposed in Figure 7.15, this feature is retained. The emission of nitrous oxides is also essentially el iminated if pure oxygen is used instead of air.

Figure 7.16 shows a PFB pilot plant (gas turbine with steam bottoming cycle) at Curtiss Wright in New Jersey (Farmer 1980). It is based on normal coal combustion with air and utilizes the reaction products (mainly $\mathrm{CO}_{2}$ and steam) as working fluid in the turbines. It thus represents a significant step beyond the current state-of-the-art, which makes use of separate steam generators. The conventional heat exchanger in the bed is retained mainly for better regulation of the bed temperature. The steam bottoming cycle, (b) shown in

(a) Equipment for exhaust gas scrubbing is expensive, adding roughly $\$ 100 / \mathrm{kW}$ to plant costs for removing $\mathrm{SO}_{2}$ (Schaefer 1979 ). $\mathrm{NO}_{x}$ removal equipment is not even included in this cost figure.

(b) Such PFB combined cycles are considered now to be among the most effective and efficient means of utilizing coal for electric power generation, with respect to both environmental considerations and the cost of electricity (General Electric 1981). 


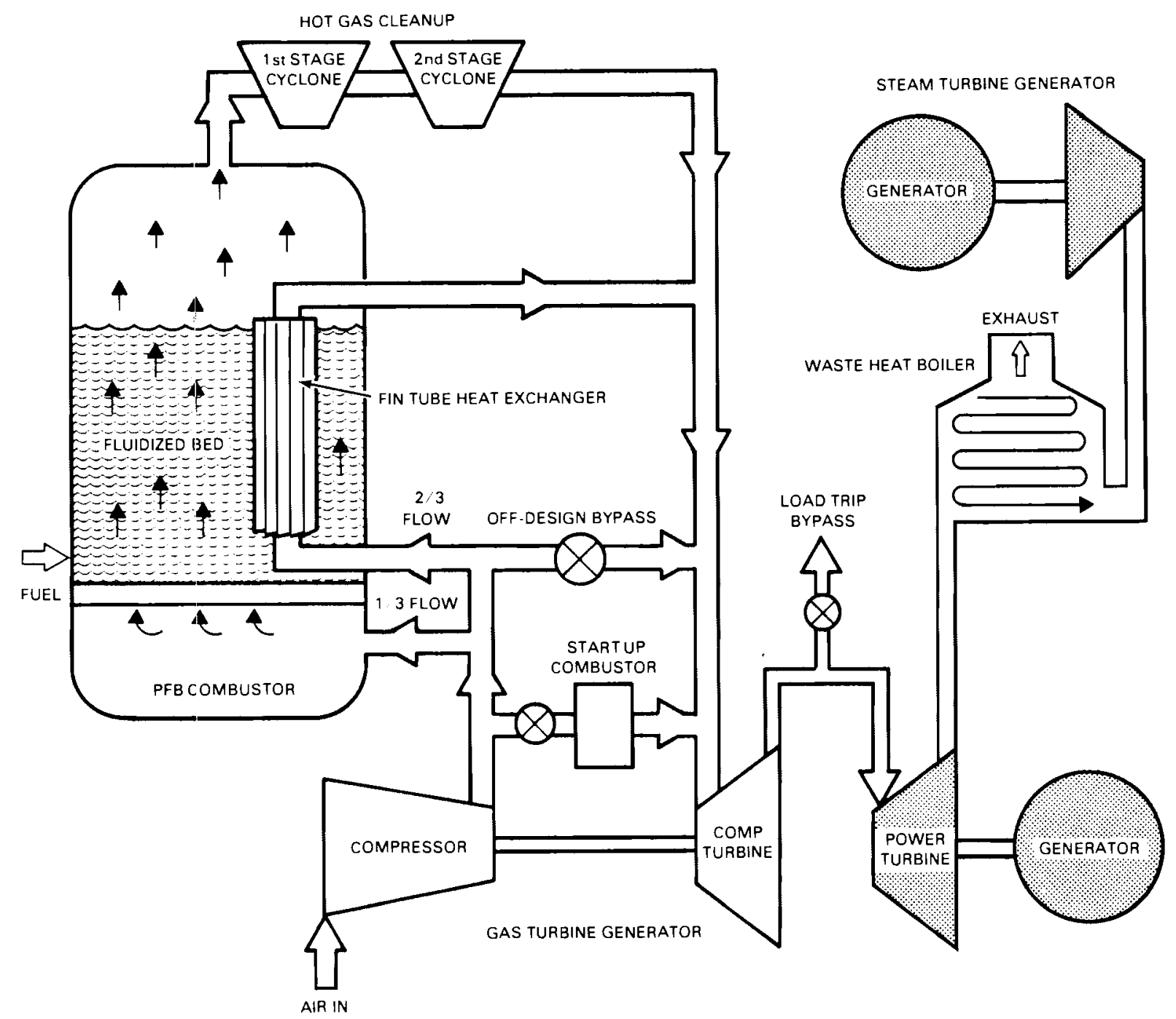

FIGURE 7.16. Pressurized Fluidized Bed Combustor in a Combined Cycle (Gas Turbine with Steam Bottoming)

Figure 7.16, represents a physically large part of the facility because it operates at relatively low pressures and temperatures, but it contributes only a small part of the overall power output.

If reaction with oxygen and partial recirculation of the exhaust gases were applied to this scheme as shown in Figure 7.17 , the bottoming cycle could be el iminated and less power would have to be expended for compressing part of the combustion air. In such a case, oxygen gas (under the same pressure as the power turbine discharge gas) would be fed into the compressor along with some 


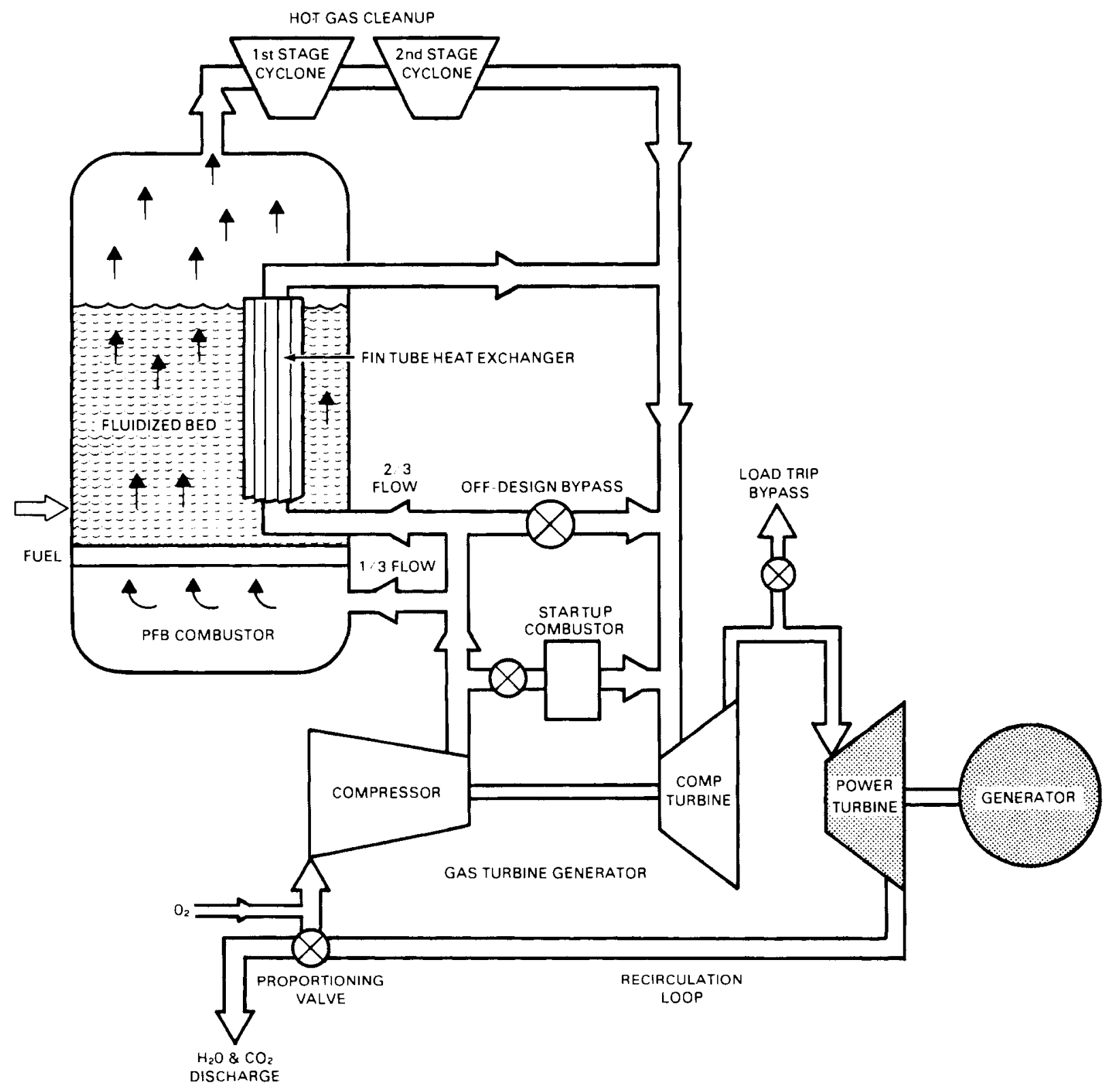

FIGURE 7.17. Pressurized Fluidized Bed Combustor in a Single Cycle with Recirculation

of the exhaust gas. The amount of fresh oxygen gas supplied compensates for the amount of combustion gas discharged. By changing the ratio of discharge flow to the total circuit flow (e.g., by adjusting the proportioning valve), an effective control of the reaction rate in the PFB becomes possible and the heat exchanger in the bed could probably be eliminated. Because these heat 
exchangers represent the major technical problem in the development of PFB facilities, the proposed change may have considerable advantages.

Figure 7.17 shows cyclone-separators installed ahead of the expander to reduce particulate matter to a tolerable level. Modern turboexpanders are far less sensitive to foreign materials and erosive/corrosive attack than conventional turbines (Holm and Swearingen 1978). They can even operate in the condensing regine of the water vapor so that relatively low discharge pressures are possible without the need for a condenser.

The main advantage of such a scheme would be the elimination of the steam generator with its attendant closed-cycle water 10op. At the same time, however, this represents a certain disadvantage, because generally higher steam pressures can be generated in a conventional steam generator than in the direct steam generation of the combustion cycle itself. One obvious advantage would be the elimination or strong reduction of common air pollutants $\left(\mathrm{NO}_{x}, \mathrm{SO}_{2}\right.$, soot) from the flue gases.

Many variations of the proposed basic cycle are possible. For example, if ammonia instead of water is used in an optional bottoming cycle, it is vaporized in the heat exchanger/condenser, expanded in an ammonia turbine, and recondensed in a dry cooling tower before being pumped back into the heat exchanger. The discharge from the condenser is mainly liquid water and gaseous $\mathrm{CO}_{2} \cdot$

The water can be used partly for reinjection at the PFB or can be discarded altogether. The $\mathrm{CO}_{2}$ can be discharged to the atmosphere or solidified and sold as dry ice. Because the offgas at this point is almost all $\mathrm{CO}_{2}$ (if pure $\mathrm{O}_{2}$ is used for combustion), this would be a rather inexpensive source for dry ice generation. (a) In fact, if the oxygen is available as $\mathrm{LO}_{2}$, the dry ice could essentially be obtained as a free byproduct if $\mathrm{LO}_{2}$ is used first for solidification of $\mathrm{CO}_{2}$ before being injected into the PFB. If left in gaseous form, the $\mathrm{CO}_{2}$ could be sold, e.g., for use in enhanced oil recovery operations.

(a) The use of cryogenic liquids as an economically viable method for $\mathrm{CO}_{2}$ condensation is being demonstrated by the Osaka Gas Company, which has operated a dry ice manufacturing plant on LNG evaporation since 1980 (Murata and Eiji 1980). 
This approach might be economically quite attractive. With an estimated price of $\$ 25 /$ ton for coal and $\$ 75 / 2.5$ ton for $\mathrm{LO}_{2}, \sim 3.5$ tons of $\mathrm{CO}_{2}$ could be obtained for $\$ 100$. Thus, the production price of dry ice would be $\sim \$ 30 /$ ton, even when disregarding entirely the power sold from the process. When this cost is compared with the wholesale price of $\sim \$ 300 /$ ton dry ice (delivered), there appears to be a sizable margin for profit.

It is still not certain, however, that the reaction rates in low temperature oxidation are fast enough to be of practical usefulness. But, as indicated above, there is probably no sharp boundary between "wet oxidation" and "burning" of wet fuels. Thus, the basic PFB scheme described above would probably be workable over the entire temperature range from about $300^{\circ} \mathrm{F}$ to $2000^{\circ} \mathrm{F}$ or even higher. Only a more thorough study combined with some explora-. tory testing would allow a quantitative technical evaluation of the actual performance of the proposed scheme. However, such work is clearly beyond the scope of the present study.

\subsubsection{In Situ Vitrification of Waste}

A byproduct of nuclear industry operations is low-level radioactive waste. In the U.S., this waste is usually buried. However, because of growing environmental concerns, such practice has come under criticism. In 1981, the Pacific Northwest Laboratory (PNL) proposed to vitrify such wastes in situ so that leaching is inhibited. The method chosen for the vitrification process is electric heating of the wastes to temperatures high enough to melt surrounding soil and rock material. The method, demonstrated in 1983, is illustrated and explained in Figure 7.18.

An alternative heating method using oxygen might prove to be more costeffective. The waste materials mixed with coal, cullet, sand, soda, etc., are buried in the pit as shown in Figure 7.19. The bottom and sides of the pit contain only sand and coal. 0xygen or oxygen-enriched air can be blown from below through the porous material mixture, which is ignited at the top. The temperatures in the combustion zone, which will move slowly downward, are high enough to melt sand, glass, and noncombustible wastes. The off gases, consisting mainly of $\mathrm{CO}_{2}, \mathrm{H}_{2} \mathrm{O}$, and possibly some traces of gaseous components that might be radioactive, are collected and piped to suitable filtering equipment, 

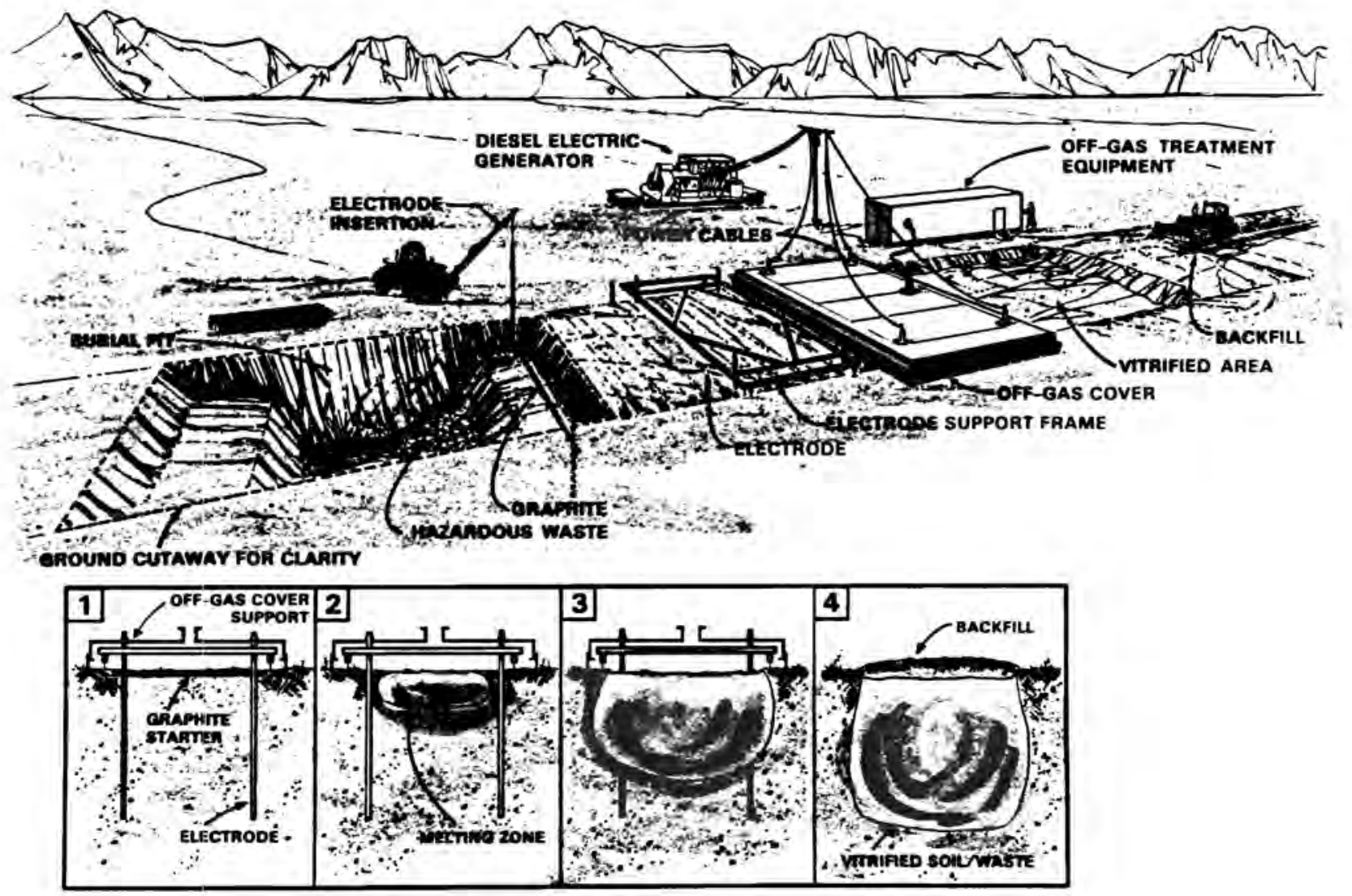

FIGURE 7.18. In Situ Waste Vitrification

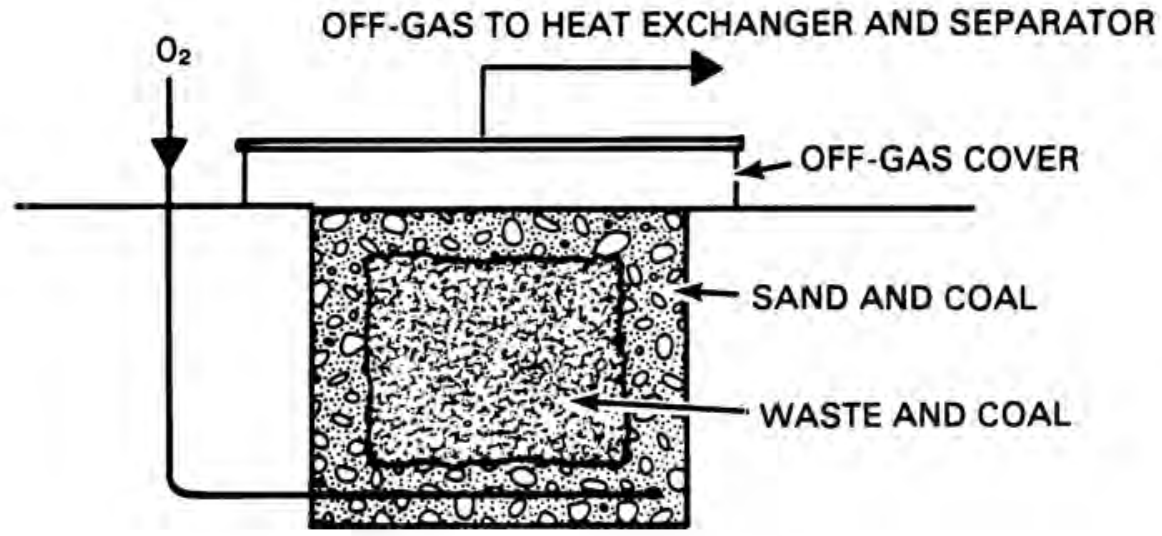

FIGURE 7.19. Alternative Concept for Solidifying and Isolating Waste Using Combustion with Oxygen 
which would retain the radioactive or otherwise poisonous material. As the liquid mass in the pit cools, it encapsulates the unburned remnants of the hazardous waste in a single glasslike solid block.

Essentially, the method thus consists of incinerating any combustible wastes and vitrifying the ashes and the noncombustibles within solid inert material (glass). Of course, incineration of hazardous wastes is a wellestablished technology (a) and is currently considered the most economical method for the total destruction of organic hazardous wastes (Ross 1980). However, the presence of inorganic or even radioactive waste material intermixed with the organic wastes complicates this process considerably, because it can el iminate the inorganic wastes only incompletely and the radioactive wastes not at all. For such cases in situ combustion and vitrification would be much more economical. Noncombustibles would be left in their final burial place and simultaneously would be isolated from the environment by vitrification.

The main advantage of this process, when compared with the electric melting approach proposed earlier by PNL, is considered to be an economic one: instead of using fuel to first generate electric energy and then using this energy for melting the wastes, it would be more cost-effective to burn the fuel (coal) directly to melt the waste materials. By using oxygen (or oxygenenriched air) for the burning process, higher temperatures could be achieved than by using plain air. Such a method would also possibly increase the heating rate well above that achievable by the relatively slow electric heating method. This again would help to minimize the overall energy requirements.

\subsubsection{In Situ Thermal Heating of Tar Sands}

$0 i 1$ recovery from tar sands by in situ thermal heating (Figure 7.20) is normally carried out by partial combustion with air leither in forward or reverse direction) of the fossil material within the mineral matrix (Amr 1981). To reach the combustion zone and maintain a sufficiently high combustion temperature, the air must penetrate the porous material at a sufficiently high flow rate. With low porosity this is sometimes difficult to achieve because large amounts of diluent nitrogen must be carried along needlessly. If pure

(a) In some cases it is possible to burn certain toxic wastes only with oxygen, because they are practically nonflammable in air (Komamiya 1978). 


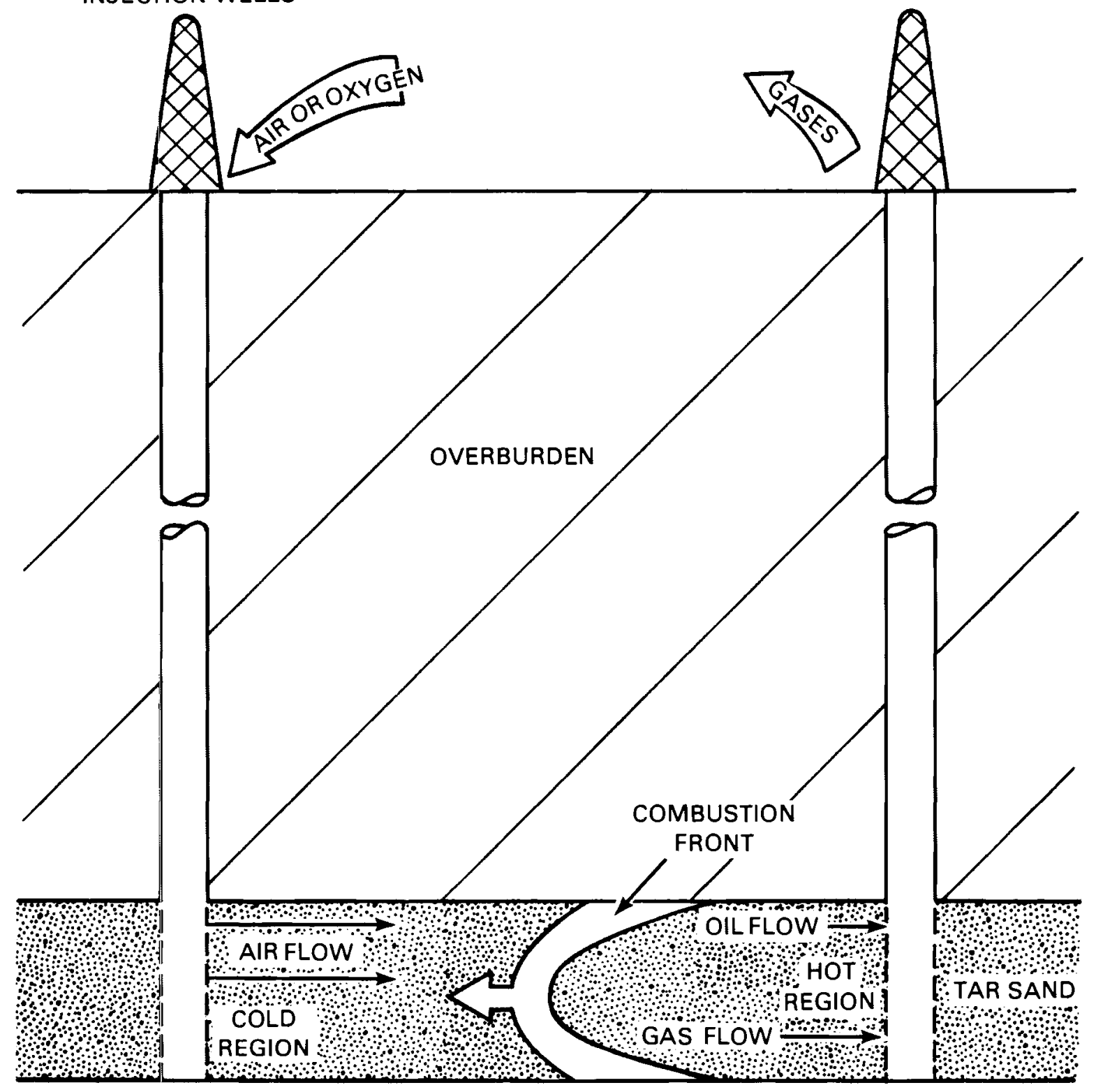

FIGURE 7.20. Reverse Combustion in Tar Sands

oxygen were used, the pumping requirements could be significantly reduced. At the same time, reaction temperatures and flame velocities could be increased so that the entire gasification process could be speeded up, thus making it more cost-effective. It is not known whether pure oxygen has ever been used for this purpose. 


\subsubsection{Gasification of Fossil Materials}

The use of oxygen in gasification processes goes back to the early beginnings of this industry in the first half of this century; e.g., water-gas production from coal or the Lurgi gasification of lignite usually have utilized almost pure oxygen (95\%). After World War II it was generally expected that the use of oxygen for this purpose would increase dramatically (Fehl ing 1948); however, the actual increase was far less than originally expected. The reason can probably be found in the abundance of inexpensive oil and gas, which lasted until 1973 and which obviated the conversion of coal to more convenient forms of energy. Since then, it gradually became more widely known that the production of synthetic fuels can be made economical if oxygen is used in the process. As a case in point, it has recently been shown (Beckman 1980) than an oxygen-blown coal gasification/combined cycle power plant system operates more economically on pure oxygen (98\%) than on oxygen-enriched air. So far, however, most of the new projects in the synfuels field are still in the planning or demonstration phase. The old, time-proven methods of generating producer gas and water gas can utilize either air or oxygen.

\subsubsection{Producer Gas and Water Gas}

Producer gas is made by passing air over highly heated carbon in such a way that it is predominantly converted to $\mathrm{C} 0$. Thus, producer gas consists primarily of carbon monoxide and nitrogen. Its heat content is rather low $\left(\sim 140 \mathrm{Btu} / \mathrm{ft}^{3}\right)$. Even early in this century, attempts were made to reduce the normal high nitrogen content of producer gas by enriching the air supply with oxygen. Theoretically, this could lead to a gas of $-300 \mathrm{Btu} / \mathrm{ft}^{3}$ (Brame and King 1967). However, in those days oxygen was not sufficiently cheap to make this approach economical.

Water gas is generated by intermittently passing steam over highly heated carbon. It consists mainly of hydrogen and carbon monoxide and has a higher heat content $\left(\sim 300 \mathrm{Btu} / \mathrm{ft}^{3}\right)$ than regular producer gas. It is possible to add air, oxygen-enriched air, or even pure oxygen to the steam. This generally allows a continuous generation process and also increases the heat content of the gas. More than 20 years ago such a water gas plant, using 360 tons of oxygen per day, was put into operation and could be operated at a profit when 
oxygen was costing $\$ 0.17$ to $\$ 0.20 / 100 \mathrm{ft}^{3}$ (Brame and King 1967). Because today's oxygen production costs are much below these values, such "synthesis gas" generation should prove to be economically quite attractive, even though coal production costs have since escalated and even though natural gas is still at a relatively low price level. But for the synthesis gas generation, which is part of most coal liquefaction schemes (see Figure 7.21) and of methods for producing ammonia from coal (see Figure 7.22), oxygen is used instead of air almost exclusively (Johnson 1979; Engelbrecht and Partridge 1979).

\subsubsection{Coal Gasification with Air or Oxygen}

A typical example for a choice between the use of air or pure oxygen in a high temperature chemical process involving partial combustion is the gasification of coal. In such a process coal is reacted with a mixture of either steam and air or steam and oxygen. (a) With the former, a low-Btu gas is produced having a heating value of 100 to $200 \mathrm{Btu} / \mathrm{scf}$. Using oxygen instead of air produces medium-Btu gas having a heating value of 250 to $400 \mathrm{Btu} / \mathrm{scf}$ (Patel 1981 ).

The medium-Btu gas is a mixture of carbon monoxide, hydrogen, methane, and carbon dioxicle (Figure 7.23). The low-Btu gas contains the same ingredients plus the nitrogen, which is contained in the air as diluent and which does not participate in the gasification process. Which gas is manufactured in a particular plant depends primarily on the marketability of the gas. In general, low-Btu gas is usually used as an onsite industrial fuel because it is uneconomical to transport due to its low heat content. The medium-Btu gas, however, can be economically pipelined for distances of 100 to 200 miles.

Peat can also be gasified in a similar reaction with steam and oxygen. This has been shown in recent demonstration tests (Rader 1979). It is even claimed that peat can be converted to synthetic natural gas (SNG) more easily, and at lower cost, than either lignite or bituminous coal (Rader 1979). According to Energy Today (December 10, 1979), SNG can be produced from peat

(a) In some of the more advanced coal gasification schemes, oxygen-steam mixtures are now used exclusively instead of air-steam mixtures (Johnson 1979). This allows higher operating temperatures for gasification $\left(\sim 3000^{\circ} \mathrm{F}\right)$ and results in molten ash ( $\left.\mathrm{s} l \mathrm{ag}\right)$ instead of fly ash. Substantial efficiency improvements have resulted. 


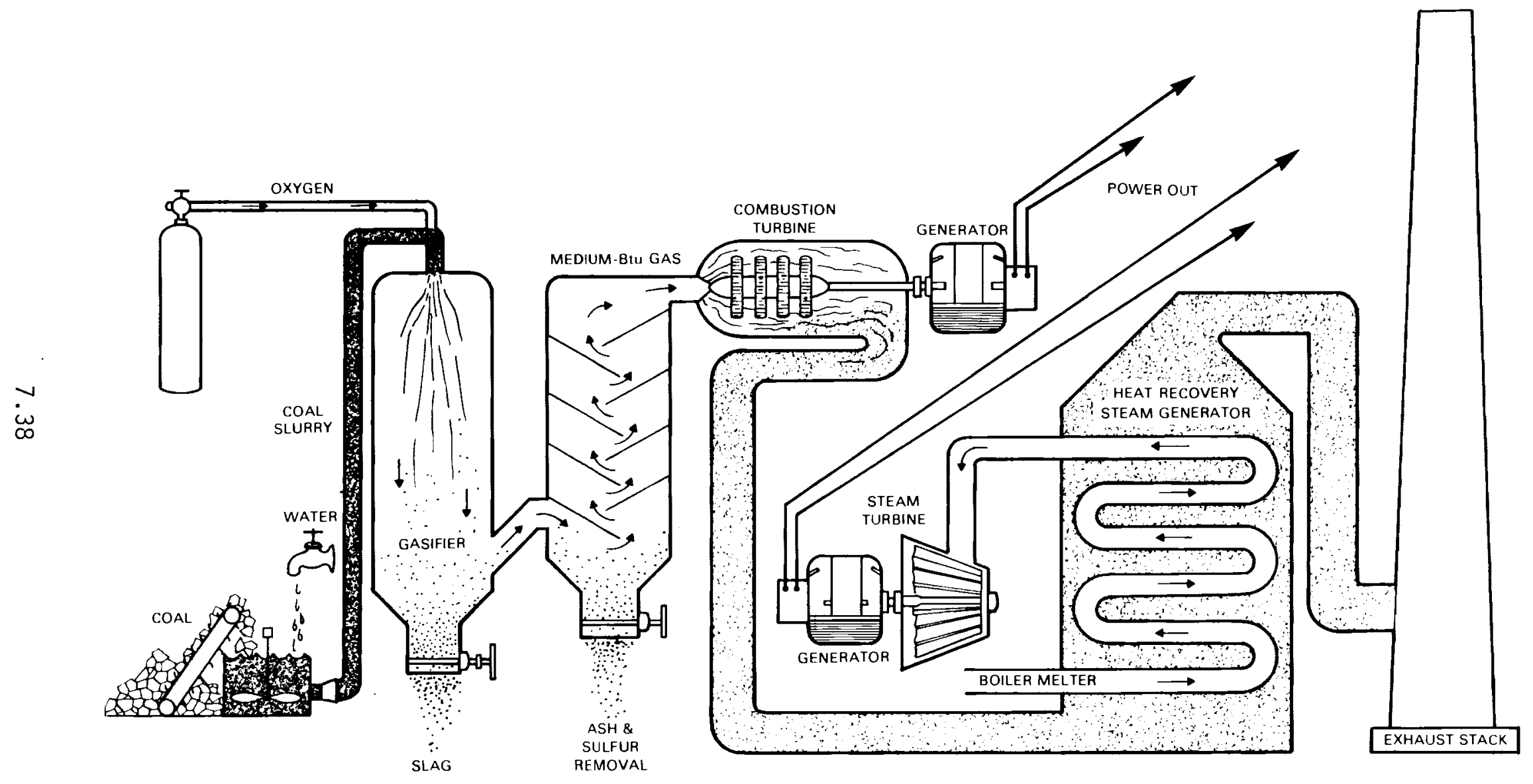

FIGURE 7.21. Coal Gasification Using 0xygen for Production of Medium-Btu Gas 


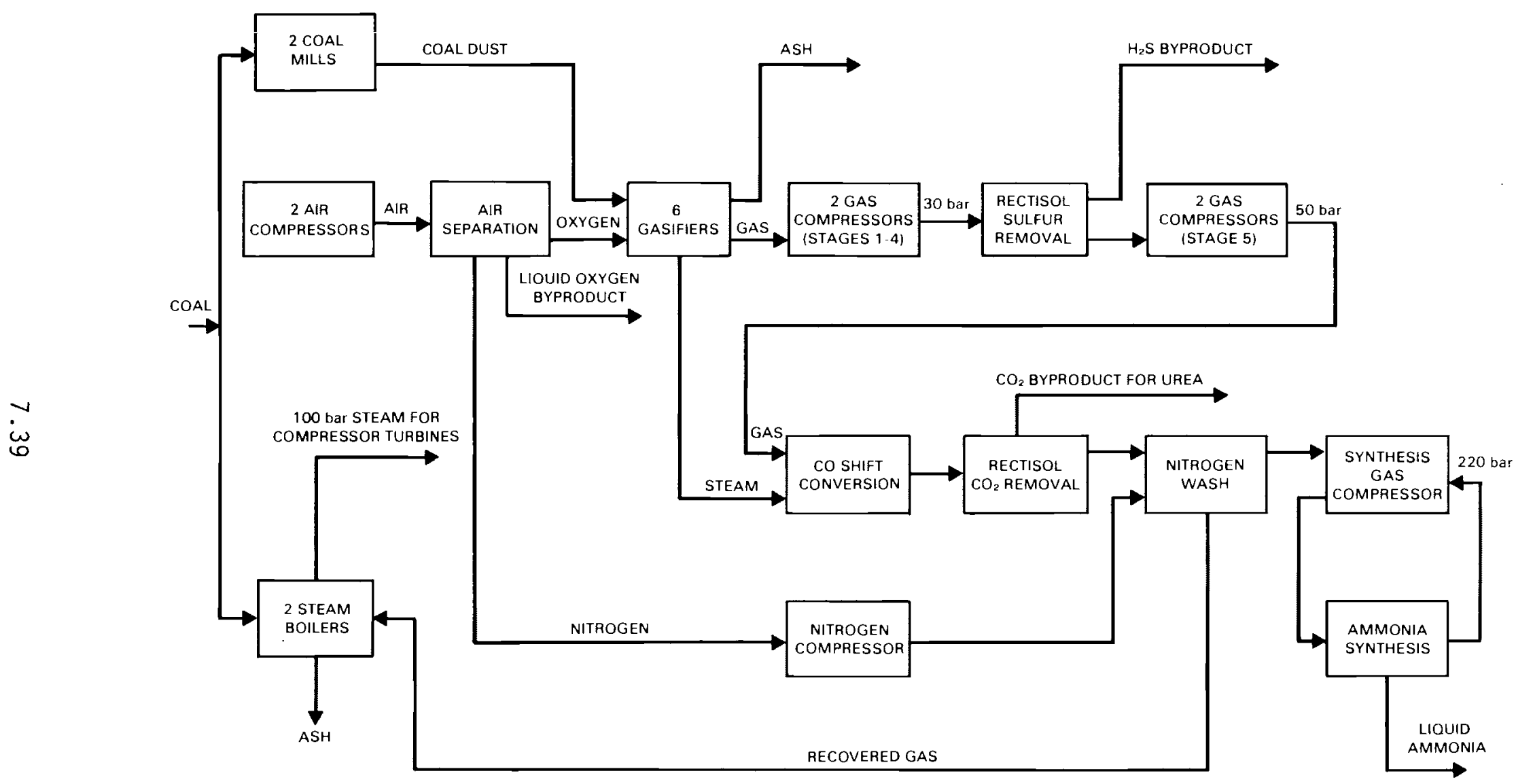

FIGURE 7.22. Ammonia Production from Coal Using 0xygen for Synthesis Gas Generation 


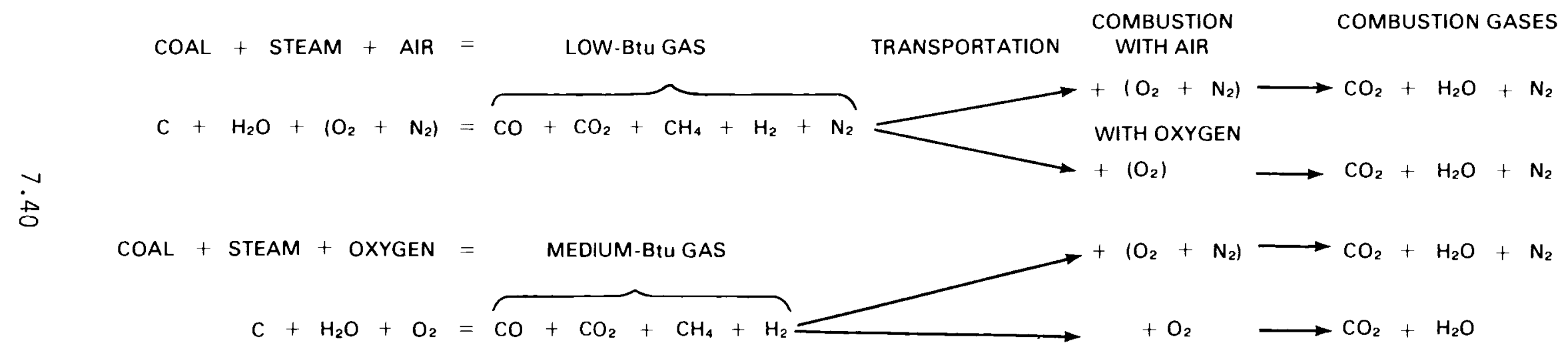

FIGURE 7.23. Basic Coal Gasification Processes Using Steam/Air or Steam/0xygen 
at costs of $-\$ 3.00 / 1000 \mathrm{ft}^{3}$, which is competitive with traditional methods. oxygen has been used experimentally to speed up the gasification process, but results have not been published yet.

In a similar way, oil sands can be gasified by in situ heating, which is effected by combusting part of the bitumen in the sands (Karim et al. 1979). The result is a low-Btu gas. If oxygen were used instead of regular air for the combustion process, higher temperatures could be achieved, which would speed up the pyrolysis and also yield a gas of higher heat content. It is not known whether any tests with oxygen have been conducted yet.

\subsubsection{Proposal for "Fire Drilling" of Horizontal Channels for In Situ Gasification}

The following paragraphs contain the description of an idea of using oxygen in a novel scheme of in situ gasification.

Because of steadily decreasing oil supplies the U.S. has to rely in the future, to a greater degree, on its own coal supplies. However, since conventional coal mining is expensive and sometimes hazardous, in situ coal gasification has become rather attractive. Therefore, numerous R\&D programs are currently in progress to develop suitable cost-efficient methods. As shown in Figure 7.24 the most basic approach consists of wells connected to each other by an underground channel through the coal seam. The initial establishment of this horizontal connection is currently one of the major technical difficulties for in situ coal gasification. Conventional drilling, use of water jets, explosives, reverse combustion, and other methods have been tested for such purposes. None of these methods is truly satisfactory or economical.

It is proposed here to use an intense oxygen flame to burn ("fire drill") a hole through the seam. This could be done in the following way.

After drilling a vertical shaft into the coal seam by conventional means, the seam itself is penetrated by an oxygen fire jet. For this purpose a flexible tube arrangement is lowered into the pit (see Figure 7.25). It consists of two concentric tubes. The inner tube carries pressurized oxygen; the outer tube carries water for cooling purposes. The oxygen jet from the center tube is directed into the coal seam and, once ignited, will burn with a very hot 


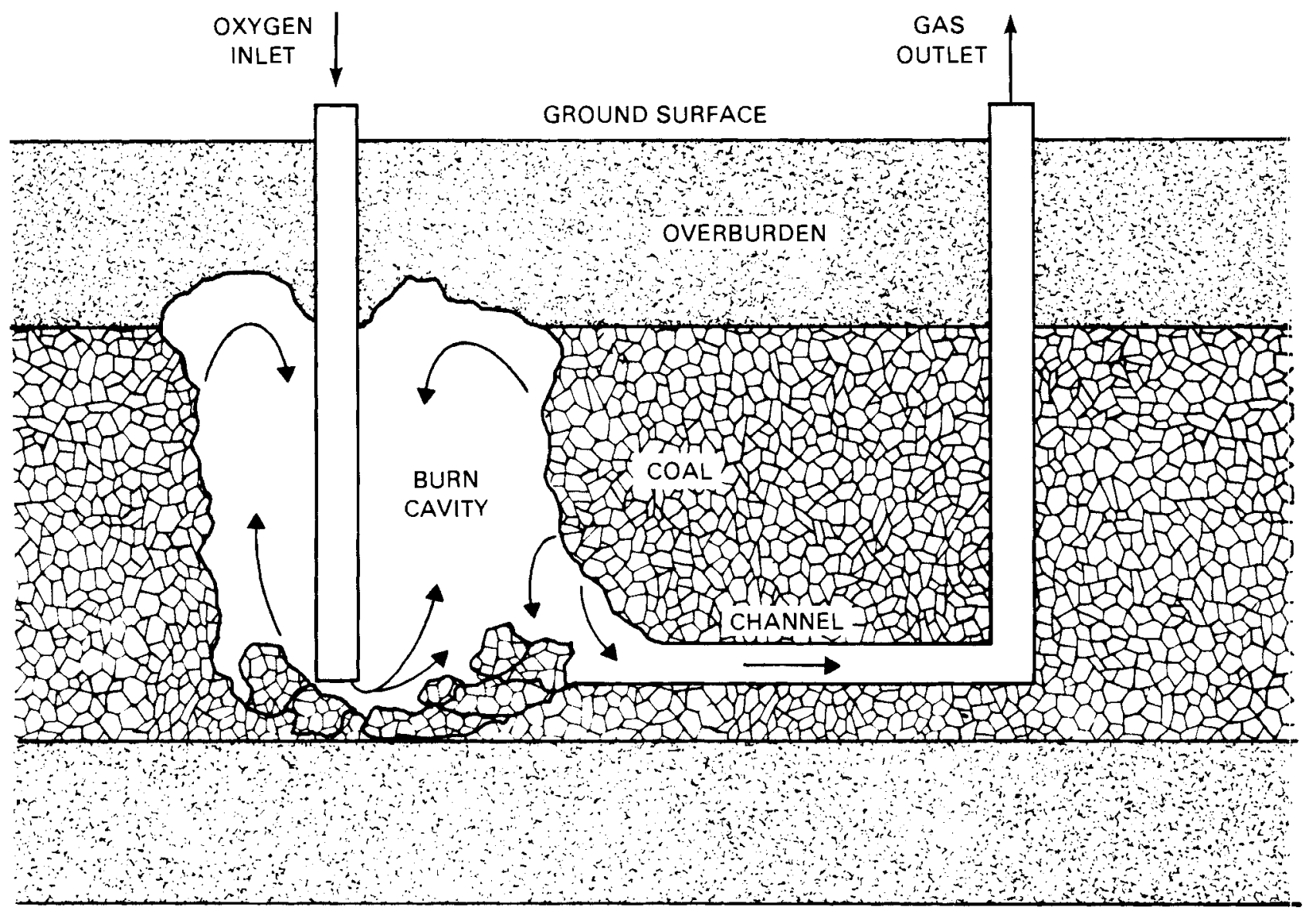

FIGURE 7.24. Underground Gasifier Using Oxygen

flame a hole into the coal (essentially acting like a cutting blowtorch). The hot combustion gases will flow backward along the flexible tube out of the shaft. For protection, the oxygen-carrying tube is surrounded by a water jacket with the water being discharged in a reverse direction, closely behind the oxygen jet as shown in Figure 7.25. The discharged water will mix with the hot combustion gases and will be vaporized. Thus, the gaseous products escaping from the shaft will contain a mixture of $\mathrm{CO}_{2}, \mathrm{CO}$, and steam. Because the water will react to a certain extent with the hot carbon near the $f 1$ ame, there is likely to be also some hydrogen in the exhaust (due to the water gas reaction, $\mathrm{C}+\mathrm{H}_{2} \mathrm{O}=\mathrm{CO}+\mathrm{H}_{2}$ ). Thus, the exhaust gases will have a heating value that could make them useful for aboveground energy generation. In this sense, the proposed scheme can be considered as a way of in situ coal gasification. 


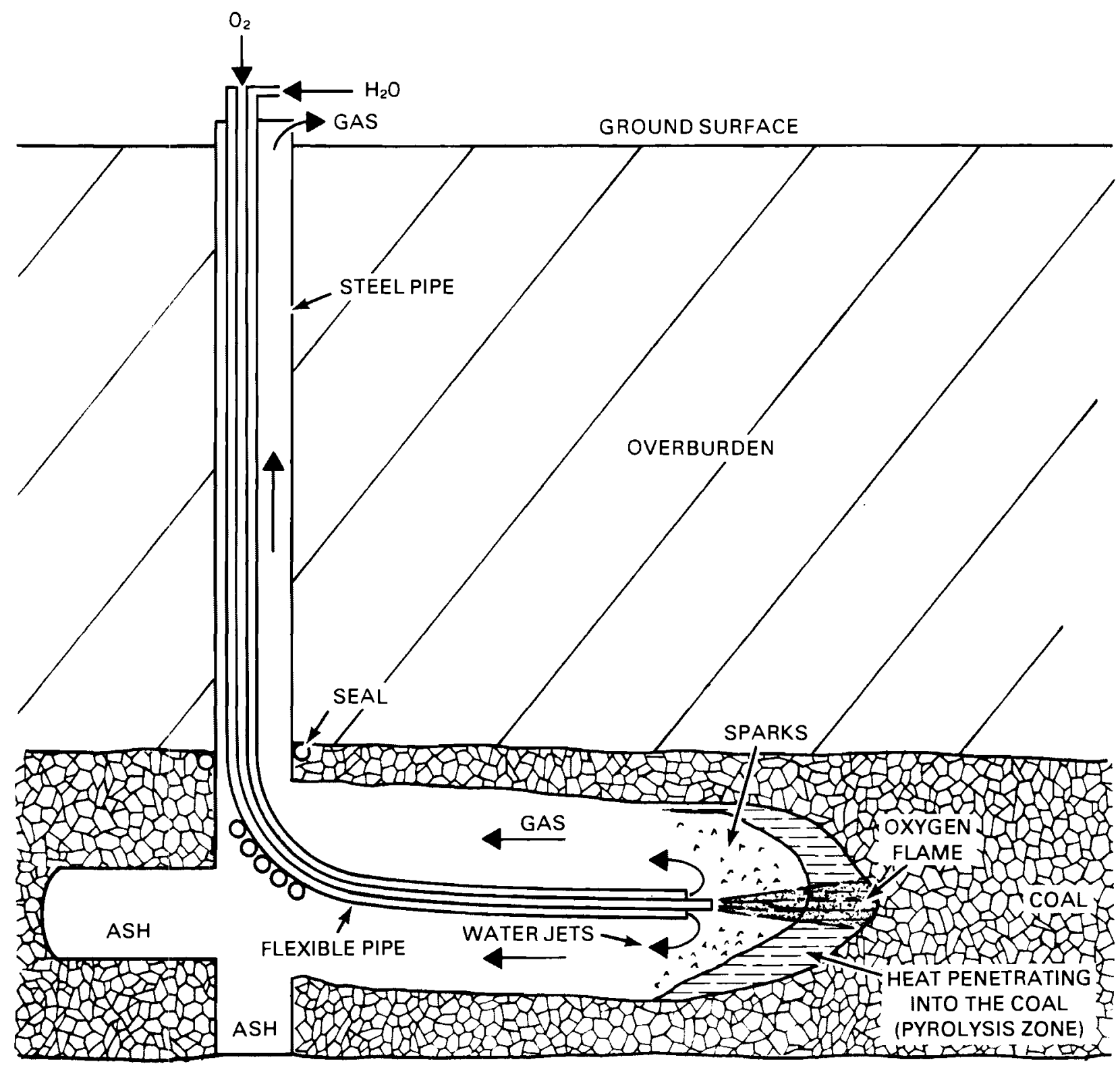

FIGURE 7.25. Fire Drilling Scheme

For mechanical protection and some themal insulation the flexible tube is surrounded by ceramic rings, thus essentially forming an armored tube. The $90^{\circ}$-turn at the entrance to the coal seam is negotiated in a gradual bend, possibly supported by rollers similar to the way in which horizontal underground drilling (Sandia 1980) is accomplished as shown in Figure 7.26. 


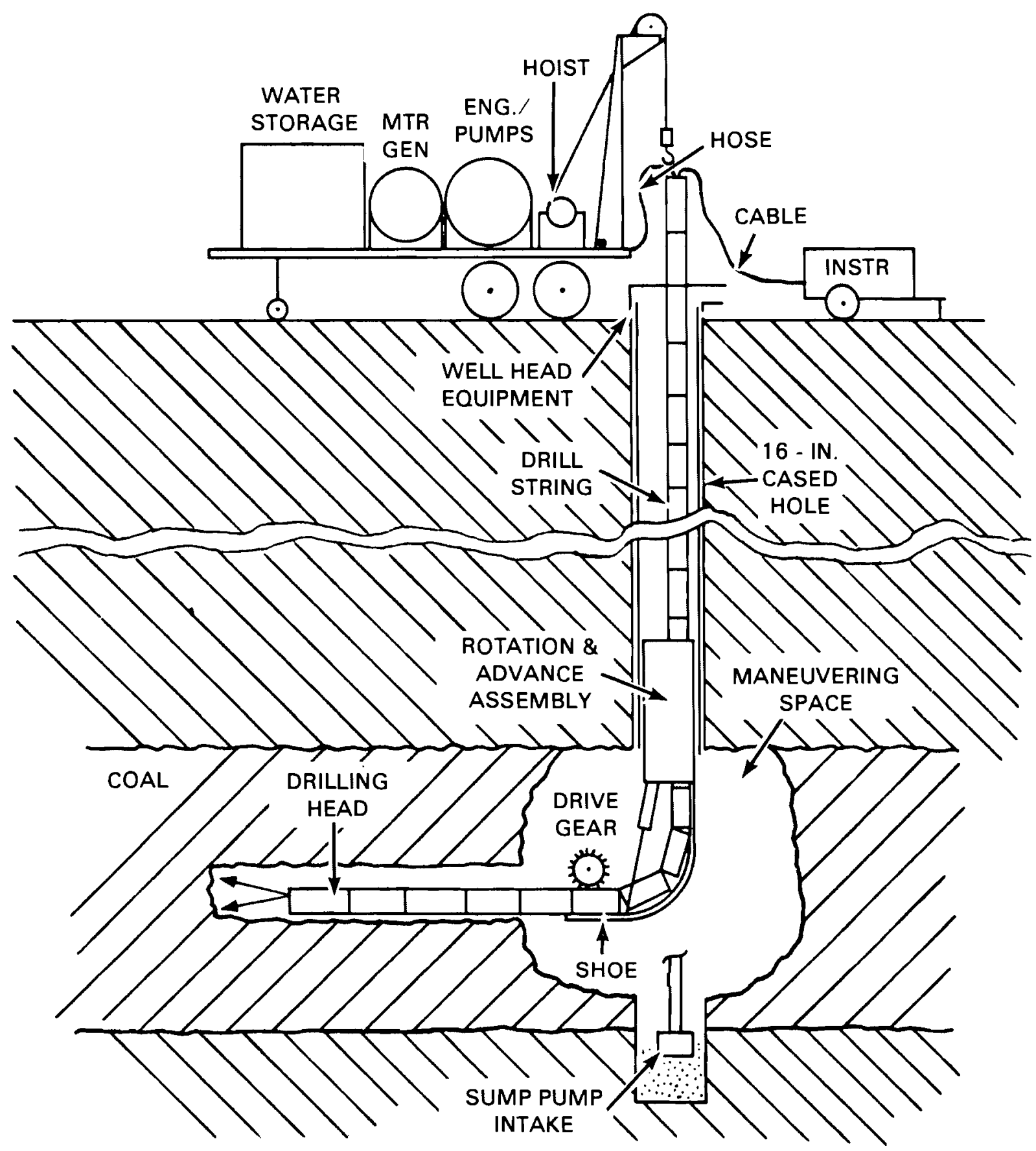

FIGURE 7.26. Drilling Horizontal Holes in Coal Beds from the Surface with Water Jets 
An oxygen torch would be self-guiding because it would not burn into rock material and, thus, would automatically remain within the coal seam. The diameter of the hole burned through the coal bed would depend primarily on the oxygen flow rate. The penetration speed would depend primarily on the oxygen jet stagnation pressure and also on the flow rate.

It is likely that the coal under the impact of the oxygen jet would rapidly heat up, oxidize, and sputter away (i.e., there would be a profuse production of sparks). As the high temperatures penetrate below the surface into the solid coal, the coal would polymerize, i.e., give off gases that rapidly build up internal pressure. As the white-hot coal particles fly back, some are oxidized to $\mathrm{CO}$ and $\mathrm{CO}_{2}$, giving off heat in this exothermic process. Others would react with the water, forming $\mathrm{CO}_{2}, \mathrm{CO}$, and $\mathrm{H}_{2}$, which are endothermic processes. Thus, it can be expected that the resulting gas will be mainly a mixture of $\mathrm{CO}_{2}, \mathrm{CO}, \mathrm{H}_{2}$, and steam. There should be little, if any, unreacted oxygen in the gas. However, some $\mathrm{NO}_{x}$ and $\mathrm{SO}_{2}$ may be present, depending on the impurities present in the coal.

Because the peak combustion temperatures will be close to $-3500^{\circ} \mathrm{C}$, it is likely that all mineral matter that might be imbedded within the coal would melt and possibly vaporize away(a) or just be blown off. Thus, this matter would not form obstacles in the path of the oxygen jet. This inert material would recondense and solidify as ash back in the cooler sections of the hole and could then be collected by centrifugal action in a corner.

There appear to be several potential advantages(b) to this method:

- The forward thrust for the oxygen lance is quite small.

- There is little difference whether the coal seam is horizontal or inclined.

- The operation can be done under pressure, if shafts are properly sealed.

(a) For example, $\mathrm{SiO}_{2}$ (sand) melts at $1710^{\circ} \mathrm{C}$ and boils at $\sim 2500^{\circ} \mathrm{C}$. CaO (1ime), one of the highest melting common minerals, melts at $\sim 2500^{\circ} \mathrm{C}$ and boils at $\sim 2850^{\circ} \mathrm{C}$.

(b) Listing sequence is random, and opinions are not explained in detail. 
- The cooling water can be utilized for generation of gas.

- The arrangement lends itself to a heat exchanger (regenerator arrangement) so that thermal efficiency is high.

- Because the forward thrust for the oxygen lance is small, the feed line can be flexible; thus, the $90^{\circ}$ turn would pose only minor problems.

- Guidance of the flame can be by oxygen outlet and/or water outlet modifications.

- Original ignition by wire igniter (electrical spark) and oxygen is rather simple.

- Feed lines can be reused.

- Collection of ash can be underground by centrifugal separator.

- Forward movement can be quite rapid (e.g., $-1 \mathrm{ft} / \mathrm{min})$.

- Rather narrow coal seams (heights less than $6 \mathrm{ft}$ ) can be exploited.

- Because of the rapid forward movement, little heat can escape as it normally does in more conventional operations, sometimes lasting for months. Thus, high efficiency is expected.

- Once a horizontal hole has been established, more conventional methods can be applied.

- Because of the small forward thrust and rapid forward movement, rather long distances can be "fire drilled."

- Runaway fires are highly unlikely to occur because initial small fires could be easily controlled.

- As an alternative to applying conventional methods, the proposed method could serve by itself as an independent means of in situ coal gasification.

- The method may be suitable also for hydrocarbon deposits other than coal, such as lignite, tar sands, or oil shales. 
- Resultant gas is not diluted with nitrogen (and very low in NO $\mathrm{x}$ content), so it could be rather rich in Btu.

- Because resulting gas (containing $\mathrm{CO}$ and $\mathrm{H}_{2}$ ) is available at high temperatures and pressures, it could be used (with the aid of suitable catalysts) for direct conversion to methanol.

- The gas from the well (under pressure and at high temperatures), could also first be expanded in a turbine (possibly in a downhole radial turboexpander that could tolerate some ash).

- Gas could be burned "as is" with additional oxygen and used to drive a gas turbine or a diesel generator to generate electricity; electric power plants would have to be located at the site.

- Scale-up appears to be straightforward; i.e., plant size would be adjustable to local conditions and needs.

- By drilling a row of tunnels of 1 imited diameter, some material could be left standing between the tunnels, which would reduce the danger of ground subsidence.

- By pressurized operation, most water originally in the coal beds would be driven out so that initial polymerization of coal would be more efficient. On the other hand, gas leaks to the surface might pose problems in some cases.

The projected scheme certainly needs additional thought for evaluating its potential usefulness, but this is clearly beyond the scope of this study.

\subsubsection{Enhanced 011 Recovery}

In most oil field operations large amounts of oil are left in the ground because there is insufficient compressed gas (mainly natural gas) within the underground oil deposits to force the oil to the surface. In some cases only as little as $3 \%$ of the existing $0 i 1$ has been recovered. (Average figures are $-30 \%$.) Thus, it is obvious that much oil remain locked up underground and can be recovered only by secondary and tertiary methods. Such methods have been widely discussed in the 1iterature (Society of Petroleum Engineers 1981) and some have been in actual use already for quite some time (Matheny 1980). These 
methods consist mainly of injecting steam or some natural gas back into the wells or injecting inert gases, such as $\mathrm{CO}_{2}$ or $\mathrm{N}_{2}$, into the underground oil deposits (Anada 1980). These, obviously, are energy-intensive processes and whether such enhanced oil recovery is economically attractive depends on the circumstances prevailing for the particular oil field (Welch 1980). Figure 7.27 shows a cost comparison of the various schemes in use today (0i1 \& Gas Journal 1981).

A similar, although less drastic situation, exists with other underground resources such as coal and oil shales. It is hardly ever possible to achieve $100 \%$ recovery of these resources; e.g., in mining of $0 i 1$ shale, between 20 and $60 \%$ is usually recoverable. $0 i 1$ shales contain a large amount of diluents, which make their mining rather uneconomical. Furthermore, substantial additional energy is required to convert the oil shales to commonly usable fuels (e.g., gasoline). Thus, in the end, only a small fraction of the total energy

HOW ENHANCED RECOVERY TECHNIQUES COMPARE

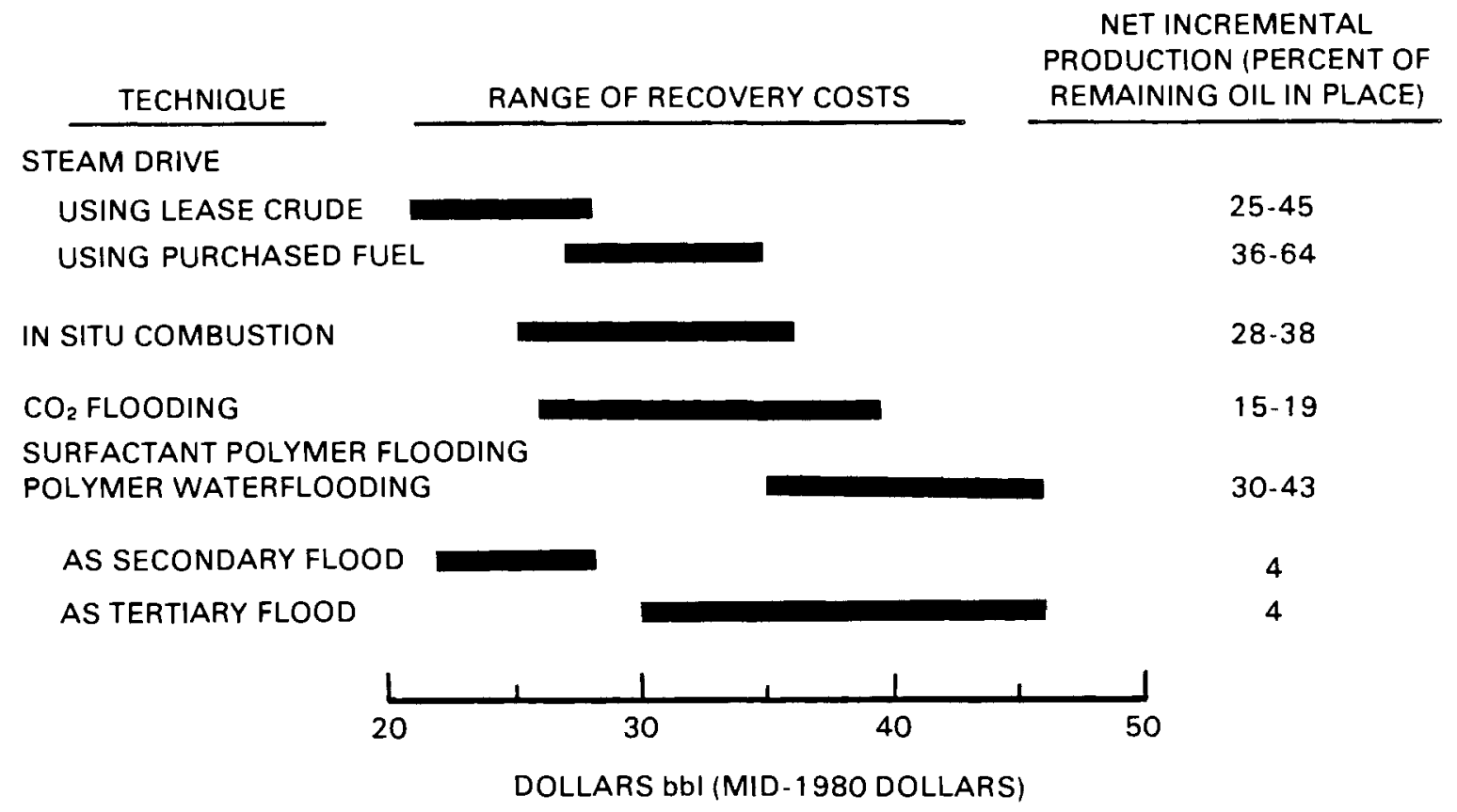

FIGURE 7.27. Cost Comparison of Various Enhanced $0 i 1$ Recovery Methods 
contained in the underground resource is put to practical use, i.e., converted to useful mechanical energy. Much thought has thus been spent to find better ways of recovering these resources.

For example, in situ retorting of the oil shale is currently being widely explored. However, this method will recover only 20 to $50 \%$ of the available shale oil from fractured shale in an underground retort. In addition -20 to $40 \%$ of the underground shale rock still must first be removed (mined) to generate sufficilent void space for the operation. This unattractive situation may be the reason why industry, up to now, only reluctantly pursued the oil shale option.

For in situ recovery, the oil shale must have enough permeability; otherwise, intentional fracture le.g., by conventional blasting methods, by leaching, or by high pressure water jets) has to be carried out (Morris 1980). It is, therefore, suggested here that this could perhaps be done by the type of oxygen torch described above. It also may be possible to use ammonia for initial fracture (Chan and Yen 1979). Even a combination of the two might be possible; first, soak the shale with ammonia, then inject oxygen and burn.

For retorting, the $0 i 1$ shale must be subjected to high temperatures $\left(\sim 540^{\circ} \mathrm{C}\right)$ and pressures ( 10 megapascals). This is usually done by injecting and burning natural gas or by injecting superheated steam. Both methods require extensive aboveground facilities (e.g., compressors for air and natural gas, steam plants). If oxygen combustion of the oil shale itself (possibly with some combustion gas recirculation) is used, the aboveground expenditures for both equipment and energy would be reduced greatly, because only liquid oxygen needs to be pumped underground.

Because injection of gases into the oil fields requires the energyintensive operation of very 1 arge compressors, it would probably be more economical if the gases were pumped as liquid and subsequently vaporized underground at high pressure. If the gases are to be used for fire flooding, (a) it is proposed that the required oxygen component be injected as a liquid in the form of an anmonia/ammonia-nitrate solution, which would decompose when heated

(a) Fire flooding or in situ combustion is one of the more advanced methods for EOR (Satman et al. 1981). 
underground to $\mathrm{NH}_{3}, \mathrm{O}_{2}$, and $\mathrm{H}_{2} \mathrm{O}$. The freed oxygen would burn part of the ammonia and of the $0 i 1$, thus generating heat and additional gases $\left(\mathrm{CO}_{2}\right.$ and $\left.\mathrm{N}_{2}\right)$, which would combine to drive more of the oil to the production wells.

The reason for this proposal is that, if pure $0_{2}$ is utilized instead of air for fire flooding purposes, it is likely that the oxygen will reach unrecovered $0 i 1$ in the pores of the substrate material more easily and in higher concentration than when diluted with nitrogen. This contention is supported by the observation that the oxygen utilization in the case of air injection for fire flooding is usually less than 100\% (Satman et al. 1981) because apparently a fraction of the air-oxygen never contacts combustible material in a high enough concentration to be within the flammability limits.

Again, the limited scope of this study does not allow further analysis of this proposed idea.

\subsection{USE OF "COLD" ENERGY FOR ADDITIONAL IMPROVEMENT OF THERMODYNAMIC EFFICIENCY}

Because such a large weight proportion $(-3 \text { to } 6)^{(a)}$ of oxygen in relation to pure fuel is required for combustion, there is a strong incentive for using the "cold" energy contained in the liquid oxygen in, for example, a Stirling engine, or a closed-cycle gas turbine. (To take full advantage of the low temperature of liquid oxygen, the gaseous working fluid in the engine must be able to be cooled to almost liquid oxygen temperatures without condensing. Thus, essentially only $\mathrm{H}_{2}$, $\mathrm{He}$, and $\mathrm{N}_{2}$ are realistic choices for such applications.) Thermodynamically, such a scheme is attractive because the waste heat from the engine is rejected at a lower absolute temperature than, e.g., in a steam turbine installation. As seen from the formula (derived from the Second Law of Thermodynamics)

$$
n=\frac{T_{H}-T_{L}}{T_{H}},
$$

(a) This requirement has several reasons: in complete combustion of carbon to carbon dioxide, two parts of oxygen are always required for one part of carbon; oxygen is also slightly heavier than carbon. Although in combusting $\mathrm{H}_{2}$ to $\mathrm{H}_{2} \mathrm{O}$ only one oxygen atom is required for two hydrogen atoms, on a weight basis six times as much oxygen is required as hydrogen. 
if $T_{L}$ approaches zero, the ideal process efficiency $n$ would approach $1 . \quad\left(T_{H}\right.$ and $T_{L}$ are the high and the low temperatures, respectively, at which heat is added or withdrawn.) Whereas the high temperature, usually limited by materials properties, cannot easily be increased beyond about 1200K, the current state-of-the-art, (a) the low temperature can be decreased without major technical problems below the commonly used ambient temperature level.

Assuming $T_{H}=1700^{\circ} \mathrm{F}(\sim 1200 \mathrm{~K})$ and $T_{L} \approx 100^{\circ} \mathrm{F}(\sim 300 \mathrm{~K})$ will result in $n=$ $900 / 1200=0.75$.

Assuming $T_{H}=1700^{\circ} \mathrm{F}(\sim 1200 \mathrm{~K})$ and $T_{L}=-276^{\circ} \mathrm{F}(\sim 100 \mathrm{~K})$ will result in $n=$ $1100 / 1200=0.92$.

These values are theoretically achievable if losses in the process are assumed to be zero. Thus, by dropping the lower temperature by $200 \mathrm{~K}$ (from 300K to 100K), the efficiency could be increased by a factor of 1.23. If, instead, the upper temperature $T_{H}$ were increased by 200K ( $i . e$. , from $1200 \mathrm{~K}$ to $1400 \mathrm{~K}$ ), $n$ would go to 0.79 , i.e., increase by only a factor of 1.05 . This shows that a drop of 200K at the low temperature end of the cycle is far more effective in raising the efficiency than a rise of $200 \mathrm{~K}$ at the high temperature end of the cycle. This is the main incentive for the above suggestion to use the "cold" energy contained in the liquid oxygen.

Thus, in an external combustion engine such as the Stirling engine, a double benefit for using liquid oxygen would be obtainable:

1. The combustion process itself becomes more efficient, particularly if combustion gas recirculation would also be applied.

2. The cycle efficiency is increased because of lowering $T_{L}$.

If other advantages of Stirling engine and closed-cycle gas turbines (such as clean-burning and low toxic emissions, usability of low-grade fuels) are taken into account, the incentive for developing such engines becomes even stronger.

(a) Intense efforts are underway to increase this temperature to about $1700 \mathrm{~K}$ (Horner 1980). 


\author{
•
}




\section{REFERENCES}

Amr, A. 1981. "Analysis of Reverse Combustion in Tar Sands." Comb. \& Fiame. $41: 301-312$.

Anada, H. A. 1980. State-of-the-Art Review of Nitrogen and Flue Gas Flooding in Enhanced 0 il Recovery. DOE/MC/08333-2, U.S. Department of Energy, Washington, D.C.

Baker, C. R. 1981. "Low Purity O2 Saves Energy in Coal Conversion." Hydrocarb. Process. 60(7):75-80.

Bammert, K. 1975. A General Review of Closed Cycle Gas Turbines. Thiemig Verlag, Munich, West Germany.

Baume ister, T., and L. S. Marks, eds. 1967. Standard Handbook for Mechanical Engineers. 7th ed. McGraw-Hill, New York, New York.

Beckman, R. F., et al. 1980. Economic Evaluation of Energy Recovery Options for Oxygen-- and Enriched Air-Blown Texaco GCC Power PTants. EPRI-AP-1624, Electric Power Research Institute, Palo Alto, California.

Bomelburg, H. J. 1980. "Ammonia as a Fuel." Liquified Gaseous Fuels Safety and Environmental Control Assessment Program, VoT. 3. DOE/EV 0085, U.S. Department of Energy, Washington, D.C.

Bonnekamp, H., et al. 1978. "Extension of the Possibilities of Utilization of Fuels by Addition of Oxygen." Stahl \& Eisen. 98:141-149.

Bourget, J. M. 1981. "LNG Cold." Hydrocarb. Process. 60:167-172.

Brame, J. S. S., and J. G. King. 1967. Fuel: Solid, Liquid and Gaseous. 6 th ed. St. Martin's Press, New York, New York.

Catterson, R. K., and J. C. Swain. 1968. Chemical-Dynamic Systems for Undersea Power. Battelle Columbus Laboratories, CoTumbus, Ohio.

Chan, M., and T. F. Yen. 1979. "Fracturing of 0il Shale by Ammonia." Paper presented to the ACS meeting of September 1.979.

Clinch, J. M. , ed. 1980. Proceedings of the Symposium on Pul se Combustion Technology for Heating AppTications. ANL/EES-TM-87, Argonne National Laboratory, Argonne, Illinois.

Critchley, G. N., ed. 1964. The Future of Fuel Technology. Pergamon Press, New York, New York.

Crowther, R. H. 1981. "Consider Compressed Combustion." Hydrocarb. Process. 80(7):85-88. 
Engelbrecht, A. D., and L. J. Partridge. 1979. "Operating Experience on a 1000 Ton/Day Ammonia Plant." Symposium on Ammonia from Coal. TVA Bulletin Y-143, Tennessee Valley Authority.

Escher, W. J. D. 1976. "Hydrogen-Oxygen Utilization Systems." Int. J. Hydrogen Energy. 1:189-198.

Farmer, R. 1980. "165-MW Coal-Fired PFB for Operation by 1985." Gas Turbine World. $10(3): 22-27$.

Fehling, H. R. 1948. "Combustion with Oxygen and Oxygen-Enriched Air." J. Inst. of Fuel. $21: 221-241$.

Fehling, H. R., and T. Lesor. 1949. "Determination of the True Composition of the Products of the Theoretical Combustion with Oxygen and Oxygen/Nitrogen Mixtures up to $2500^{\circ} \mathrm{C}$ at Atmospheric Pressure." Proceedings of the 3rd Symposium on Combustion, Flame and Explosion Phenomena, pp. 634-640. The Williams \& Wilkins Co., Baltimore, Maryland.

Gas Research Institute. 1980. Gas Research Institute 1980 Annual Report. Chicago, Illinois.

Gat, N. 1980. "The Effect of Exhaust Gas Recirculation and Turbulence on the Burning Velocity, Dead Space Thickness and Minimum Ignition Energy in PreMixed Methane-Air Combustion." Comb. Sci. Technol. 23:1-15.

General Electric Company. 1981. PFB Coal-Fired Combined Cycle Development Program Final Report. DOE/ET/1037T-T1, U.S. Department of Energy, Washington, D.C.

Gerlach, G. 1969. "Concentrating $\mathrm{H}_{2} \mathrm{SO}_{4}$ by Submerged Combustion." ChemieIng.-Techn. 42:452-456.

Glassman, I. 1977. Combustion. Academic Press, New York, New York.

Griswold, J. W., and M. C. Wehrey. 1981. "System Considerations of MHD by the Utility." Paper 819650. Proceedings of the 16th Intersociety Energy Conversion Engineering Conference. American Society of Mechanical Engineers, New York, New York.

Halstead, C. J., and D. R. Jenkins. 1970. "Rates of $H+H+M+H_{2}+M$ and $\mathrm{H}+\mathrm{OH}+\mathrm{M}+\mathrm{H}_{2} \mathrm{O}+\mathrm{M}$ Reaction in Flames." Comb. \& Flame. 14:321-324.

Hampartsoumian, E., and B. M. Gibbs. 1981. "Combustion of Low Grade Fuels in a Fluidized Bed." Energy Dev. 5(1):18-19.

Horner, M. W. 1980. High Temperature Turbine Technology Program. DOE/ET/10340-T3, U.S. Department of Energy, Washington, D.C.

Ivernel, A., et al. 1978. "The Role of Oxygen in Improving the Combustion of Blast Furnace Gas." Rev. Gen. Therm. Fr. 196:385:392. 
Ivernel, A., and P. Vernotte. 1979. "Experimental Study of the Improved Heat Transfer in Furnaces by Combustion with Oxygen." Rev. Gen. Therm. Fr. 210-211:375-391.

Iyer, P. A., and C. Chiu. 1971. "Submerged Combustion." Desalination. $9: 19-31$.

Johnson, B. C. 1979. "Coal Processing Technology." Chem. Eng. Prog. $V I: 94-97$.

Karim, G. A., et a1. 1979. "Combustion of 0 il Sand Fragments in Hot 0xidizing Streams." Comb. \& Flame. 36:291-303.

Keilor, R. D. 1948. "Combustion and Fundamental Research--The Tunnel Burner." Ind. Gas Times. 11:334-338.

Kentfield, J. A. C., et a1. 1977. "A Simple Pressure-Gain Combustor for Gas Turbines." J. Eng. Power. 99:153-156.

Komamiya, K. 1978. "Incineration of Polychlorinated Biphenyls with an Oxygen Burner." Env. Sci. Techn. 12:1205-1208.

Kurz, G. 1968. "Immersion Heater." Verfahrenstech. 2:374-378.

Lamparter, R. 1979. Coal Combustion by Wet Oxidation. FE 3402-T1, U.S. Department of Energy, Washington, D.C.

Lennox News. 1980. "Pulse Combustion: Giant Step in Furnace Technology." Lennox News:- 34(8):1-2.

Long, W. D., et al. 1981. "High Performance Ceramic Engine Applications." Paper 819615, Proceedings of the 16th Intersociety Energy Conversion Engineering Conference. American Society of Mechanical Engineers, New York, New York.

MacNair, E. J. 1971. "Closed Cycle Diesel Engines for Underwater Power." Paper 719080, Proceedings of the 6th Intersociety Energy Conversion Engineering Conference. Society of Automotive Engineers, Inc., Warrendale, Pennsylvania.

Magison, E. C. 1978. "Explosion Fundamentals." In Electrical Instruments in Hazardous Locations. 3rd ed. Instrument Society of America, Pittsburgh, Pennsylvania.

Marzouk, E. S., and J. A. C. Kentfield. 1974. "Pressure-Gain Combustion, a Means of Improving the Efficiency of Thermal Plants." Paper 749155, Proceedings of the 9th Intersociety Energy Conversion Engineering Conference. American Society of Mechanical Engineers, New York, New York.

Masi, F., et a1. 1947. "Oxygen Boost of Engine Power at Altitude." SAE Quart. Trans. 1:76-86. 
Matheny, S. L. 1980. "EOR Methods Help U1timate Recovery." Oil and Gas J. $78(13): 79-124$.

Morris, W. A. 1980. Explosively Produced Fracture of 0il Shale. LA-8396-PR, Los Alamos Scientific Laboratory, Los Alamos, New Mexico.

Murata, I., and N. Eiji. 1980. "How Osaka Gas Uses the Cold from LNG." Pipeline \& Gas J. 121(3):23-38.

Nicholls, J. A., and M. Sichel. 1980. Initiation of Detonation in Unconfined Natural Gas-Air Clouds. PB81-113292, National Technical Information Service, Springfield, Virginia.

Nunz, G. J. 1975. The Stirling Automotive Power System, Vol. II, No. 6. JPL SP 43-17, Jet Propulsion Laboratory, Pasadena, California.

0i1 \& Gas. 1981. "DOE Updates Enhanced Recovery Economics." 0il \& Gas J. JuTy 13, $1981: 43-44$.

Pate1, J. G. 1981. "Low, Medium-Btu Gas from Coal Lead Conversion Routes." 0 il \& Gas J. June 29, 1981.

Potter, 0. E. and A. J. Keogh. 1981. "Drying High-Moisture Coals Before Liquefaction or Gasification." Fuel Proc. Techn. 4:217-227.

Rader, A. M. 1979. "Synthetic Natural Gas from Peat." Ind. Eng. Chem. Prod. Res. Dev. 18:291-296.

Reader, G. J. 1978. "Aspects of Pulsating Combustion." Paper 789251, Proceedings of the 13th Intersociety Energy Conversion Engineering Conference. Society of Automotive Engineers, Inc., Warrendale, Pennsylvania.

Reese, R. M., and A. D. Carmichael. 1971. "A Proposed Hydrogen-0xygen Fueled Steam Cycle for the Propulsion of Deep Submersibles." Paper 719079, Proceedings of the 6th Intersociety Energy Conversion Engineering Conference. Society of Automotive Engineers, Inc., Warrendale, Pennsylvania.

Ross, R. D. 1980. "Burn Hazardous Waste." Chem. Tech. 10:708-712.

Sandia. 1980. Drilling Horizontal Holes in Coal Beds from the Surface with Water Jets. SAND 80-0057C, Sandia National Laboratory, ATbuquerque, New Mexico.

Satman, A., et al. 1981. In Situ Combustion Models for the Steam Plateau and for Fieldwide 0il Recovery. DOE/ET/12056-11, U.S. Department of Energy, Washington, D.C.

Schachter, Y. 1979. "0il Shale: Burn It Already." Chem. Tech. 9:568-570. 
Schaefer, R. 1979. Cost Estimate of Fluidized Bed Combustor Air Heater for Gas Turbines. EPRI-FP 995, Electric Power Research Institute, PaTo ATto, California.

Schmidt, E. 1956. Thermodynamics. Springer-Verlag, Berlin, West Germany.

Schuetz, M. 1980. Design and Development of Stirling Engines for Stationary Power Generation Applications in the 500 to 3000 Horsepower Range. DOE/ET/15207-T2, U.S. Department of Energy, Washington, D.C. Shaner, R. L. et al. 1978. "Oxygen: 2000 Tons/Day." Mech. Eng.
101(1):38-42.

Shen, S. Y., and A. M. Wolsky. 1980. Energy and Materials Flows in the Production of Liquid and Gaseous Oxygen. ANL/CNSV-15, Argonne National Laboratory, Argonne, Illinois.

Smith, R. T. 1981. Environmental Aspects of Alternative Wet Technologies for Producing Energy from Peat. DOE/FC/10169-T1, U.S. Department of Energy, Washington, D.C.

Society of Petroleum Engineers. 1981. Second Joint SPE/DOE Symposium on Enhanced Dil Recovery. CONF-810433, National Technical Information Service, SpringfieTd, Virginia.

Taylor, C. F. 1977. The Internal Combustion Engine in Theory and Practice. 2nd ed. MIT Press, Cambridge, Massachusetts.

Uherka, K. L., et al. 1981. "Overview of DOE's Large Stationary Stirling Engine Deveiopment Program." Paper 819780, Proceedings of the 16 th Intersociety Energy Conversion Engineering Conference. American Society of Mechanical Engineers, New York, New York.

Underwood, P., and P. Dieges. 1971. "Hydrogen/0xygen Combustion for Pollution-Free Operation of Existing Standard Automobile Engines." Paper 719046, Proceedings of the 6th Intersociety Energy Conversion Engineering Conference. American Society of Automotive Engineers, Inc., Warrendale, Pannsylvania.

Weil, K. H. 1972. "The Hydrogen I. C. Engine--Its Origins and Future in the Emerging Energy/Transportation/Environment System." Paper 729212, Proceedings of the 7 th Intersociety Energy Conversion Engineering Conference. American Chemical Society, Washington, D.C.

Welch, L. W. 1980. "Status of EOR Technology." Proceedings of the First Symposium on Enhanced 0il Recovery. CONF 800411, National Technical Information Service, Springfield, Virginia.

Zabetakis, M. G. 1976. "Flammability Characteristics of Combustible Gases and Vapors." Bulletin 627, Bureau of Mines, U.S. Department of the Interior, Washington, D.C. 
. 


\section{BIBLIOGRAPHY}

Barr, J. 1949. "Behavior of a Combustion System Using Exhaust Gas Recirculation." Fuel. 28:241-242.

Energy Today. 1979. "Peat Energy." Energy Today. 7:51-52.

Gilbert-Commonweal th. 1980. Oxygen-Enriched Air Production for MHD Power Plants. DOE/ET/11058-T4, U.S. Department of Energy, Washington, D.C.

Gilbert-Commonweal th. 1979. Oxygen Enrichment for Open Cycle Magnetohydrodynamic Power Systems. DOE/ET711058-T1, U.S. Department of Energy, Washington, D.C.

Holm, J., and J. S. Swearingen. 1978. "Turboexpanders for Energy Conservation." Mech. Eng. 100(9):34-40.

Iammartino, N. R. 1976. "Fluidized Bed Combustion: A Better Way to Burn Coal." Chem. Eng. 83:69-71.

Johnson, A. J., ed. 1951. Fuels and Combustion Handbook. McGraw-Hill, New York, New York.

Kentfield, J. A. C., and M. A. Read. 1979. "A Pressure-Gain Combustor Utilizing Twin Valveless Pulse Combustors Operating in Antiphase." Paper 799378, Proceedings of the 14 th Intersociety Energy Conversion Engineering Conference. American Chemical Society, Washington, D.C.

Lee, J. H. S., and I. D. Moen. 1980. "The Mechanism of Transition from Deflagration to Detonation in Vapor Cloud Explosions." Prog. Energy Combust. Sci. 6:359-389.

Lewis, B., and G. von Elbe. 1961. Combustion, Flames and Explosions of Gases. 2nd ed. Academic Press, New York, New York.

Meister, R. 1968. "The Use of Oxygen in Glass-Me1ting Furnaces." Glastechn. Ber. $37: 557-565$.

Spiers, H. M. 1961. Technical Data on Fuels. 6th ed. World Power Conference, London, Engl and.

Stephens, D. R. 1980. Introduction to Underground Coal Gasification. UCID-18801, University of California, Lawrence Livermore Laboratory, Livermore, California.

U.S. Steel Corporation. 1980. Use of Coal Injection and 0xygen in a Blast Furnace. IDO-10089, Idaho National Engineering Laboratory, Idaho Falls, Idaho. 
Wald, D. E. 1979. "New Low-Btu Gas Burner Systems for Industrial Applications." In New Fuels and Advances in Combustion Technologies, pp. 365-376. Institute of Gas Technology, Chicago, ITIinois. 
APPENDIX

BURNING COAL WITH AIR 


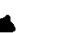


APPENDIX

BURNING COAL WITH AIR

A coal to be burned with dry air may have the following analys is (in wt\%): $\mathrm{C}=84 \%, \mathrm{H}_{2}=4 \%, \mathrm{O}_{2}=5 \%, \mathrm{~N}_{2}=1 \%$, ash $=6 \%$. For burning all the carbon contained in $1 \mathrm{~kg}$ of this coal, $0.84 \times 32 / 12=2.24 \mathrm{~kg}$ of $\mathrm{O}_{2}$ are required. For burning the hydrogen, $0.04 \times 16 / 2=0.32 \mathrm{~kg}$ of $\mathrm{O}_{2}$ are required. If it is assumed that the oxygen contained in the coal takes part in the reaction, a total of $2.24+0.32-0.05=2.51 \mathrm{~kg}$ of external $0_{2}$ are required for the combustion of this particular coal.

Since the weight ratio of $\mathrm{O}_{2} / \mathrm{N}_{2}$ in air is $23.2 / 76.8=0.302$, there are $2.51 / 0.302=8.31 \mathrm{~kg} \mathrm{~N}_{2}$ associated with the $2.51 \mathrm{~kg} 0_{2}$. Thus, a total amount of $8.31+2.51=10.82 \mathrm{~kg}$ of air is required for burning $1 \mathrm{~kg}$ of coal.

The combustion gases $(\mathrm{a})$ consist of $2.24+0.84=3.08 \mathrm{~kg} \mathrm{CO} 2,0.36 \mathrm{~kg} \mathrm{H} \mathrm{H}^{0}$, and $8.32 \mathrm{~kg} \mathrm{~N}$, which amounts to a total of $11.76 \mathrm{~kg}$.

If it is assumed that the flue gases are exhausted to the atmosphere at $320^{\circ} \mathrm{C}$, the volume fraction of the $\mathrm{CO}_{2}$ gases amounts to $3.08 \mathrm{~kg} \times 22 \mathrm{~m}^{3} / 44 \mathrm{~kg} \times$ $2.17=3.35 \mathrm{~m}^{3}$. The water fraction is $0.95 \mathrm{~m}^{3}$, and the nitrogen fraction is $14.18 \mathrm{~m}^{3}$. (The factor 2.17 is the gas expansion factor for $320^{\circ} \mathrm{C}$.) Thus, the total exhaust volume is $18.48 \mathrm{~m}^{3}$ and consists of $18 \mathrm{vol} . \% \mathrm{CO}_{2}, 5 \% \mathrm{H}_{2} \mathrm{O}$, and $77 \% \mathrm{~N}_{2}$.

Since the specific heat of the combustion products is $-0.5 \mathrm{kcal} / \mathrm{kg}^{\circ} \mathrm{C}$, $\sim 1770 \mathrm{kcal} / \mathrm{kg}$ are discharged into the atmosphere. This means that $\sim 1770 / 8000=$ $22 \%$ of the heat is lost through the stack. Most of this energy could be saved if exhaust gas recirculation were applied.

(a) $\mathrm{NO}_{\mathrm{x}}$ formation is disregarded in this simplified example. 
.

• 


\section{DISTRIBUTION}

No of

Copies

\section{OFFSITE}

50 M. Gunn

U.S. Department of Energy

Energy Conversion and

Utilization Division

1G-080 Forrestal Building

Washington, D.C. 20585

J. Brogan

U.S. Department of Energy

Off. of Energy Sys. Research

Washington, D.C. 20585

J. Kane

Basic Energy Sciences

U.S. Department of Energy

ER-10

Washington, D.C. 20545

W. Thielbar

U.S. Department of Energy

Idaho Operations Office

550 Second Street

Idaho Falls, ID 83401

27 DOE Technical Information Center

C. Blomquist

Argonne National Laboratory

9700 5. Cass Avenue

Argonne, IL 60439

M. Clinch

Argonne National Laboratory

9700 S. Cass Avenue

Argonne, IL 60439

R. Holtz

Argonne National Laboratory

Building 330

9700 S. Cass Avenue

Argonne, IL 60439
No of

Copies

F. Marble

Mechanical Engineering Dept.

California Intitute of Technology

1201 East California Blvd.

Pasadena, CA 91125

R. Abarcar

Energetics, Inc.

9210 Route 108

Columbia, MD 21045

C. Fink

Energetics, Inc.

9210 Route 108

Columbia, MD 21045

C. R. Amann

Engine Research

General Motors Corp.

Twelve Mile \& Mound Rds.

Warren, MI 48090

C. Bankston

The Jet Propulsion Laboratory 4800 Oak Grove Drive

Pasadena, CA 91103

J. Bellam

The Jet Propulsion Laboratory 4800 0ak Grove Drive

Pasadena, CA 91103

R. M. Clayton

The Jet Propulsion Laboratory 4800 Oak Grove Drive

Pasadena, CA 91103

P. Massier

The Jet Propulsion Laboratory

4800 Oak Grove Drive

Mai1 Stop 122-123

Pasadena, CA 91103 
No of

Copies

J. Mocanin

The Jet Propulsion Laboratory 4800 Oak Grove Drive

Mail Stop 122-123

Pasadena, CA 91103

Y. Nakamura

The Jet Propulsion Laboratory 4800 Oak Grove Drive

Mail Stop 502-307

Pasadena, CA 91103

R. H. Phen

The Jet Propulsion Laboratory 4800 Oak Grove Drive

Pasadena, CA 91103

\section{G. Voecks}

The Jet Propulsion Laboratory 4800 Oak Grove Drive

Pasadena, CA 91103

K. G. Kreider

U.S. Department of Commerce National Bureau of Standards Physics B-250

Washington, D.C. 20234

J. A. Carpenter

Oak Ridge National Laboratory P.0. Box $X$

Building 4508 North Room 263

Oak Ridge, TN 37830

C. Ferguson

Department of Mechanical

Engineering

Purdue University

West Lafayette, IN 47907

R. Edelman

SAI

9760 Owensmouth Avenue

Chatsworth, CA 91311
No of

Copies

C. T. Bowman

Department of Mechanical

Engineering

Stanford University

Stanford, CA 94305

G. Strasser

Strasser Associates, Inc.

2616 Pine Knot Drive

Vienna, VA 22180

S. E. Elghobashi

University of California at Irvine

School of Engineering

35 Cool Brook

Irvine, CA 92715

ONSITE

DOE Richland Operations

H. E. Ransom

49 Pacific Northwest Laboratory

W. B. Ashton

J. M. Bates

H. J. Bomelburg (20)

D. L. Brenchley (10)

R. S. Campbel1

A. D. Chockie

A. J. Currie

G. J. Hane

H. Harty

S. G. Hauser

D. R. Johnson

R. G. Rivera

Economics Library (2)

Publishing Coordination (2)

Technical Information Files 